\title{
Degradation and Failure Characteristics of NPP Containment Protective Coating Systems
}

by

R. L. Sindelar

Westinghouse Savannah River Company

Savannah River Site

Aiken, South Carolina 29808

M. E. Dupont

N. C. Iyer

P. S. Lam

T. E. Skidmore

F. R. Utsch
P. E. Zapp

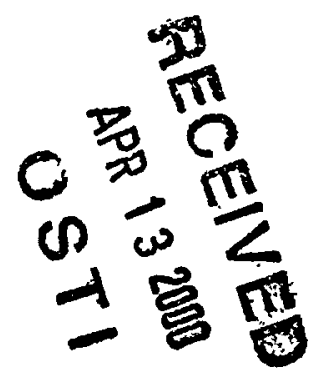

DOE Contract No. DE-AC09-96SR18500

This paper was prepared in connection with work done under the above contract number with the U. S.

Department of Energy. By acceptance of this paper, the publisher and/or recipient acknowledges the U.S.

Government's right to retain a nonexclusive, royalty-free license in and to any copyright covering this paper, along with the right to reproduce and to authorize others to reproduce all or part of the copyrighted paper. 
WSRC-TR-2000-00079

\section{Degradation and Failure Characteristics of NPP Containment Protective Coating Systems (U) Interim Report}

Prepared by

M. E. Dupont, N. C. Iyer, P. S. Lam, R. L. Sindelar, T. E. Skidmore, F. R. Utsch and P. E. Zapp

Savannah River Technology Center Westinghouse Savannah River Company Aiken, SC 29808

For

Division of Engineering Technology Office of Nuclear Regulatory Research

U.S. Nuclear Regulatory Commission Washington, DC 20555

NRC Job Code W6959

NRC Project Manager: A. W. Serkiz

Publication Date: March 2000

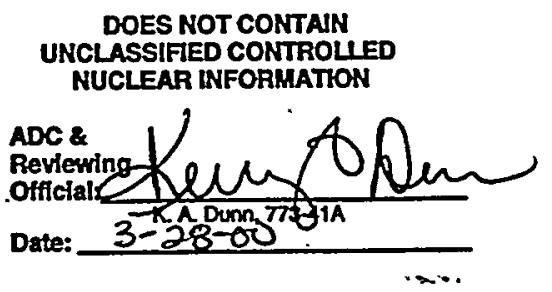

Westinghouse Savannah River Company Savannah River Site Aiken, SC 29808

This document was prepared in connection with work done under Contract No. DE-AC09-96SR18500 with the U. S. Department of Energy 


\section{DISCLAIMER}

This report was prepared as an account of work sponsored by an agency of the United States Government. Neither the United States Government nor any agency thereof, nor any of their employees, makes any warranty, express or implied, or assumes any legal liability or responsibility for the accuracy, completeness, or usefulness of any information, apparatus, product or process disclosed, or represents that its use would not infringe privately owned rights. Reference herein to any specific commercial product, process or service by trade name, trademark, manufacturer, or otherwise does not necessarily constitute or imply its endorsement, recommendation, or favoring by the United States Government or any agency thereof. The views and opinions of authors expressed herein do not necessarily state or reflect those of the United States Government or any agency thereof.

This report has been reproduced directly from the best available copy.

Available for sale to the public, in paper, from: U.S. Department of Commerce, National Technical Information Service, 5285 Port Royal Road, Springfield, VA 22161, phone: (800) 553-6847

fax: (703) 605.6900

email: orders@ntis.fedworld.gov

online ordering: http://www.ntis.gov/ordering.htm

Available electronically at http://www.doe.gov/bridge

Available for a processing fee to U.S. Department of Energy and its contractors, in paper, from: U.S. Department of Energy, Office of Scientific and Technical Information, P.O. Box 62, Oak Ridge, TN 37831-0062, phone: (865) 576-8401

fax: (865) 576.5728

email: reports@adonis.osti.gov 


\section{DISCLAIMER}

Portions of this document may be illegible in electronic image products. Images are produced from the best available original document. 
DOCUMENT: WSRC-TR-2000-00079

TITLE: Degradation and Failure Characteristics of NPP Containment Protective Coating Systems (U)

\section{APPROVALS}

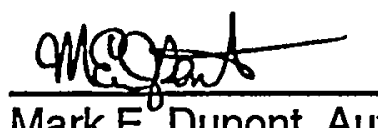

Mark E. Dupont, Author

Date: $3 / 23 / 00$

Materials Applications \& Process Technology Group

Materials Technology Section

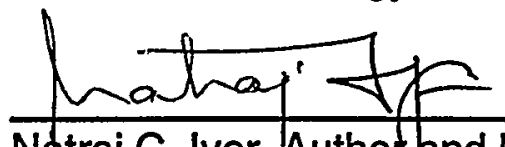

Natraj C. lyer, Authortand Manager

Materials Technology Section

$$
\text { PS lam }
$$

Poh-Sang Lam, Author

Materials Applications \& Process Technology Group

Engineering Development Section

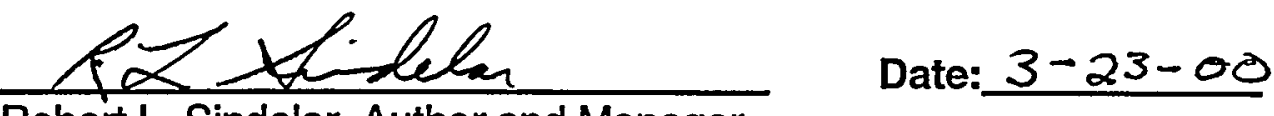

Robert L. Sindelar, Author and Manager

Materials Applications \& Process Technology Group

Materials Technology Section

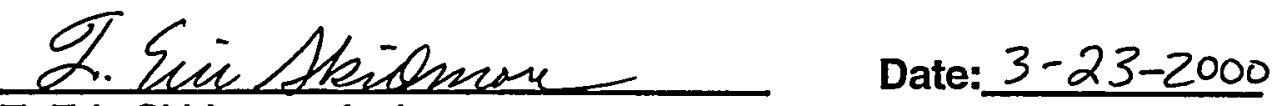

T. Eric Skidmore, Author Materials Consultation Group Materials Technology Section

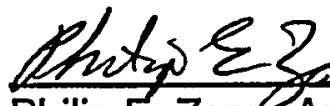

Philip E. Zapp, Author

Materials Performance \& Corrosion Technology Group

Materials Technology Section

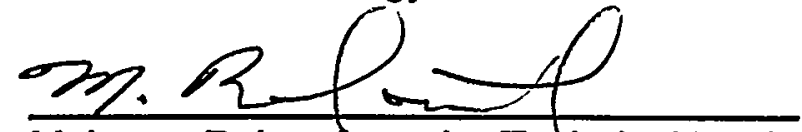

McIntyre R. Louthan, Jr., Technical Reviewer

Date: $3 / 23 / 00$ 
WSRC-TR-2000-00079

\begin{abstract}
A research program to investigate the performance and potential for failure of Service Level I coating systems ${ }^{1}$ used in nuclear power plant containment is in progress. The research activities are aligned to address phenomena important to cause failure as identified by the industry coatings expert panel. The period of interest for performance covers the time from application of the coating through 40 years of service, followed by a medium-to-large break loss-of-coolant accident scenario, which is a design basis accident (DBA) scenario.

The SRTC program consists of three major elements: Materials Properties Development, Failure Modeling Development, and DBA Performance Testing. These elements are directed at determining Service Level I coatings performance under simulated DBA conditions. The coating materials properties data (not previously available) are used in predictive coatings failure models which are then compared against coating behavior under simulated DBA conditions to obtain insights into failed coating materials characteristics and degree of failure (i.e. amount of coatings debris). The resulting data and insights are used in NRC's GSI-191, "PWR Sump Blockage" research program. The effects of aging on coating materials properties and performance are addressed by applying an aging treatment (irradiation to $10^{9} \mathrm{R}$, per ASTM D4082-95) to test specimens.
\end{abstract}

The interactive program elements are discussed in this report and the application of these elements to the System 5 coating system (polyamide epoxy topcoat, polyamide epoxy primer, carbon steel substrate) is used to evaluate performance.

\footnotetext{
${ }^{1}$ The Service Level designation of coatings in nuclear power plants is described in ASTM Standard D5144-97
} 
WSRC-TR-2000-00079

\section{Table of Contents}

Abstract. $\ldots v$

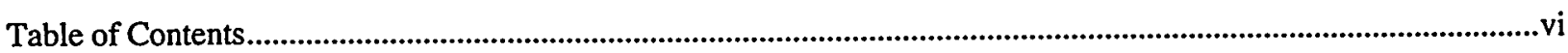

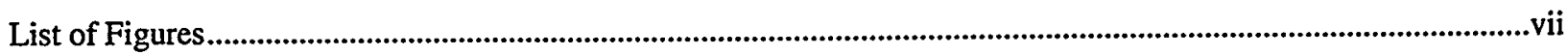

List of Tables viii

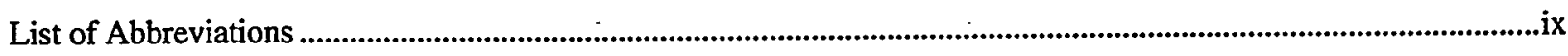

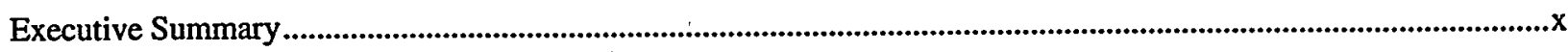

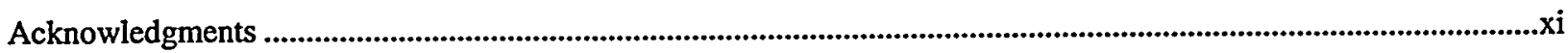

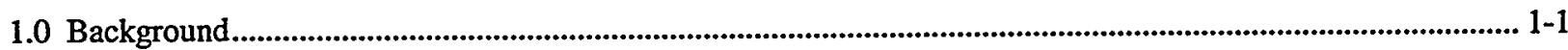

2.0 SRTC Program Elements and Structure ........................................................................................................ 2-1

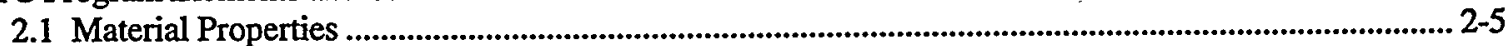

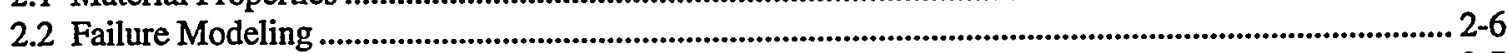

2.3 Measured Performance Under DBA Conditions …….............................................................................. 2-7

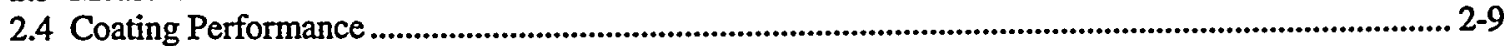

3.0 Coating System 5 Performance................................................................................................................ 3-1

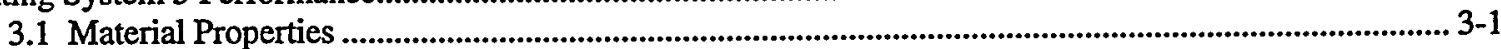

3.2 Failure Modeling .......................................................................................................................... 3-7

3.3 Measured Performance Under DBA Conditions ....................................................................................... 3-14

3.4 Coating Performance .............................................................................................................................. 3-17

4.0 Summary and Significant Findings.................................................................................................................. 4-1

4.1 Coating Research Program ....................................................................................................................... 4-1

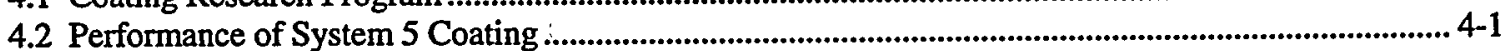

4.3 Summary of Major Findings for System 5 Performance ........................................................................... 4-3

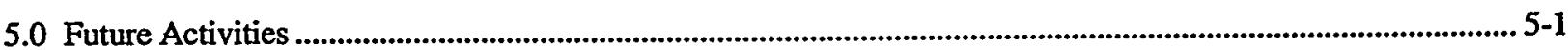

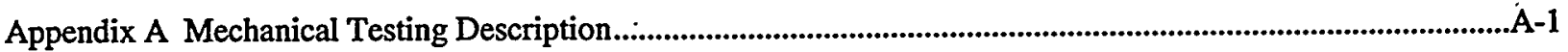

Appendix B Irradiation Aging of Protective Coatings.................................................................................................

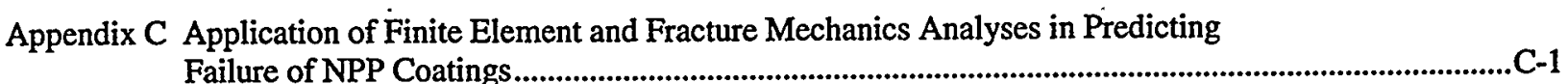

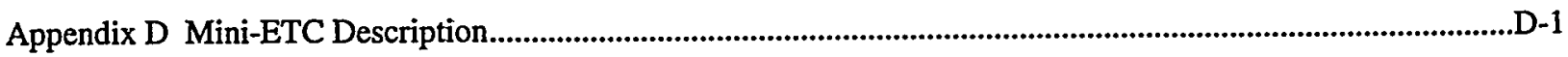

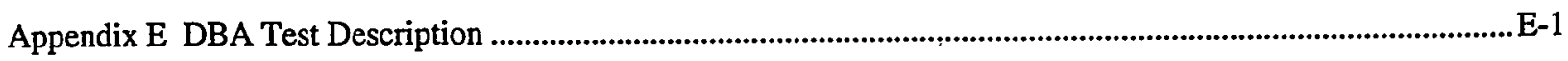

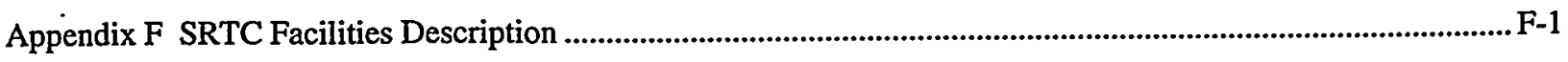

Appendix G Phenomena Identification and Ranking Table Process ....................................................................G-1 


\section{List of Figures}

Task Logic Diagram for SRTC Project

Type 1 Defect in Coating System

Type 2 Defect in Coating System

Laboratory Plate Specimens Coated with Amercoat ${ }^{\otimes} 370$ before and after Exposure to $10^{9} \mathrm{Rad}$ per ASTM D4082-95

"Full DBA" Profile for PWR per ASTM D3911-95 ............................................................................ 2-8

"Abbreviated DBA" Profile

"Pulse DBA" Profile to Simulate a Plant-Specific DBA Temperature/Pressure Profile .............................. 2-9 Blister Formation in Near-Surface Region of Amercoat ${ }^{\circledR} 370$ Following Irradiation to $10^{9} \mathrm{Rad}$ and a Water Soak

Free-film tensile test results for Amercoat ${ }^{\otimes} 370$

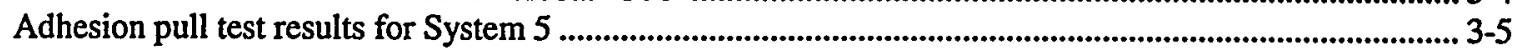

3-3 Half-inch-diameter puller fracture surfaces showing the mixed modes of separation from a System 5 test coupon .

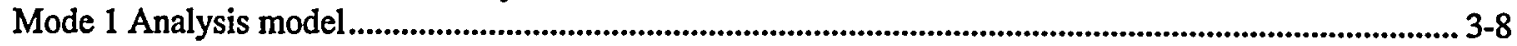

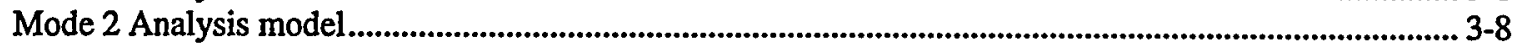

Applied G-Values at the Edge of a dry Defect (Diameter 1/2") during DBA Test Applied G-Values at the Edge of a Vapor Pressurized Defect (Diameter 1/2") during DBA Test................. 3-10 Applied G-Values at the Edge of a Small Vapor Pressurized Defect (Diameter 1/8') during DBA Test

3-11 Applied G-Values at the Edge of a Small Vapor Pressurized Defect (Diameter 1/8") during Cooling Phase in DBA Test

Typical Pressurized Water Reactor Design Basis Accident (DBA) Testing

Parameters (from ASTM D3911-95).

Temperature-pressure Profile Used in SRTC Abbreviated DBA Tests...................................................... 3-15

Zion Plant-Specific Temperature-Pressure Pulse Simulation using MELCOR ............................................ 3-16

Temperature-Pressure Curves from SRTC Pulse Test....................................................................... 3-17

3-18 System 5 coupons before (left) and after (right) irradiation to $10^{9} \mathrm{Rad}$......................................................3-18

3-19 Cross-section of System 5 coating, irradiated to $10^{9}$ Rad.................................................................... 3-18

3-20 Aged System 5 coupon showing incipient mode 1 and mode 2 failures ....................................................3-19

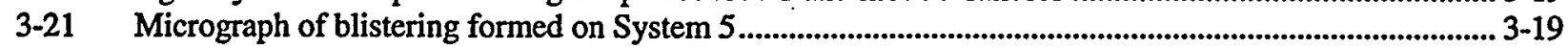

3-22 Cross-section of System 5 aged, DBA-tested showing blister formation

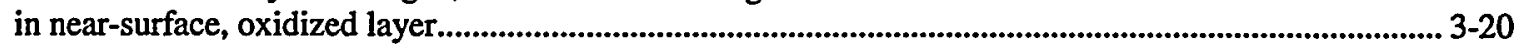

3-23 Ruptured blister, original magnification at 64X............................................................................... 3-20

3-24 Ruptured blister of Figure 3-23 in profile; blister is 15 mils tall, original magnification $64 \mathrm{X}$...................... 3-21

3-25 Checking in System 5 following "Full DBA" test (Mag 7X) ....................................................................... 3-22 
WSRC-TR-2000-00079

\section{List of Tables}

2-1 Cross-Reference Table for Coating Systems Presently Investigated by the SRTC Project and Those Evaluated by the Industry Coatings PIRT

2-2 Project Alignment with High-Ranked Industry PIRT System d Phenomena/Processes (SRTC System 5: Steel Substrate, Epoxy Primer, Epoxy Topcoat) ................................................................ 2-4

2-3 Material Property Parameters Used in Analyzing Coating Performance...................................................... 2-5

3-1 Material Properties for Coating Failure Analysis Using Modes 1 and 2 Failure Models .............................. 3-3

3-2 Free-Film Tensile Test Results for Amercoat ${ }^{\circledR}$ 370................................................................................ 3-4

3-3 Adhesion Pull Test Results for System 5 ............................................................................................... 3-5

3-4 Adhesion G-Value Test Results for System 5 ............................................................................................ 3-6

3-5 Analysis of Percentage of Blistered and Rupture Material in Aged DBA-Tested System 5 Coupon........ 3-21 
WSRC-TR-2000-00079

\section{List of Abbreviations}

$\begin{array}{ll}\text { AE } & \text { Acoustic Emission } \\ \text { ASTM } & \text { American Society for Testing and Materials } \\ \text { BWR } & \text { Boiling Water Reactor } \\ \text { CSS } & \text { Containment Spray System } \\ \text { DBA } & \text { Design Basis Accident } \\ \text { DFT } & \text { Dry Film Thickness } \\ \text { DSC } & \text { Differential Scanning Calorimetry } \\ \text { ECCS } & \text { Emergency Core Cooling System } \\ \text { EIS } & \text { Electrochemical Impedance Spectroscopy } \\ \text { EPRI } & \text { Electric Power Research Institute } \\ \text { ETC } & \text { Environmental Test Chamber } \\ \text { FT-IR } & \text { Fourier Transform-Infrared Spectroscopy } \\ \text { IOZ } & \text { Inorganic Zinc } \\ \text { LOCA } & \text { Loss of Coolant Accident }\end{array}$

AE Acoustic Emission

BWR Boiling Water Reactor

CSS Containment Spray System

DBA Design Basis Accident

DFT Dry Film Thickness

DSC Differential Scanning Calorimetry

ECCS Emergency Core Cooling System

Electrochemical Impedance Spectroscopy

FT-IR Fourier Transform-Infrared Spectroscopy

LOCA Loss of Coolant Accident

\author{
NACE National Association of Corrosion Engineers \\ NMRS Nuclear Magnetic Resonance Spectroscopy \\ NPP Nuclear Power Plant \\ NRC (U.S.) Nuclear Regulatory Commission \\ PIRT Phenomena Identification and Ranking Table \\ PTFE Polytetrafluorethylene \\ PWR Pressurized Water Reactor \\ SEM Scanning Electron Microscopy \\ SIMS Secondary Ion Mass Spectroscopy \\ SRTC Savannah River Technology Center \\ SSC Structure, System, and Component \\ SSPC Steel Structures Painting Council \\ TEM Transmission Electron Microscopy \\ TGA Thermogravimetric Analysis \\ XRD X-ray Diffraction
}




\section{Executive Summary}

The US Nuclear Regulatory Commission (NRC) has identified the potential for degradation and failure of "qualified" protective coatings applied to exposed surfaces within nuclear power plant primary containment during the design life of such plants, and has communicated such concerns to license holders in NRC Generic Letter 98-04 dated July 14, 1990. As a consequence of this letter, the NRC commissioned the Savannah River Technology Center (SRTC) to investigate the potential for degradation and failure of such coating systems when subjected to DBA conditions, and to characterize failed coating debris. The formation and transport of some types of coating debris to a PWR ECCS sump debris screen was judged to have an undesirable safety impact during the post-LOCA period.

The SRTC coatings program and illustrative findings provided in this report illustrate the investigative approach and significant findings obtained for a epoxy-polyamide primer and topcoat applied to a steel substrate (designated as System 5). The experimental approach is a combination of measurement of critical coating materials properties at conditions representative of a post-LOCA period, the development of a predictive coating system failure model, subjecting such coating systems to DBA conditions, comparing model and test results to judge predictive capability, documenting the degree of failure and characterization of failed coating debris which will be integrated into the PWR sump blockage research program (GSI-191).

The research results reported in this interim report arrive at the following preliminary conclusions:

1. Properly applied "qualified" coatings systems can be expected to exhibit adequate adhesion strength to a steel substrate following exposure to simulated DBA conditions.

2. Artificial aging of System 5 (related to gamma radiation exposure as defined in ASTM Standard D-4082-95) exhibited some near surface degradation of the epoxy polymer materials. This degradation appears to the consequence of coating oxidation resulting from irradiation and temperature effects and would be expected to vary with oxygen availability and permeability in a particular coating system.

3. Although a properly applied System 5 coating system exhibited only blistering without detachment when subjected to a simulated LOCA, it is projected that this coating system (if there were coating flaws which had entrapped moisture) could fail during the rapid containment cool down introduced by activation of containment spray systems.

The research approach described in this report will be extended to investigate Service Level I protective coating systems applied to internal PWR containment surfaces in the early and mid 1970s. Such findings, when available, will be discussed in public meetings and also incorporated into the final project report. 


\section{Acknowledgments}

The following individuals have made contributions to the success of the SRTC Coatings Evaluation Program:

Nuclear Regulatory Commission:

Aleck Serkiz

Savannah River Technology Center:

Chris Beam

Glen Chapman

Mark Dupont

Natraj Iyer

Poh-Sang Lam

Doug Leader

Mac Louthan

Tommy McCoy

Bridget Miller

Mike Morgan

Tracy Murphy

Harold Peacock

Curt Sexton

David Silver

Bob Sindelar

Eric Skidmore

Tina Stefek

Craig Stripling

Karthik Subramanian

Frank Utsch

Phil Zapp

Principal investigators in bold.

Bechtel Savannah River Company

Bobby Hill

PIRT Panel Members:

Jon Cavallo, Chm.

Corrosion Control, Consultants and Labs, Inc.

Tim Andreycheck Westinghouse Electric Corp, Pittsburgh, PA

Jan Bostelman

Dr. Brent Boyack

Garth Dolderer

David Long

ITS Corporation

Los Alamos National Laboratory

Florida Power and Light

Keeler and Long (now retired). 


\subsection{Background}

Nuclear power plants (NPPs) must ensure that the emergency core cooling system (ECCS) or safety-related containment spray system (CSS) remains capable of performing its design safety function throughout the life of the plant. This requires ensuring that long-term core cooling can be maintained following a postulated loss-of-coolant accident (LOCA). Adequate safety operation can be impaired if the protective coatings fail, producing transportable debris which could then accumulate on BWR ECCS suction strainers or PWR ECCS sump debris screens located within primary containment.

Service Level I coatings were used on the interior containment steel shells, concrete walls and floors, and other structures, thereby providing environmental protection to these substrates and facilitating decontamination, as necessary. The coatings, which were applied during plant construction, were expected to last throughout the 40-year license period or design life of the plant, except for minor local damage due to mechanical impact or cleaning chemicals. These coatings were selected based on demonstrated adequate survivability under simulated DBA LOCA conditions as described in ASTM Standard D-3911-95, or earlier ANSI standards. The assumption was that qualified coatings that were properly selected and applied at time of construction would not fail during normal plant operation or during a LOCA. Coating condition monitoring and maintenance were considered unnecessary.

However, there is clear evidence for failure of qualified coatings during plant design life. Such failures are described in attachments to NRC GL 98-04, "Potential for Degradation of Emergency Core Cooling System and Containment Spray System after a Loss-of-Coolant Accident Because of Construction and Protective Coating Deficiencies and Foreign Material in Containment," July 14, 1998. This evidence resulted in NRC's Office of Nuclear Reactor Regulation requesting that research (NRR 6/2/97) be directed at debris generation testing of protective coatings that are likely to fail during an accident. The research would determine the timing of the coating failure during an accident (e.g., minutes, hours, days) and the characteristics of the failed coating debris (e.g., chips, large strips, particulate materials). This research need was the basis for NRC's Office of Nuclear Regulatory Research, Division of Engineering Technology, initiating a program through the Savannah River Technology Center to research the performance of aged containment coatings under simulated LOCA conditions.

SRTC's program is designed to investigate NPP containment coatings through a better understanding of coating materials properties (e.g., property changes introduced by elevated temperature and irradiation effects), development of a predictive coating failure model, and DBA performance testing of coating samples representative of coatings applied in NPPs. The ultimate goal is to establish a coating debris database that characterizes and quantifies the failed material. The SRTC program elements and interactive approach are described in Sections 2 and 3, and the results for a reference System 5 coating are described in Section 3.

This Interim Report highlights research findings that have been reported in monthly letter status reports to the NRC since project initiation in July 1998. Research results have been reported also in public meetings, held on November 5 1998, April 15 1999, and November 22 1999, at NRC Headquarters. Licensees, industry NPP coatings groups, and individual NPP coatings specialists have shown considerable interest and offered assistance to the program. Similar public interaction will be continued throughout the research project, which is scheduled for completion in December 2000 . The data obtained is continually integrated into NRC's Generic Safety Issue (GSI) 191, PWR Sump Blockage project. Research findings also have a potential to identify a need for review and revision to ASTM Standards (e.g., ASTM Standard D-5144, - "Standard Guide for Use of Protective Coating Standards in Nuclear Power Plants and other support standards) currently used by licensees. This need will be endorsed by the NRC in the issuance of Draft Regulatory Guide -1076, "Service Level I, II, and III Protective Coatings Applied to Nuclear Power Plants," March 1999. 


\subsection{SRTC Program Elements and Structure}

The Savannah River Technology Center coatings research program is designed to investigate the potential degradation and failure of Service Level I protective coatings under postulated LOCA conditions. The key program elements and interactive paths are shown in Figure 2-1. The program goal is to obtain insights into the performance of "qualified" coating systems. Coating behavior could range from no failure to disbonding accompanied by the production of debris that could degrade the performance of PWR ECCS sumps. The assumption has been that properly selected and applied "qualified" coatings will not fail during the normal plant design life (i.e. 40 years) nor following a LOCA. Minor blistering and cracking are not considered a failures. Coating disbondment is considered a failure and the accompanying "free" material constitutes a debris source.

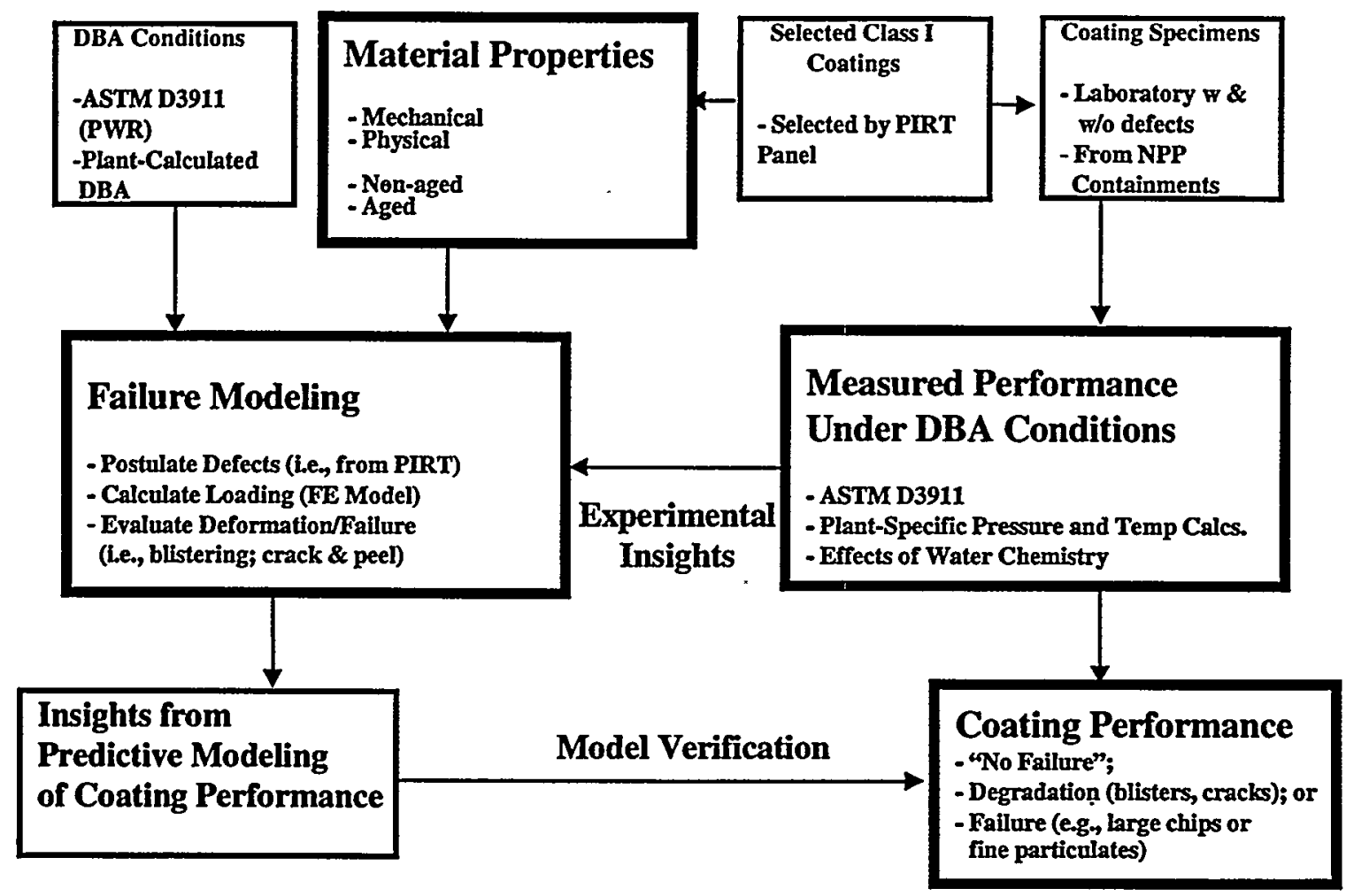

Figure 2-1. Task Logic Diagram for SRTC Project

The four principal program elements are: a) measuring key coating materials properties, b) developing a predictive coatings failure model, c) subjecting selected coatings to design basis accident conditions, or simulated LOCA conditions, and measuring performance, and d) providing insights into the performance of Service Level I coatings and, if failures occur, identifying debris source characteristics which include size, shape, and amount (per unit exposed area).

Protective coating materials applied in NPPs were identified from the EPRI "Coatings Handbook for Nuclear Power Plants," EPRI TR-106160, June 1996 [2.1], from plant specific responses, and from surveys performed by several industry groups. Although EPRI TR-106160 lists data collected from 29 nuclear industry respondents and represents over 200 unique coating products in over 1000 different plant-specific applications, the data set does not lend itself to identification of a limited set of generic coating systems to focus on. This need to identify generic 


\section{WSRC-TR-2000-00079}

coating systems that represent widespread use in NPPs was facilitated by formation of an industry Phenomena Identification and Ranking Table panel. A detailed description of a generic PIRT process is described in reference 2.2. The specific PIRT process, panel members and the completed PIRTs for the nuclear industry coating systems [2.3] are discussed in Appendix G.

The generic coatings systems identified by the PIRT panel for consideration in the SRTC program are:
a. Steel substrate, inorganic zinc primer, epoxy phenolic topcoat,
b. Steel substrate, epoxy phenolic primer, epoxy phenolic topcoat,
c. Steel substrate, inorganic zinc primer, epoxy topcoat,
d. Steel substrate, epoxy primer, epoxy topcoat
e. Concrete substrate, surfacer, epoxy phenolic topcoat,
f. Concrete substrate, surfacer, epoxy topcoat,
g. Concrete substrate, epoxy phenolic. primer, epoxy phenolic topcoat,
h. Concrete substrate, epoxy primer, epoxy topcoat

These generic coating systems encompass NPP Service Level I protective coatings that date back to the early 1970s. Coating systems applied to PWR containment internal steel surfaces and to concrete walls or floors are to be investigated. PIRT System "a" was identified to be of primary interest due to an instance of significant "area of detachment" of the topcoat from the IOZ primer in an NPP and also based on insights from the PIRT completed for that system. The PIRT system " $f$ " was identified as the primary concrete coating system since this is the most widely used system.

Nuclear industry accepted ASTM standards for preparation of coating test samples (ASTM D-5139-90)[2.4], irradiation of test samples (ASTM D-4082-95)[2.5], and simulation of DBA testing (ASTM D-3911-95)[2.6] are an integral part of this research program. These standards form the basis for test sample procurement and testing. Thus, the procurement of coating materials and preparation of "qualified" test samples becomes a path-limiting activity. An example is the procurement of coating formulation materials needed for System "a" which became very difficult and protracted because a particular type of asbestos was a principal constituent of the CZ11 primer used in NPPs in the 1970s. Delays have been encountered also in the acquisition of coated concrete samples. Therefore alternate coatings systems were used to move the program forward in a "proof-of-approach" mode. Table 2.1 identifies the available coating products selected and discussed in this report, and also cross-references such materials with the PIRT panel's generic descriptions.

The PIRT panel recommended use of SRTC coating System 5 to benchmark the adequacy and success of property measurements, predictive failure analysis models, performance under DBA conditions, and evaluating coating performance (including coating debris source identification). The majority of findings reported here are therefore for SRTC System 5 (steel substrate, Amercoat ${ }^{\otimes} 370$ primer, and Amercoat ${ }^{\circledR} 370$ topcoat).

The PIRTs completed for coating systems "a", "f" and " $\mathrm{d}$ " (System 5) are described and discussed in Appendix G. The integration of PIRT panel evaluations (which are derived from identification of phenomena and processes that could lead to coating failure, and the ranking thereof) is illustrated in Table 2.2. The linking of project activities and PIRT phenomena/process elements is represented by the central column identifying physical properties and phenomena of importance. Project resources will be directed at PIRT phenomena/processes ranked high and to a lesser degree to the PIRT phenomena/processes of medium rank.

Section 3 of this report details results to date for material property testing, predictive failure modeling, DBA test findings and coating performance following a DBA test for SRTC System 5. Significant insights are provided in Section 4, and Section 5 discusses near-term and planned concluding activities for this project. 
Table 2-1. Cross-Reference Table for Coating Systems Presently Investigated by the SRTC Project and Those Evaluated by the Industry Coatings PIRT Panel

\begin{tabular}{|c|c|c|c|c|}
\hline Substrate & Generic Description & $\begin{array}{l}\text { Coating Products } \\
\text { Tested at SRTC }\end{array}$ & $\begin{array}{c}\text { SRTC } \\
\text { System No. }\end{array}$ & $\begin{array}{c}\text { PIRT } \\
\text { System Letter } \\
\end{array}$ \\
\hline Steel & $\begin{array}{l}\text { Epoxy-phenolic over inorganic } \\
\text { zinc }\end{array}$ & $\begin{array}{l}\text { Phenoline }^{\otimes} 305 \text { over Carbozinc } \\
11\end{array}$ & $x_{2}$ & 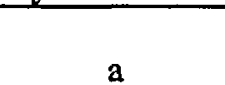 \\
\hline Concrete & Epoxy-phenolic over surfacer & Phenoline $^{\otimes} 305$ over surfacer & 2 & $\mathrm{e}$ \\
\hline Steel & $\begin{array}{l}\text { Phenolic-modified epoxy over } \\
\text { inorganic zinc }\end{array}$ & $\begin{array}{l}\text { Amercoat }{ }_{9}^{\otimes} \text { 90HS over Dimetcote }{ }^{\otimes} \\
\end{array}$ & 3 & \\
\hline Steel & $\begin{array}{l}\text { Phenolic-modified epoxy over } \\
\text { epoxy-polyamide }\end{array}$ & $\begin{array}{l}\text { Amercoat }^{(2} \text { 90HS over Amercoat } \\
370\end{array}$ & 4 & \\
\hline Steel & $\begin{array}{l}\text { Epoxy-polyamide over epoxy- } \\
\text { polyamide }\end{array}$ & $\begin{array}{l}\text { Amercoat }^{\theta} 370 \text { over Amercoat } \\
370\end{array}$ & 5 & d \\
\hline Steel & Inorganic zinc & Dimetcote $^{\otimes} 9$ & 6 & \\
\hline Steel & $\begin{array}{l}\text { Epoxy-phenolic over epoxy- } \\
\text { phenolic }\end{array}$ & & & b \\
\hline Steel & Epoxy over inorganic zinc & & & c \\
\hline Concrete & Epoxy over surfacer & 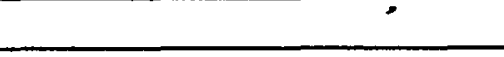 & & f \\
\hline Concrete & $\begin{array}{l}\text { Epoxy-phenolic over epoxy- } \\
\text { phenolic }\end{array}$ & & & g \\
\hline Concrete & Epoxy over epoxy & & & $\mathrm{h}$ \\
\hline
\end{tabular}


Table 2-2. Project Alignment with Industry PIRT System d (SRTC System 5: Steel Substrate, Epoxy Primer, Epoxy Topcoat)

\begin{tabular}{|c|c|c|c|}
\hline $\begin{array}{l}\text { High-Ranked Industry PIRT } \\
\text { Phenomena/Processes }\end{array}$ & $\begin{array}{l}\text { Time } \\
\text { Phase }\end{array}$ & $\begin{array}{l}\text { Related Inputs and Physical } \\
\text { Properties from SRTC Factor } \\
\text { Table }\end{array}$ & Related Project Activities \\
\hline $\begin{array}{l}\text { Blistering and Delamination at } \\
\text { Substrate-Primer Interface }\end{array}$ & $2,3,4,5$ & $\begin{array}{c}\text { Adhesive Strength, Tensile } \\
\text { Strength, Ductility } \\
\end{array}$ & $\begin{array}{l}\text { Adhesion Testing, Free-Film Testing, Mode } 1 \\
\text { \& } 2 \text { Failure Modeling }\end{array}$ \\
\hline $\begin{array}{l}\text { Oxidation at Substrate-Primer } \\
\text { Interface }\end{array}$ & $3,4,5$ & Corrosion & DBA Testing of Defect 2 Coupons \\
\hline $\begin{array}{l}\text { Environmental Exposure to } \\
\text { Primer }\end{array}$ & 1 and 5 & $\begin{array}{c}\text { Total Radiation Dose, } \\
\text { Temperature/Humidity History, } \\
\text { Decontamination Chemicals, } \\
\text { Corrosion, Erosion, Abrasion } \\
\end{array}$ & $\begin{array}{l}\text { Radiation Aging and Thermal Aging of } \\
\text { Laboratory Specimens, Characterization and } \\
\text { Testing of Plant Specimens }\end{array}$ \\
\hline $\begin{array}{l}\text { Mechanical Damage to Primer } \\
\& \text { Topcoat }\end{array}$ & 1 & Adhesive Strength & DBA Testing of Defect 2 Coupons \\
\hline $\begin{array}{l}\text { Minor Coating Anomalies in } \\
\text { Primer }\end{array}$ & 5 & Substrate Cleanliness & $\begin{array}{l}\text { Adhesion and DBA Testing with Defect } 1 \\
\text { Coupons }\end{array}$ \\
\hline $\begin{array}{l}\text { Air, Water, \& Chemical } \\
\text { Intrusion } \\
\text { Into Primer Above Pool }\end{array}$ & 5 & $\begin{array}{l}\text { Water Permeation and Water } \\
\text { Chemistry }\end{array}$ & DBA Testing \\
\hline $\begin{array}{l}\text { Air, Water, \& Chemical } \\
\text { Intrusion } \\
\text { Below Pool }\end{array}$ & 5 & $\begin{array}{l}\text { Water Permeation and Water } \\
\text { Chemistry }\end{array}$ & DBA Testing \\
\hline $\begin{array}{l}\text { Blistering and Delamination at } \\
\text { Primer-Topcoat Interface }\end{array}$ & $1,2,3,4,5$ & $\begin{array}{l}\text { Adhesive Strength, Tensile } \\
\text { Strength, Ductility }\end{array}$ & $\begin{array}{l}\text { Adhesion Testing, Free-Film Testing, Mode } 1 \\
\text { \& 2 Failure Modeling }\end{array}$ \\
\hline $\begin{array}{l}\text { Environmental Exposure to } \\
\text { Topcoat }\end{array}$ & 1 & $\begin{array}{c}\text { Total Radiation Dose, } \\
\text { Temperature/Humidity History, } \\
\text { Decontamination Chemicals, } \\
\text { Corrosion, Erosion, Abrasion } \\
\end{array}$ & $\begin{array}{l}\text { Radiation Aging and Thermal Aging of } \\
\text { Laboratory Specimens, Characterization and } \\
\text { Testing of Plant Specimens }\end{array}$ \\
\hline \multicolumn{4}{|l|}{$\begin{array}{l}\text { Medium-Ranked Industry } \\
\text { PIRT Phenomena/Processes }\end{array}$} \\
\hline $\begin{array}{l}\text { Environmental Exposure to } \\
\text { Primer }\end{array}$ & $2,3,4$ & $\begin{array}{l}\text { Total Radiation Dose, } \\
\text { Temperature/Humidity } \\
\text { History, Decontamination } \\
\text { Chemicals, Corrosion, } \\
\text { Erosion, Abrasion }\end{array}$ & $\begin{array}{l}\text { Radiation Aging and Thermal Aging of } \\
\text { Laboratory Specimens, Characterization } \\
\text { and Testing of Plant Specimens }\end{array}$ \\
\hline $\begin{array}{l}\text { Minor Coating Anomalies in } \\
\text { Primer }\end{array}$ & $2,3,4$ & Substrate Cleanliness & $\begin{array}{c}\text { Adhesion and DBA Testing with Defect } 1 \\
\text { Coupons }\end{array}$ \\
\hline $\begin{array}{l}\text { Air, Water, \& Chemical } \\
\text { Intrusion } \\
\text { Into Primer Above Pool }\end{array}$ & 3,4 & $\begin{array}{l}\text { Water Permeation and Water } \\
\text { Chemistry }\end{array}$ & DBA Testing \\
\hline $\begin{array}{l}\text { Environmental Exposure to } \\
\text { Topcoat }\end{array}$ & $2,3,4,5$ & $\begin{array}{l}\text { Total Radiation Dose, } \\
\text { Temperature/Humidity } \\
\text { History, Decontamination, } \\
\text { Chemicals, Corrosion, } \\
\text { Erosion, Abrasion }\end{array}$ & $\begin{array}{l}\text { Radiation Aging and Thermal Aging of } \\
\text { Laboratory Specimens, Characterization } \\
\text { and Testing of Plant Specimens }\end{array}$ \\
\hline $\begin{array}{l}\text { Topcoat } \\
\text { Expansion/Contraction }\end{array}$ & 2 & $\begin{array}{l}\text { Coefficients of Thermal and } \\
\text { Hygroscopic Expansion }\end{array}$ & DBA Testing and Modeling of Stresses \\
\hline $\begin{array}{l}\text { Minor Coating Anomalies in } \\
\text { Topcoat }\end{array}$ & $2,3,4,5$ & $\begin{array}{l}\text { Coefficients of Thermal and } \\
\text { Hygroscopic Expansion }\end{array}$ & $\begin{array}{l}\text { Modeling of Stresses Including Thermal } \\
\text { Coefficients of Expansion }\end{array}$ \\
\hline $\begin{array}{l}\text { Air, Water, \& Chemical } \\
\text { Intrusion } \\
\text { Into Topcoat Above Pool }\end{array}$ & $3,4,5$ & $\begin{array}{l}\text { Water Permeation and Water } \\
\text { Chemistry }\end{array}$ & DBA Testing \\
\hline
\end{tabular}

Phase 1: Normal service to 40 years.

Phase 2: 0 to 40 seconds into loss-of-coolant accident. Phase 3: 40 seconds to 30 minutes after LOCA.
Phase 4: 30 minutes to 2 hours after LOCA. Phase 5: Beyond 2 hours after LOCA. 


\subsection{Material Properties}

The coating system materials properties being assembled in the coatings research program are a fundamental set of properties that are used to analyze coating performance and potential for coating failure. The properties may be dependent on temperature and wetness, and may be changed by aging mechanisms (e.g. oxidation, irradiationinduced scissioning, and thermally-induced cross-linking or scissioning) active during the service period and/or the design basis accident (DBA) scenario.

Materials properties are required input to analytical models of coating deformation and failure (see Figure 2-1). The input parameters used for coating System 5 are contained in Table 2-3. The table also includes several property parameters, not used directly as inputs to modeling, that provide a quantitative measure of the effects of aging and DBA exposure conditions on the potential for coating failure. One such parameter being measured in the research program is the adhesion strength; it is a simple measurement with sensitivity to detect differences in specimens tested at various conditions of temperature, wetness, and irradiation exposure. A reduction in the adhesion strength indicates an increase in potential for failure. The properties have been categorized as either "properties for loading" or "properties for mechanical response." The properties for loading are those used to calculate the stress distribution in the coating system; the properties for mechanical response are those used to calculate deformation of the coating system. The steps in analytical modeling are outlined in section 2.2 .

Table 2-3. Material Property Parameters Used in Analyzing Coating Performance*

\begin{tabular}{|c|c|c|c|}
\hline $\begin{array}{c}\text { Material Property } \\
\text { Parameter }\end{array}$ & Topcoat & Primer & Substrate \\
\hline \multicolumn{4}{|c|}{ Properties for Mechanical Response } \\
\hline $\begin{array}{l}\text { Ultimate Tensile } \\
\text { Strength }\left(\sigma_{u}\right)\end{array}$ & Applicable & Applicable & Not Applicable \\
\hline $\begin{array}{c}\text { Ductility (Total Strain at } \\
\text { Failure, } \varepsilon_{f} \text { ) }\end{array}$ & Applicable & Applicable & Not Applicable \\
\hline Young's Modulus (E) & Applicable & Applicable & Applicable \\
\hline Poisson's Ratio (v) & Applicable & Applicable & Applicable \\
\hline $\begin{array}{l}\text { Adhesion Strength to } \\
\text { Under Layer }\end{array}$ & Applicable & Applicable & Not Applicable \\
\hline $\begin{array}{l}\text { Adhesion Energy to } \\
\text { Under Layer (G) }\end{array}$ & Applicable & Applicable & Not Applicable \\
\hline Cohesion Energy & Applicable & Applicable & Not Applicable \\
\hline \multicolumn{4}{|c|}{ Properties for Loading } \\
\hline $\begin{array}{c}\text { Coefficient of Thermal } \\
\text { Expansion }\left(\alpha_{\mathrm{T}}\right)\end{array}$ & Applicable & Applicable & Applicable \\
\hline $\begin{array}{c}\text { Coefficient of } \\
\text { Hygroscopic Expansion }\end{array}$ & Applicable & Applicable & Not Applicable \\
\hline $\begin{array}{l}\text { Glass Transition } \\
\text { Temperature }\end{array}$ & Applicable & Applicable & Not Applicable \\
\hline Thermal Conductivity & Applicable & Applicable & Applicable \\
\hline Specific Heat & Applicable & Applicable & Applicable \\
\hline Density $(p)$ & Applicable & Applicable & Applicable \\
\hline
\end{tabular}

Most of these parameters are not available either in the open literature or from the coatings vendors. The properties that are available are either not at specific environmental conditions of interest (e.g. temperature and wetness of a DBA) or may not be accurate for the specific formulation of a coating of interest (e.g. Phenoline ${ }^{\otimes} 305$ ). Therefore, the coating-specific properties are being measured at DBA-relevant conditions in the coatings research program. The temperature range $\left(100-300^{\circ} \mathrm{F}\right)$ and wetness (dry and wet) at which the properties are being measured span the conditions of the ASTM DBA profile for a PWR [2.6]. Section 3.1 describes the properties that have been 
measured for Amercoat ${ }^{\circledR} 370$ and also the relevant literature data for epoxy. These properties are collected in embedded look-up tables as described in section 3.1.

The testing methods to measure the properties for loading are ASTM standard methods. The testing methods for the mechanical response have been developed in the research program. The mechanical test methods are described in detail in Appendix A of this report.

An irradiation exposure to $1 \times 10^{9} \mathrm{Rad}$ at $120^{\circ} \mathrm{F}$, in accordance with ASTM standard D4082-95 [2.5], is being applied to the mechanical test specimens as an aging treatment. Properties for the parameters in Table 2-3 are collected for coatings in both the "non-aged" condition, to represent a properly formulated, properly cured coating in its initial condition, and the D4082-95 treatment to represent a coating in the "aged" condition. Appendix B describes the aging treatment in detail. Section 3.1 contains the properties for the non-aged and aged Amercoat ${ }^{\otimes}$ 370 coating.

\subsection{Failure Modeling}

Analytical modeling is used to predict coating performance under the environmental conditions of the DBA. These conditions include elevated temperatures and pressures from steam, including expected transient and steady-state conditions. Environmental conditions can create stresses in the coating that, if high enough, can cause cracking in the coating, or delamination of the coating, or both. Either cracking or delamination events are the precursors in the production of a debris source (e.g., free chip). It is the production of debris that constitutes failure of the coating.

The analytical modeling is capable of predicting cracking and delamination events. The approach is to build finite element analysis models of the topcoat/primer/substrate system and input the conditions of interest to analyze the system response. There are three fundamental categories of inputs to the models:

1. Configuration - includes an initial defect postulate, location of the defect in the coating system, number of coatings and coating thickness, and the type of substrate onto which the coating is applied.

2. Materials Properties - includes mechanical and physical properties of the coating layers and substrate materials.

3. Loading - includes both direct loads (e.g. impingement of water) and environmental conditions that lead to coating stresses.

There are several parts in the analysis of coating performance. The first part is the determination of the stress distribution in a non-defected coating system at a time period of interest in the DBA cycle and a check of the following criterion for cracking:

$$
\sigma_{\text {material failure }} \leq \sigma_{\text {applied }} \text { or } \varepsilon_{\text {material failure }} \leq \varepsilon_{\text {applied }}
$$

The second part is the consideration of a so-called Type 1 defect, defined as a local delaminated region beneath the surface of the coating, as shown in Figure 2-2. This type of defect may be subject to "Mode 1 deformation" that is the formation of a blister dome, followed by delamination, and cracking. The stress-strain and applied $G$ distributions are determined at a time period of interest in the DBA profile and these two criteria are checked for delamination and cracking, respectively:

$$
\begin{aligned}
& \mathrm{G}_{\text {material }} \leq \mathrm{G}_{\text {applied }} \text { and } \\
& \sigma_{\text {material failure }} \leq \sigma_{\text {applied }} \text { or } \varepsilon_{\text {material failure }} \leq \varepsilon_{\text {applied }}
\end{aligned}
$$

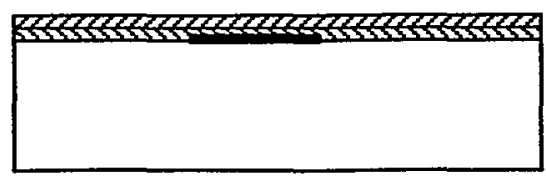

Figure 2-2. Type 1 Defect in Coating System 
The third part is the consideration of a Type 2 defect, defined as a local hole through the coating, as shown in Figure 2-3. This type of defect may be subject to "Mode 2 deformation" that is a peel-back of the coating, followed by cracking. As in the evaluation of Mode 1 deformation, the stress-strain and applied G distributions are determined and the two criteria for delamination and cracking are checked.

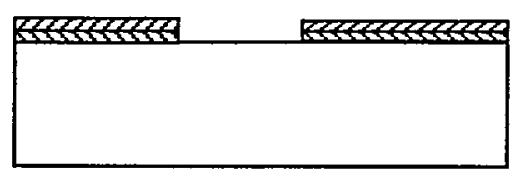

Figure 2-3. Type 2 Defect in Coating System

The details of analytical modeling are outlined in Appendix $C$ of this report. Section 3.2 provides the results of the analyses of coating System 5 for various specific Type 1 and Type 2 defect postulates and DBA profiles using the measured properties for Amercoat $^{\circledR} 370$ as listed in section 3.1.

\subsection{Measured Performance Under DBA Conditions}

Direct measurement of coating systems performance is achieved by exposing laboratory specimens, with and without initial design defects and in as-applied and irradiation-aged conditions, to DBA profiles. The specimens are characterized with standard metallurgical practices to quantify blistering, cracking, and debris.

Carbon steel plates, 4"x6"x 1/4" are coated and used as laboratory specimens for both the mechanical tests (adhesion strength tests (i.e., pull tests) and adhesion energy tests (i.e., G-tests)) and for DBA testing. Figure 2.4 shows a plate specimen with the System 5 coating before and after the irradiation aging treatment. The irradiation aging treatment is described in detail in Appendix B.

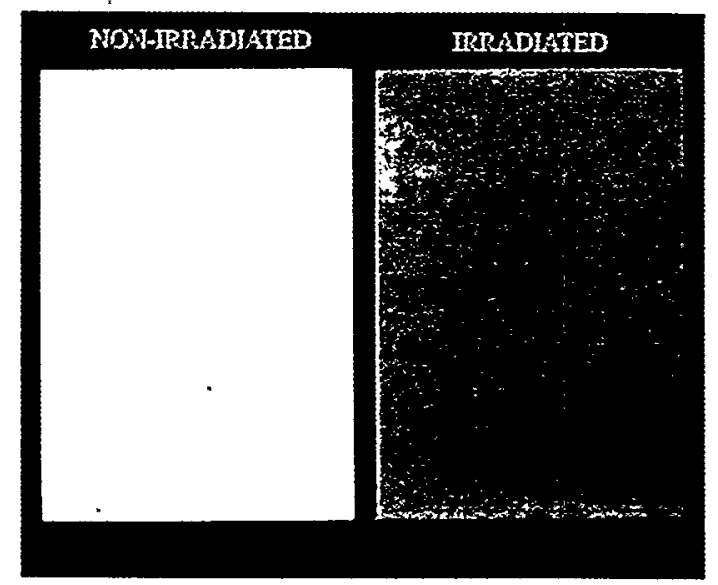

Figure 2-4. Laboratory Plate Specimens Coated with Amercoat ${ }^{\oplus} 370$ before (plate on left) and after (plate on right) Exposure to $10^{9}$ Rad per ASTM D4082 -95

The plate specimens also are fabricated to contain a Type 1 (delamination under the coating) or a Type 2 (hole through coating) defect. Figures 2-2 and 2-3 show drawings of the Type 1 and Type 2 defects. The fabrication of Type 1 defects is described in Appendix A to this report; Type 2 defects are created by drilling through the coating with a 0.5 -inch-diameter end mill.

There are three DBA profiles investigated in this study. The standard DBA temperature and pressure profile for qualification of coating system is given in ASTM standard D3911-95 [2.6] and is termed the "full DBA profile" in this report. Figure 2-5 below shows this profile, which is run for a total exposure period of approximately one week. 


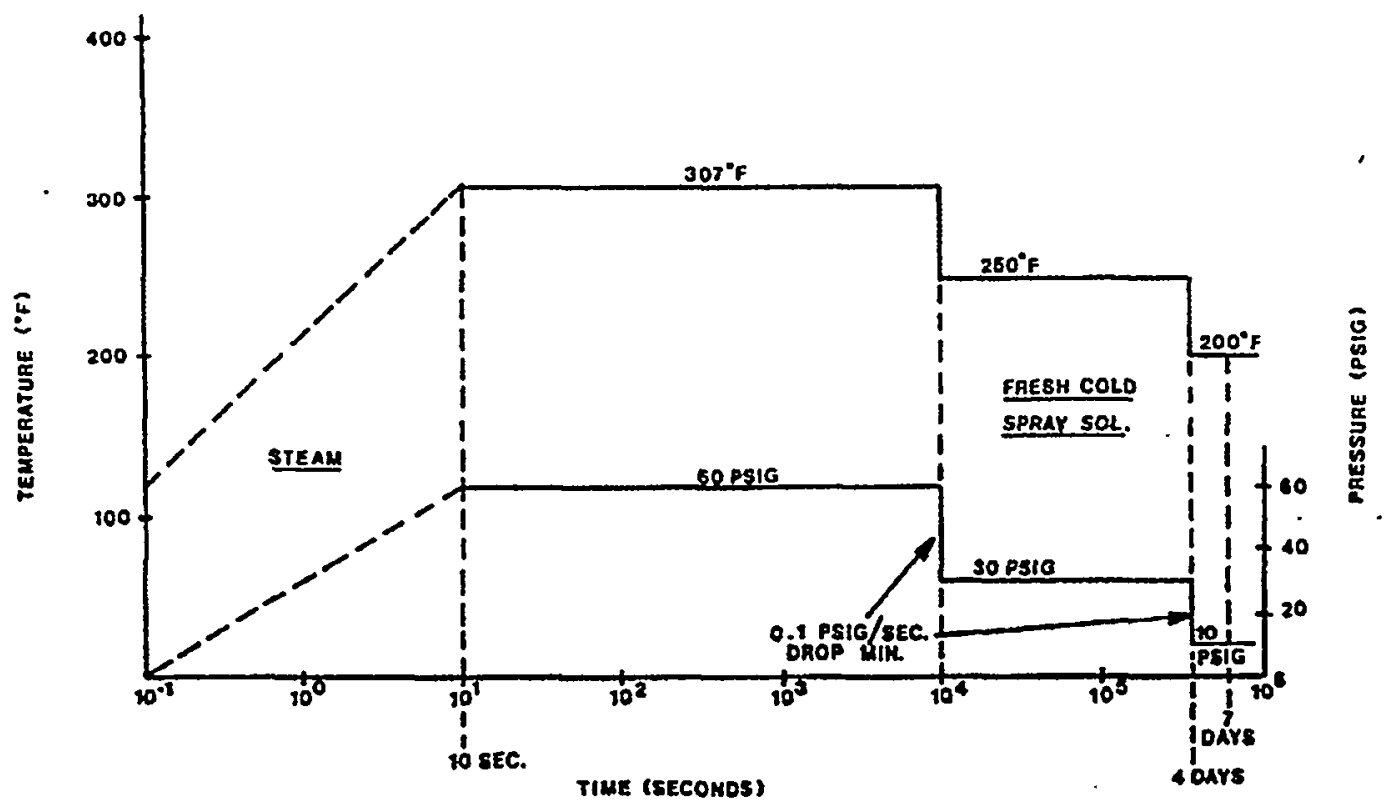

Figure 2-5. "Full DBA" Profile for PWR per ASTM D3911-95

An abbreviated version of the DBA profile was used in the program to facilitate acquisition of data quickly to determine insights and to allow many tests to be performed in the SRTC Mini-Environmental Test Chamber. A description of the unique facility which is fully-equipped for video monitoring and recording and data logging is provided in Appendix D of this report. A typical "abbreviated DBA" profile, shown in Figure 2-6 captures the initial transient features in the full DBA profile. The exposure period of this profile is nominally 3 hours at ${ }^{\circ}$ controlled temperature and pressure.

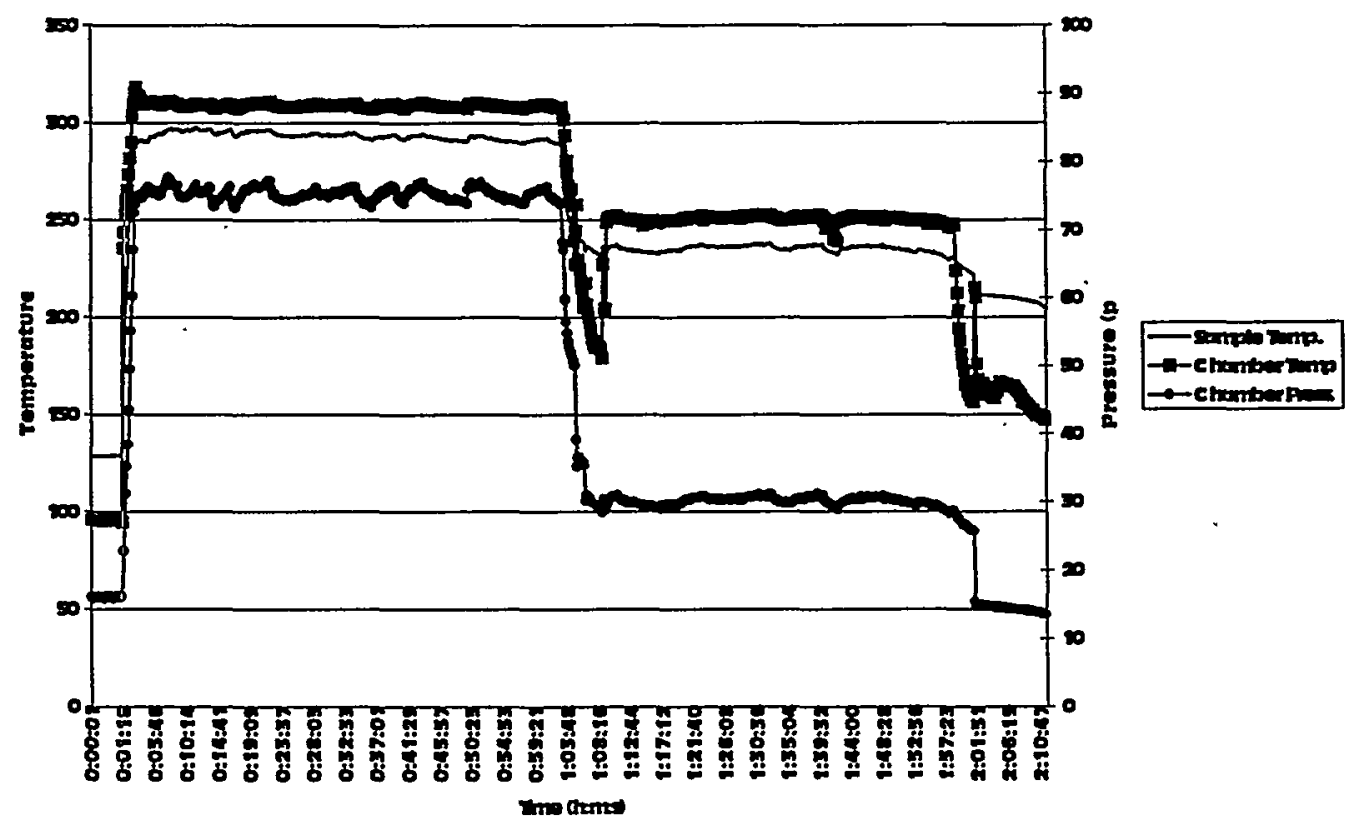

Figure 2-6. “Abbreviated DBA” Profile 
A "pulse DBA" was used in the program to investigate the performance of a coating under severe heat-up and cooldown pulse. Figure 2-7 shows a typical pulse profile in the DBA testing. Calculations of plant-specific transients typically contain this feature, which is not incorporated in the D3911-95 DBA profile.

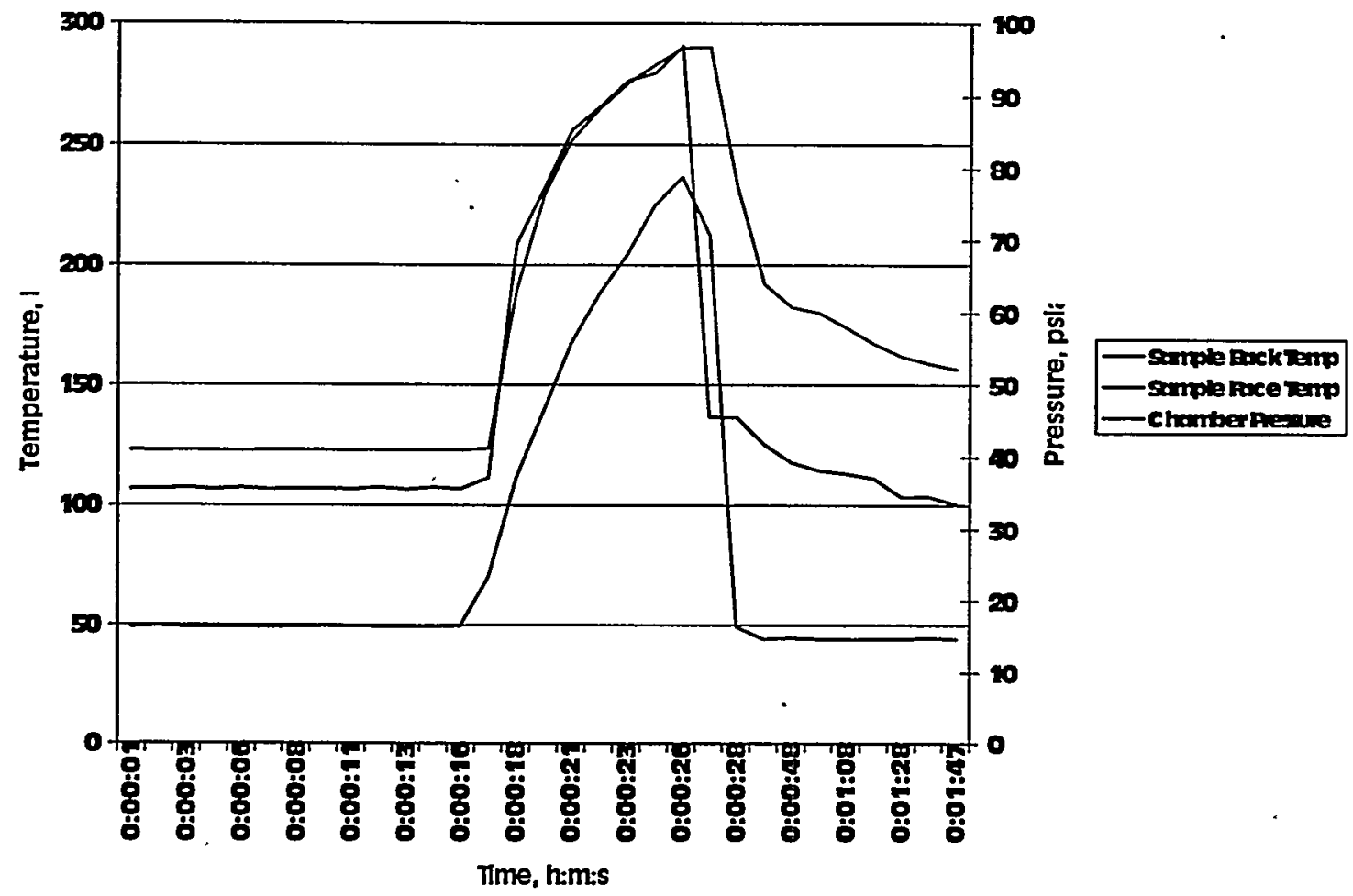

Figure 2-7. “Pulse DBA" Profile to Simulate a Plant-Specific DBA Temperature/Pressure Profile

The details of the DBA testing of coating performance are contained in Appendix E of this report.

\section{$2.4 \quad$ Coating Performance}

Measurement of coating performance following combinations of irradiation aging and DBA exposure are performed by a variety of standard metallurgical and analytical techniques. Chemical and compound information is obtained using SEM/EDS and FT-IR Spectroscopy. Optical and SEM microscopy is used to provide details on the structure and debris source term geometric characteristics. Appendix F contains a description of the techniques applied to the coating specimens in the coatings research program at SRTC. Section 3.4 of this report provides the results of characterization of System 5 following irradiation, DBA exposure, and irradiation plus DBA exposure. Figure 2-8 below shows an example of blistering that has occurred in the irradiation-aged System 5 coating following a water soak exposure at atmospheric pressure. This blistering emphasizes the role moisture or wetness can play in the development of coating failure.

The coatings research program includes characterization and DBA testing of NPP plant specimens. The intent is to investigate and compare the performance of plant specimens with aged laboratory specimens. 


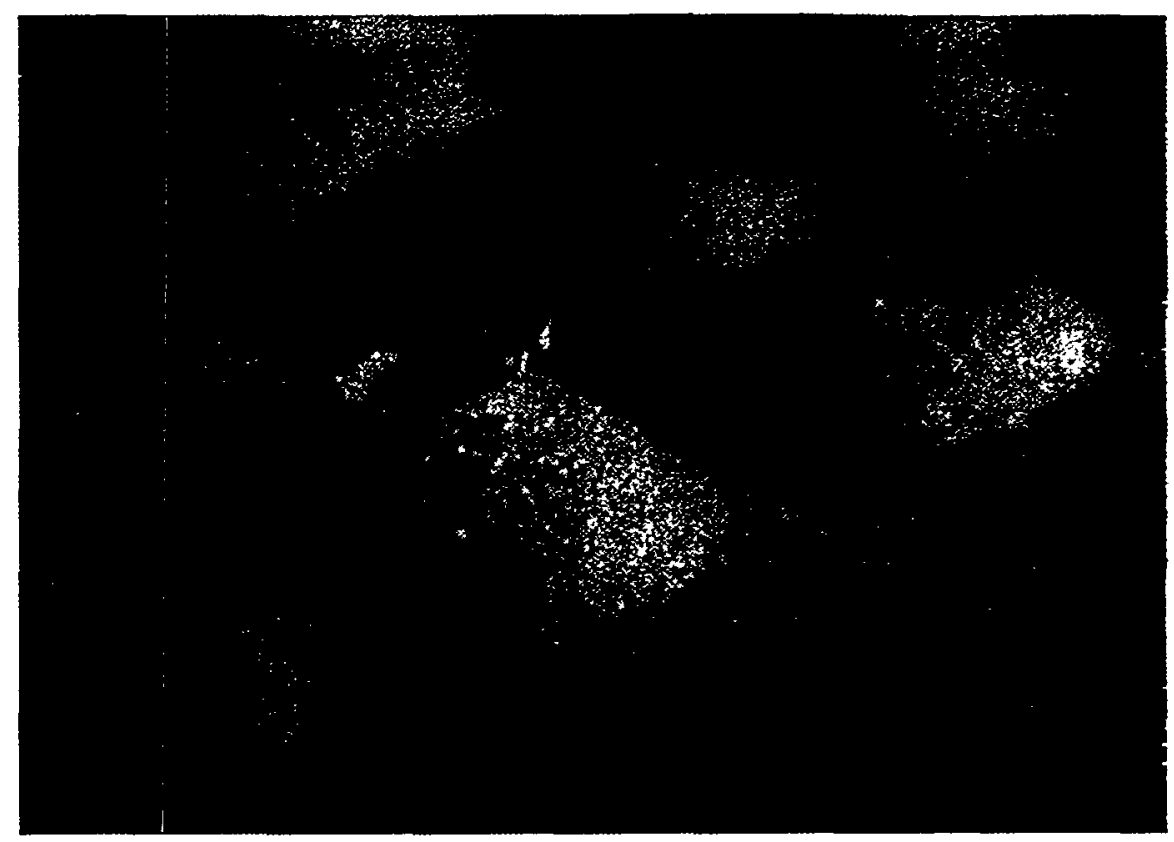

Figure 2-8. Blister Formation in Near-Surface Region of Amercoat ${ }^{\circledR} 370$ Following Irradiation to $10^{9}$ Rad and a Water Soak.

\section{References for Section 2}

2.1 "Coatings Handbook for Nuclear Power Plants," EPRI TR-106160, June 1996.

$2.2 \quad$ G. E, Wilson and B. E. Boyack, Nuclear Engineering and-Design 186, 23-37, 1998.

2.3 Industry Coatings PIRT Report No. IC99-01, July 21, 1999, "Interim Report: PWR Containment Coatings Research Program Phenomena Identification and Ranking Tables (PIRTs)," by Jon R. Cavallo, Tim Andreychek, Jan Bostelman, Brent Boyack, Garth Dolderer, and David Long.

2.4 ASTM D5139-90, "Standard Specification for Sample Preparation for Qualification Testing of Coatings to be Used in Nuclear Power Plants."

2.5 ASTM D4082-95, "Standard Test Method for Effects of Gamma Radiation on Coatings for Use in LightWater Nuclear Power Plants."

2.6 ASTM D3911-95, "Standard Test Method for Evaluating Coatings Used in Light-Water Nuclear Power Plants at Simulated Design Basis Accident (DBA) Conditions." 


\subsection{Coating System 5 Performance}

WSRC-TR-2000-00079

\subsection{Material Properties}

This section reports the values of the physical and mechanical properties for analyzing the performance of a coating system. The properties of a specific coating product, Amercoat ${ }^{\circledR} 370$, a polyamide epoxy used in coating System 5 , are reported.

As discussed in section 2.1, the properties are functions of temperature, aging condition, and wetness or moisture content. The limits of these variables were enumerated in a statistical design developed for the coatings program. The temperature range was 100,200 , and $300^{\circ} \mathrm{F}$; the aging condition was non-aged (no irradiation) and aged (irradiation to $10^{9} \mathrm{rad}$ at $120^{\circ} \mathrm{F}$ ); and either wet (by soaking in water for 16 hours) or dry (no soak). The effect of moisture on mechanical properties was evaluated at 100 and $200^{\circ} \mathrm{F}$. Physical properties, including thermal conductivity, coefficient of thermal expansion, specific heat, and glass transition temperature, were measured by a program subcontractor using standard laboratory techniques. Mechanical properties were measured at SRTC, with techniques developed specifically for this program. Appendix A describes the mechanical property testing techniques.

The measured data for coating System 5, along with literature data for epoxy and the steel substrate, are organized in Table 3-1 for data from the unaged condition and the aged condition. The connections of the data in Table 3-1 to the failure model are emphasized through the grouping of (1) those properties that govern the mechanical response of the coating and (2) those properties that govern the loading on the coating induced by the DBA environment. Entries in these tables either are data values themselves or are references to subsequent tables ("embedded tables") which then list the values of the specific property under all the measurement conditions. The tabulated data for adhesion, adhesion G-value, and free-film tensile strength are supplemented with load/extension or stress/strain curves at selected conditions. The mechanical properties are discussed in the order of their appearance in Table 3-1 in the following sections.

\subsubsection{Tensile Properties: Tensile Strength, Ductility (strain at failure), and Modulus}

Tensile properties were measured on free-film specimens, prepared with methods described in Appendix A. The specimens were generally 0.010 inch in thickness with a gage length of 1.5 inches and a gage width of 0.25 inches. The irradiated specimens swelled in thickness to 0.013 to 0.015 inch. The tensile specimens were pulled to failure in an Instron universal testing machine. The extension rate was $0.02 \mathrm{in} . / \mathrm{min}$, with some tests at $0.005 \mathrm{in} . / \mathrm{min}$. Figure 3-1 shows stress-strain curves calculated from the load-displacement data obtained from the Instron. (The dips in the Figure 3-1 curves were caused by the manually controlled operation of the oven. Turning on the oven heaters caused the specimen to expand slightly, which caused the temporary unloading.) The important parameters from these curves are peak stress, elastic modulus, strain at failure, and they are listed in Table 3-2. The elastic moduli were calculated from the hand-fit tangents to the stress-strain curves. These moduli are in fact much lower in magnitude than moduli provided by the test method of dynamic mechanical analysis. Subsequent calculations of the $\mathrm{G}$-value will employ the tensile test-derived modulus values.

The data show that temperature is a significant variable to the mechanical properties. The 200 and $300^{\circ} \mathrm{F}$ modulus values are much lower than those at $100^{\circ} \mathrm{F}$, and the strain at failure is higher at the higher temperatures. Thus higher temperature softens and makes more ductile the polyamide epoxy. The specimen intended for testing at $100^{\circ} \mathrm{F}$ in the aged condition broke in handling, and a retest was not attempted. This experience suggests that that specimen would have shown a higher elastic modulus and lower ductility than measured in the 200 and $300^{\circ} \mathrm{F}$ aged specimens. In other words, the higher temperatures might have the effect of restoring some of the coating's flexibility that had been lost during irradiation.

\subsubsection{Adhesion (Adhesion Strength to Under Layer)}

The adhesion test, also referred to as the adhesion pull test to distinguish it better from the adhesion G-value test below, measures the adhesion strength of the coating to its under layer(s). The adhesion strength is calculated by dividing the peak load from the load-extension curve by the area of the puller. Separation of the puller from the coated test coupon usually does not occur through a single coating primer or topcoat layer or along a single 
interface, such as the substrate-to-primer interface. Separation is often of mixed mode. The measured adhesion strength is therefore a sort of lower bound on the strength of the various interfaces and layers.

The adhesion strengths measured for System 5 are listed in Table 3-3. The first three values, for the $100^{\circ} \mathrm{F}$, unaged, dry condition, show good reproducibility, as well as consistency between the two epoxy adhesives used to affix the puller to the test coupon. Selected load-extension curves from the System 5 testing are shown in Figure 3-2. As in the free-film tensile testing, increasing temperature decreases the strength and softens the coating system. This results in the tails of the $200^{\circ} \mathrm{F}$ curves, which reveal the tearing of a final ligament of coating between coupon and puller, compared to the abrupt separation of puller from coupon in the $100^{\circ} \mathrm{F}$ tests. Note that aging further lowers the adhesion strength. As will be discussed below in Section 3.4, aging by irradiation in air appears to degrade the near surface coating material, as evidenced by the color change and, especially, the easier scraping off of that material. The adhesion pull test data reflect that weakened near surface layer.

Examples of the mixed mode of coating failure during the adhesion pull test are shown in Figure 3-3. Failure or separation can occur between the aluminum puller and the epoxy adhesive, between the adhesive and the Amercoat ${ }^{(\infty)}$ 370 topcoat, and within or between layers of the Amercoat ${ }^{\otimes} 370$. No determination was made concerning the relative areas of separation within a single layer of $A$ mercoat ${ }^{\oplus} 370$ or at the interface between the primer and topcoat layer. Separation between the primer layer and the steel substrate was not observed.

\subsubsection{Adhesion G-Value (Adhesion Energy to Under Layer)}

The adhesion G-value test measures the adhesion energy between layers of a coating, or in other words the resistance to separation of layers. This novel method of coating performance measurement is adapted from fracture mechanics concepts, as discussed above. A comparison of the coating material's intrinsic G-value with a calculated G-value that represents the environmental loading on the coating permits one to predict whether or not a coating defect will grow or enlarge.

As described in Appendix A, the G-value test is an adhesion test with the puller affixed to the coating directly over a zero-adhesion defect, created by a layer of polytetrafluorethylene. A successful G-value test requires that the coating release from the steel substrate at the defect. Such a result was observed in all unaged coupon tests. In the aged coupon tests the requirement was not met, for the pullers separated from the coating surface at the puller adhesive-topcoat interface. This result may have been due to the degradation of the relatively radiation-susceptible PTFE, and the destruction of its non-adhesive characteristic. Table 3-4 lists the tests conditions and peak loads from the limited number of completed tests. The load-extension curves for some adhesion G-value tests are shown in Figure 3-4. Table 3-4 also shows the material G-values in $\mathrm{kJ} / \mathrm{m}^{2}$ calculated from the peak loads, the displacement of the coating at peak load, and the elastic moduli in Section 3.1. Note that the material $\mathrm{G}$ values reported here are much higher than the previously reported $150 \mathrm{~J} / \mathrm{m}^{2}$, calculated with the dynamic modulus.

It is further noted that the coating tensile properties are assumed to be isotropic. Specifically, the elastic modulus, tensile strength, and ductility are not expected to with direction in the coating.

\subsubsection{Cohesion Energy}

Cohesion energy is a test of tearing resistance in free-film specimens subjected to a tensile test. The test specimen is similar to the 'dog-bone' used to determine tensile strength, but contains a defect in the form of an edge notch in the middle of the gage length. Cohesion energy measurements have not yet been made. 
Table 3-1. Material Properties for Coating Failure Analysis Using Mode 1 and 2 Failure Models ${ }^{\text {ab }}$

\begin{tabular}{|c|c|c|c|c|}
\hline \multirow{2}{*}{ Material Property } & \multicolumn{2}{|c|}{ Non-Aged Condition } & \multicolumn{2}{|c|}{$\begin{array}{l}\text { Aged Condition Representing } 40 \text { Years } \\
\text { of Service including } 10^{9} \text { Exposure }\end{array}$} \\
\hline & Epoxy & Steel & Epoxy & Steel \\
\hline \multicolumn{5}{|c|}{ Properties for Mechanical Response } \\
\hline $\begin{array}{l}\text { Tensile Strength } \\
\text { (psi) }\end{array}$ & $\begin{array}{c}\text { See Table } 3.2 \\
4000-13,000[1]\end{array}$ & $43,000[10]$ & See Table 3.2 & \\
\hline $\begin{array}{l}\text { Ductility (Total } \\
\text { Strain at Failure) } \\
(\%)\end{array}$ & $\begin{array}{c}\text { See Table } 3.2 \\
1.35-5.7[3]\end{array}$ & $30[10]$ & See Table 3.2 & \\
\hline Modulus (psi) & See Table 3.2 & $30,000[11]$ & See Table 3.2 & \\
\hline Poisson's Ratio & $0.35[15]$ & $0.285[12]$ & $0.35[15]$ & $0.285[12]$ \\
\hline $\begin{array}{l}\text { Adhesion Strength } \\
\text { (psi) to Under } \\
\text { Layer }\end{array}$ & $\begin{array}{c}\text { See Table } 3.3 \\
2000[4]\end{array}$ & N/A & See Table 3.3 & N/A \\
\hline $\begin{array}{l}\text { Adhesion Energy } \\
\left(\mathrm{kJ} / \mathrm{m}^{2}\right) \text { to Under } \\
\text { Layer }\end{array}$ & 1.53 & N/A & & N/A \\
\hline $\begin{array}{l}\text { Cohesion Energy } \\
\text { (in-lb/in') }\end{array}$ & . & $1000-5000$ & & \\
\hline \multicolumn{5}{|c|}{ Properties for Loading } \\
\hline $\begin{array}{l}\text { Coefficient of } \\
\text { Thermal } \\
\text { Expansion } \\
\left(\mathbf{m} / \mathbf{m} /{ }^{\circ} \mathbf{C}\right)\end{array}$ & $14.5 \times 10^{-5}$ & $1.8 \times 10^{-5}$ & $\begin{array}{c}2.8 \times 10^{-5}[2] \\
10-16 \times 10^{-5}[6]\end{array}$ & $1 \times 10^{-5}[7]$ \\
\hline $\begin{array}{l}\text { Coefficient of } \\
\text { Hydgroscopic } \\
\text { Expansion (in/in) }\end{array}$ & $2-8 \times 10^{-3}[5]$ & & $2-8 \times 10^{-3}[5]$ & \\
\hline $\begin{array}{l}\text { Glass Transition } \\
\text { Temperature }\left({ }^{\circ} \mathrm{F}\right)\end{array}$ & 82.5 & & & \\
\hline $\begin{array}{l}\text { Thermal Conductivity } \\
(W / \mathrm{m} / \mathrm{K})\end{array}$ & $0.7349-0.7830$ & $49[8]$ & $0.17-0.2[6]$ & $49[8]$ \\
\hline Specific Heat $(\mathrm{J} / \mathrm{kg} / \mathrm{K})$ & $930-1125$ & 450 [9] & $1050[14]$ & 450 [9] \\
\hline Density (kg/m3) & 2192 & $7840[13]$ & $1060-1400[1]$ & $7840[13]$ \\
\hline
\end{tabular}

${ }^{2}$ Listed properties are a function of moisture content and temperature and are for dry films near room temperature

bTable values without [] are measured values 
Table 3-2. Free-Film Tensile Test Results for Amercoat ${ }^{\mathscr{\otimes}} 370$

\begin{tabular}{|c|c|c|c|c|c|c|} 
Temp. ${ }^{\circ} \mathrm{F}$ & \multicolumn{2}{c}{ Aging } & Condition & \multicolumn{2}{c}{ Peak Load (lb) } & \multicolumn{2}{c}{$\begin{array}{c}\text { Peak Stress } \\
(\mathrm{psi})\end{array}$} & $\begin{array}{c}\text { Modulus } \\
(\mathrm{psi})\end{array}$ & $\begin{array}{c}\text { \% Strain at } \\
\text { Failure }\end{array}$ \\
\hline 100 & Unaged & Dry & 3.3 & 1300 & 62000 & 5.7 \\
\hline 200 & Unaged & Dry & 0.5 & 140 & 1300 & 9.6 \\
\hline 300 & Unaged & Dry & 0.4 & 160 & 2200 & 9.0 \\
\hline 100 & Unaged & Wet & 1.8 & 780 & 22000 & 7.9 \\
\hline 200 & Unaged & Wet & 1.1 & 480 & 4300 & 11.6 \\
\hline & & & & & & \\
\hline 200 & Aged & Dry & 0.7 & 84 & 300 & $12^{*}$ \\
\hline 300 & Aged & Dry & 0.5 & 130 & 790 & 16.6 \\
\hline
\end{tabular}

*Gage width adjusted to account for failure in grip area.

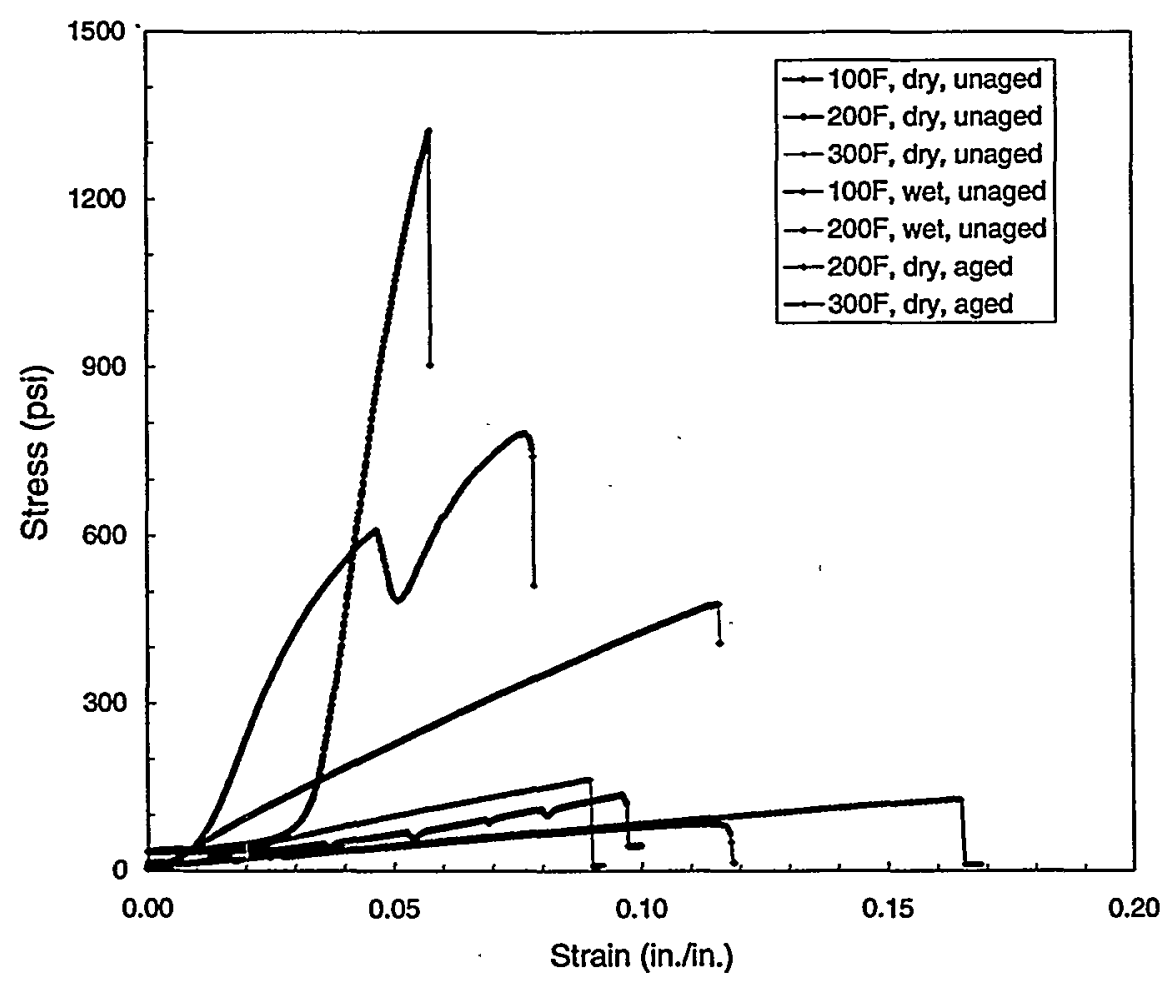

Figure 3-1. Free-film tensile test results for Amercoat ${ }^{\oplus}$ 370. The large dip in the $100^{\circ} \mathrm{F}$, wet, unaged curve and the small ones in the $200^{\circ} \mathrm{F}$, dry, unaged curve were caused by the functioning of the oven heater. 
Table 3-3. Adhesion Pull Test Results for System 5

\begin{tabular}{|c|c|c|c|c|}
\hline Temperature $^{\circ} \mathrm{F}$ & Aging & Condition & Peak Load (lb) & $\begin{array}{l}\text { Adhesion Strength } \\
\text { (psi) }\end{array}$ \\
\hline 100 & Unaged & Dry & $623^{a}$ & 3100 \\
\hline 100 & Unaged & Dry & 542 & 2700 \\
\hline 100 & Unaged & Dry & 544 & 2700 \\
\hline 100 & Unaged & Wet & $558^{\mathrm{a}}$ & 2800 \\
\hline 200 & Unaged & Dry & $107^{2}$ & 540 \\
\hline 200 & Unaged & Dry & 122 & 610 \\
\hline 300 & Unaged & Dry & $78.3^{\mathrm{a}}$ & 390 \\
\hline 100 & Aged & Dry & 376 & 1900 \\
\hline 100 & Aged & Wet & 319 & 1600 \\
\hline 200 & Aged & Dry & 26.5 & 130 \\
\hline
\end{tabular}

${ }^{2}$ Araldite ${ }^{\mathrm{TM}} 2014$ adhesive used; for all others Cotronics 4525 adhesive used

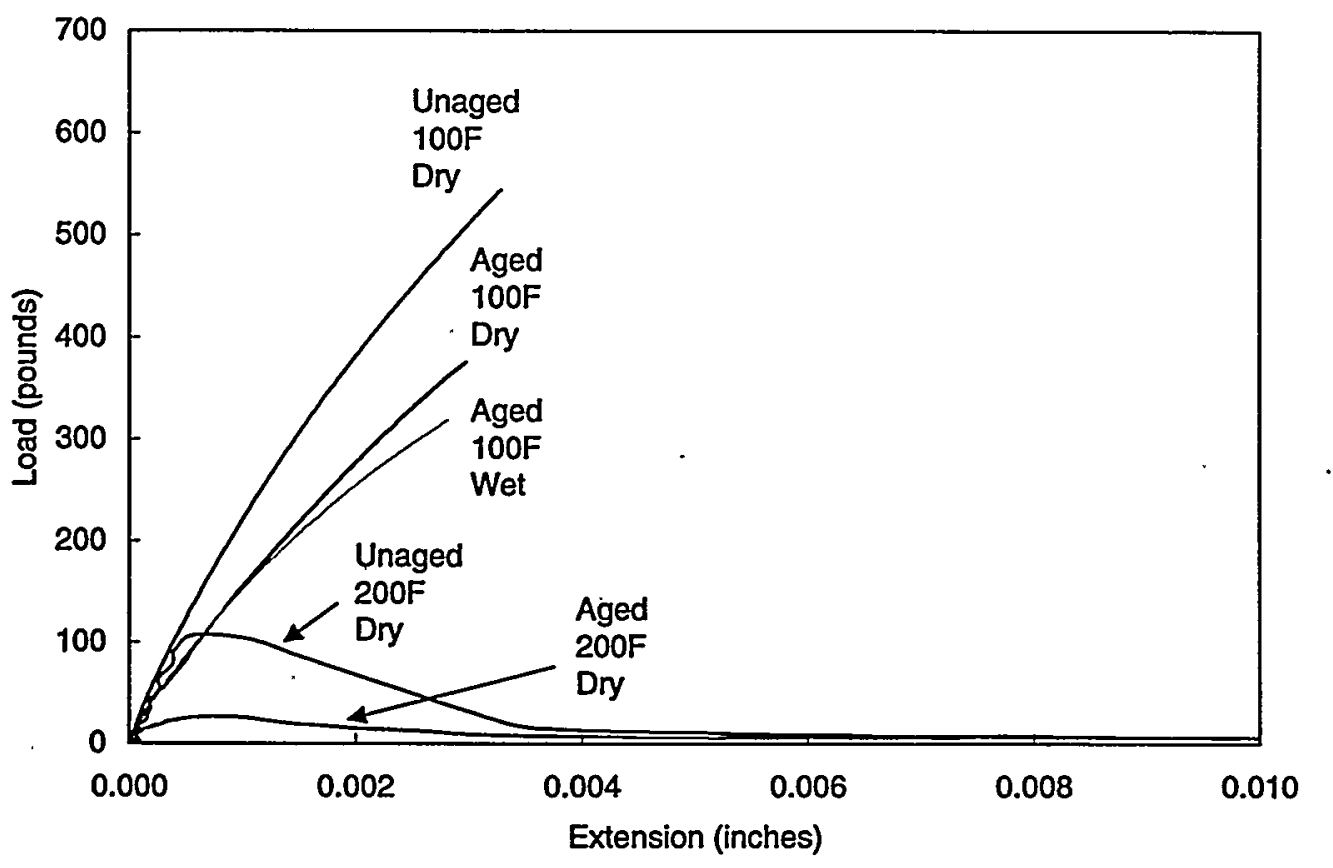

Figure 3-2. Adhesion pull test results for System 5 


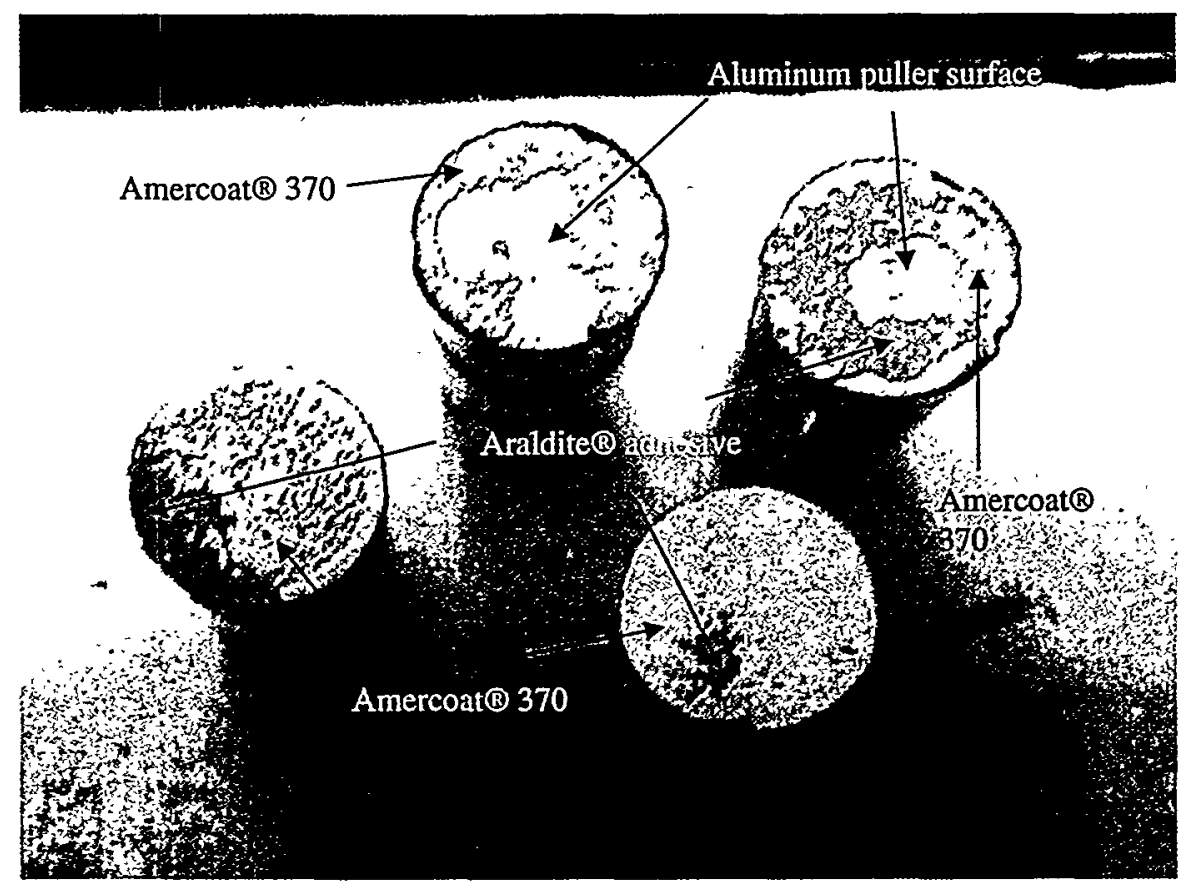

Figure 3-3. Half-inch-diameter puller fracture surfaces showing the mixed modes of separation from a System 5 test coupon: clockwise from left, $100^{\circ} \mathrm{F}$ wet, $300^{\circ} \mathrm{F}$ dry, $200^{\circ} \mathrm{F}$ dry, and $100^{\circ} \mathrm{F}$ dry.

Table 3-4

Adhesion G-Value Test Results for System 5

\begin{tabular}{|c|c|c|c|c|c|}
\hline Temperature ${ }^{\circ} \mathrm{F}$ & Aging & Condition & Peak Load (lb) & $\begin{array}{c}\text { Material } \\
\text { G-Value }\left(\mathrm{kJ} / \mathrm{m}^{2}\right)\end{array}$ & $\begin{array}{l}\text { Failure at } \\
\text { Substrate? }\end{array}$ \\
\hline 100 & Unaged & Dry & $65^{2}$ & & yes \\
\hline 100 & Unaged & Dry & 116 & 1.28 & yes \\
\hline 100 & Unaged & Dry & 127 & 1.53 & yes \\
\hline 100 & Unaged & Dry & $146^{D}$ & & yes \\
\hline 100 & Unaged & Dry & $183^{D}$ & . & yes \\
\hline 100 & Unaged & Wet & 151 & 6.01 & yes \\
\hline 100 & Unaged & Wet & $143^{D}$ & & yes \\
\hline 200 & Unaged & Dry & 41.5 & 7.92 & yes \\
\hline 200 & Unaged & Dry & $46.2^{\mathrm{D}}$ & & yes \\
\hline 200 & Unaged & Wet & $54.6^{D}$ & 4.11 & yes \\
\hline 300 & Unaged & Dry & TBD & & \\
\hline & & & & & \\
\hline 100 & Aged & Dry & 257 & & no \\
\hline 100 & Aged & Wet & 173 & & no \\
\hline 200 & Aged & Dry & 27.7 & & no \\
\hline 300 & Aged & Dry & 5.0 & & no \\
\hline
\end{tabular}

Coating cut through to substrate around puller

${ }^{D}$ Tested after abbreviated DBA exposure in mini-ETC 


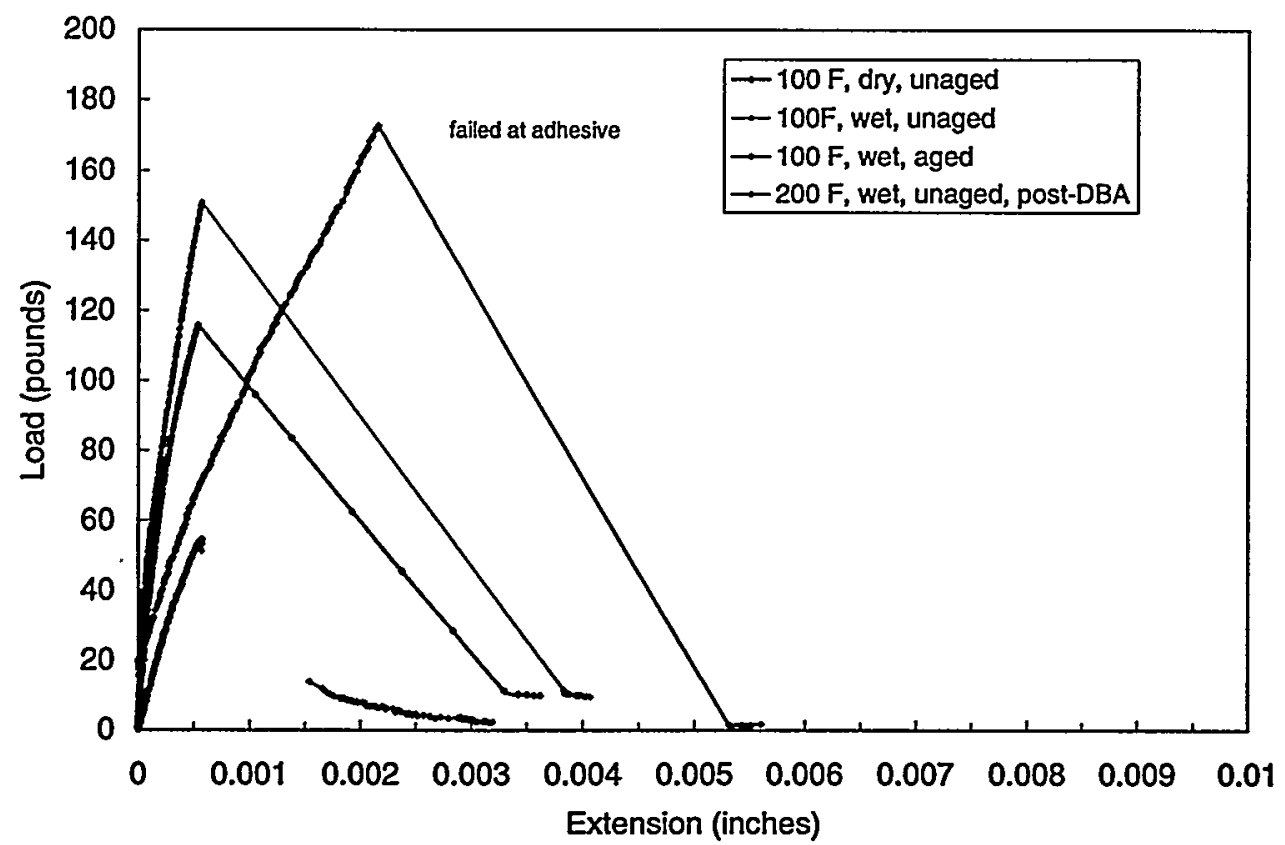

Figure 3-4. Adhesion G-value test results for System 5

\subsection{Failure Modeling}

Analytical modeling is used to predict the performance of coating system 5 under the temperature and pressure conditions of the DBA. The temperature and pressure conditions include both transient and steady-state. Coating stresses and deformations are calculated using finite element analysis. The resulting coating conditions are evaluated with respect to: 1) stress/strain overloads; and 2) fracture instabilities in order to determine the onset of coating failure. Appendix $\mathrm{C}$ provides the details of the finite element method to analyze coating performance.

Two separate models (Mode 1 and Mode 2) were established to analyze conditions in which a blister first forms (Mode 1 deformation) or a crack first forms (Mode 2 deformation). Figures 3-5 is a schematic of the Mode 1 deformation model. For Mode 1 analysis, it is assumed that the defect may exist in the coating materials (topcoat or primer) or on the material interfaces (between topcoat and primer or between primer and the substrate). The Mode 1 defect would lead to form a blister that may grow in size or crack or both under DBA conditions. The second type of defect model, Figure 3-6, is a coating defect emanating from the end of surface scratch or a through-coating crack. This defect may increase in size or "peel back" under DBA conditions.

The analytical results may be compared with experimental results in the investigation of coating performance. Type 1 (Figure 2-2) and Type 2 (Figure 2-3) defects are fabricated in separate laboratory specimens. The Type 1 laboratory defect is similar to the Mode 1 model in the analysis; that is, a specimen contains a circular non-bound area between the coating and the substrate. The Type 2 laboratory specimen contains a circular region in which the coating material is removed and exposed the bare substrate. Both Type 1 and Type 2 specimens are subject to DBA testing conditions (e.g. ASTM D3911-95 for PWR containment).

This section provides the results of the analysis of the coating system 5 for the following general cases under the transient conditions of the DBA:

- Non-irradiated, non-defected

- Non-irradiated, Type 1 defect, no trapped water 
- Non-irradiated, Type 1 defect, trapped water

- Non-irradiated, Type 2 defect

The objective of the analytical modeling is to predict coating performance under DBA exposure using the temperature-dependent and wetness-dependent material properties. The most severe events of the DBA exposure in terms of thermal excursion are 1) heating during the first 10 seconds and 2) the cool-down after long-term (10,000 seconds) steady state exposure. Therefore, a 10 -second rise time from $120^{\circ} \mathrm{F}$ to $307^{\circ} \mathrm{F}$ and a 5 -second fall from $307^{\circ} \mathrm{F}$ to $250^{\circ} \mathrm{F}$ were evaluated as the first two transients in the ASTM D3911-95 DBA profile.

The materials properties used in this analysis are those from section 3.1 .

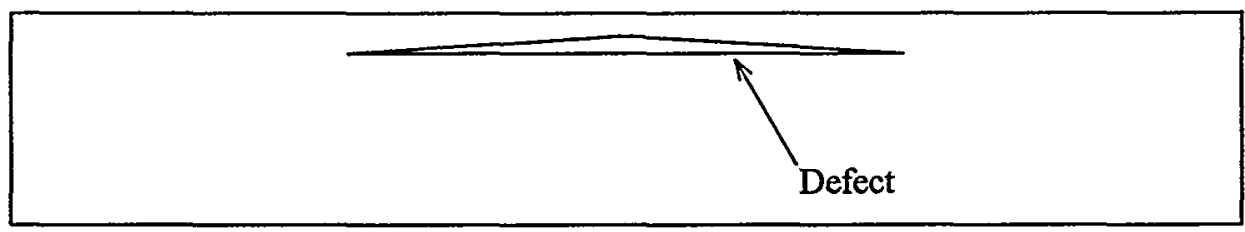

Figure 3-5. Mode 1 Analysis model

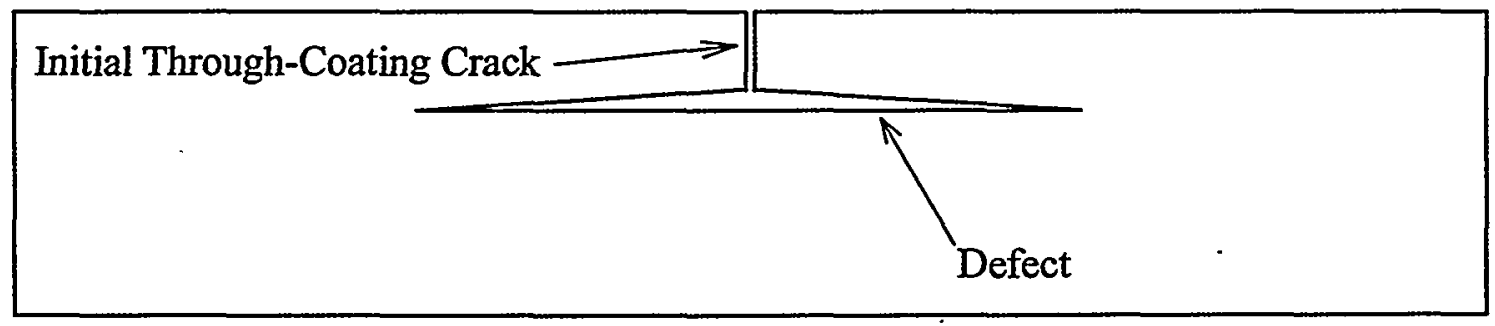

Figure 3-6. Mode 2 Analysis model

\subsubsection{Thermal-Stress Analysis for Coating System 5}

The coating systems with or without defects under DBA temperature were calculated with the temperature dependent Young's moduli (Table 3-1). For this analysis it was assumed that the deformation of the coating system will not affect the heat transfer characteristics of the model. Therefore, the temperature distributions in the coatingsubstrate system were first calculated with a thermal transient finite element analysis. These temperature distributions were then input to the stress analysis using the same finite element mesh but with continuum type of elements. The Young's modulus determined at $200^{\circ} \mathrm{F}$ was used for the temperatures above $200^{\circ} \mathrm{F}$ where the data are not yet available.

\subsubsection{Failure Prediction for Coating System 5}

The thermal-stress analysis of an intact coating system without defects showed that that the stress along the coated surface is always under compression during the DBA test. Therefore, through-coating cracks would not be developed in a non-irradiated intact coating layer during the DBA. Furthermore, if a through-coating crack, such as a scratch, or a Type 2 defect (hole in coating) exists, then peel-back deformation (Mode 2) would not occur during the DBA for an non-irradiated coating system. This occurs for the case where the thermal expansion of the coating material is higher than that of the substrate, as it is for Amercoat ${ }^{\circledR 3} 370$. Therefore, it can be concluded that the intact Amercoat $^{\circledR} 370$ will not fail under these conditions. 
For a Type 1 defect (delamination beneath coating at coating/substrate interface), an analysis was performed using the non-irradiated and wet Amercoat ${ }^{\circledR} 370$ mechanical properties (Table 3-1). The case with no moisture entrapped was considered first. With the temperature profile across the coating during the DBA being the only loading condition, the $G_{\text {applied }}$ was calculated at the edge of a defect of diameter $1 / 2$ ". Figure 3-7 shows that the $G_{\text {applied }}$ reaches a peak value at the end of heating stage $\left(307^{\circ} \mathrm{F}\right)$. However, this peak value is much lower than the $G_{\text {material }}$ as shown in Table 3-1. Therefore, the defect will not grow in a self-similar manner, that is, the delamination will not occur. Note that this $\mathrm{G}_{\text {applied }}$ is associated with the buckling due to thermal expansion mismatch in the defected area. This buckled region becomes flattened when the entire coating-substrate system reaches a uniform temperature.

In the stress analyses, the Young' modulus was assumed to remain unchanged when the temperature was beyond $200^{\circ} \mathrm{F}$. However, the value of $\mathrm{G}_{\text {material }}$ was extrapolated to higher temperatures (say, $307^{\circ} \mathrm{F}$ as seen in Figure 3-8) to demonstrate its assumed temperature dependency.

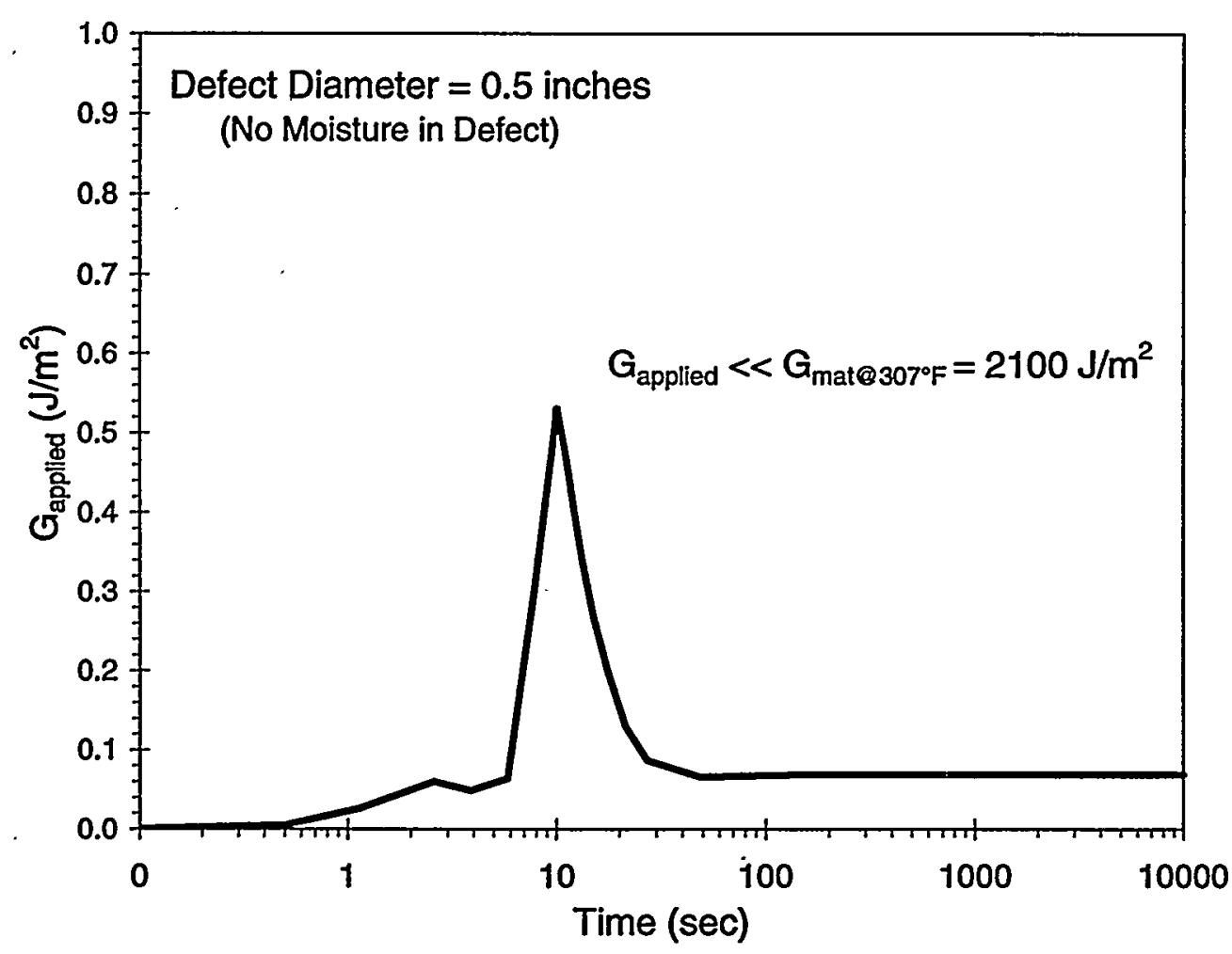

Figure 3-7. Applied G-Values at the Edge of a dry Defect (Diameter ${ }^{1 / 2}$ (") $^{\prime}$ during DBA Test.

For a Mode 1 defect with entrapped moisture, the defect will be subject to vapor pressure loading when the saturated vapor pressure inside the defect overcomes the ambient pressure prescribed by the DBA testing. This would occur when the DBA test begins to spray cool water in the test chamber so the ambient pressure drops accordingly. The value of $G_{\text {applied }}$ rapidly jumps to a high value associated with a blister formation. This can be seen in Figure 3-8. The variation of $G_{\text {material }}$ was also plotted. The intersection point of the $G_{\text {applied }}$ and $G_{\text {material }}$ defines the time of delamination. A linear time scale between 10,010 and 10,015 seconds is used in Figure 3-9. It can be seen that the delamination would occur at 2.3 seconds after the DBA begins the cooling phase. Again, the extrapolated $G_{\text {material }}$ was used to demonstrate the temperature dependency. 
WSRC-TR-2000-00079

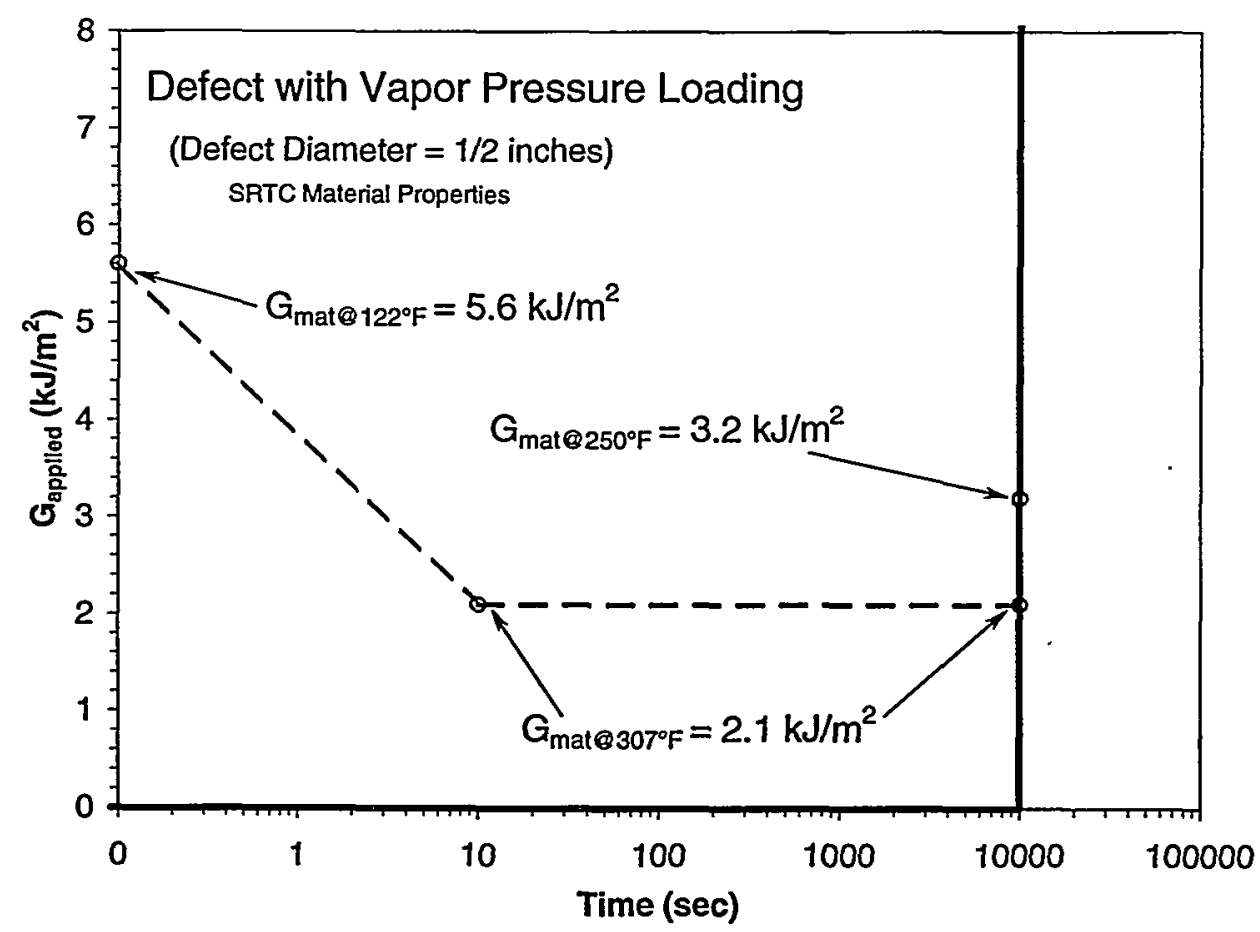

Figure 3-8. Applied G-Values at the Edge of a Vapor Pressurized Defect (Diameter ${ }^{1 / 2}{ }^{\prime \prime}$ ) during DBA Test (Logarithmic Time Scale).

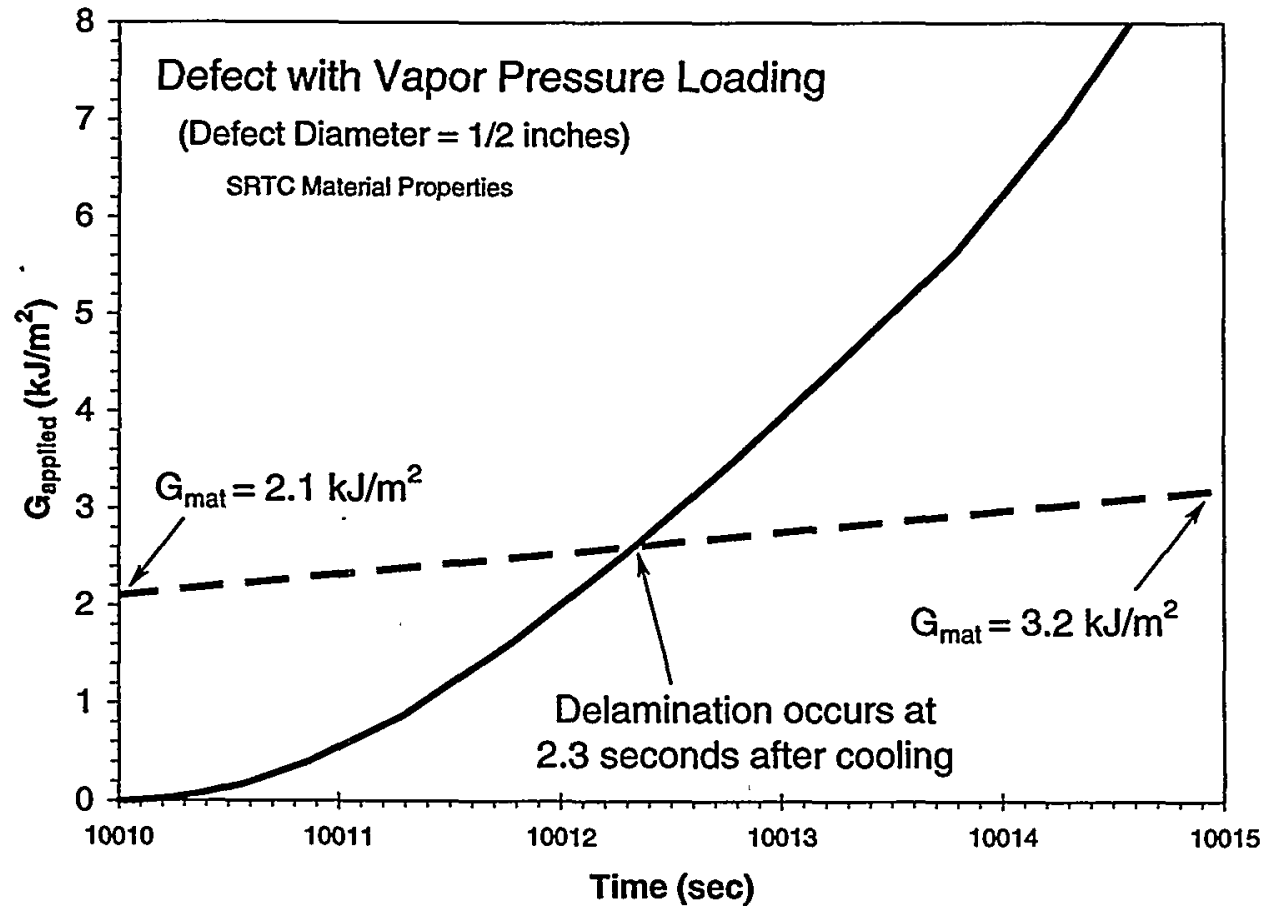

Figure 3-9. Applied G-Values at the Edge of a Vapor Pressurized Defect (Diameter ${ }^{1 / 2} \mathbf{2}^{\prime}$ ) during Cooling Phase in DBA Test (Linear Time Scale). 
A smaller defect with 1/8" diameter was also analyzed. Figures 3-10 and 3-11 show that the delamination will not occur because the peak value of $G_{\text {applied }}$ is below the $G_{\text {material }}$. Note that in Figure 3-10, the vanishingly small $G_{\text {applied }}$ peak is visible near the end of heating stage ( 10 seconds). This small peak is due to the buckling of the material above the defect as a result of thermal expansion mismatch. This small peak is invisible in Figure 3-8 because of the graphical scale.

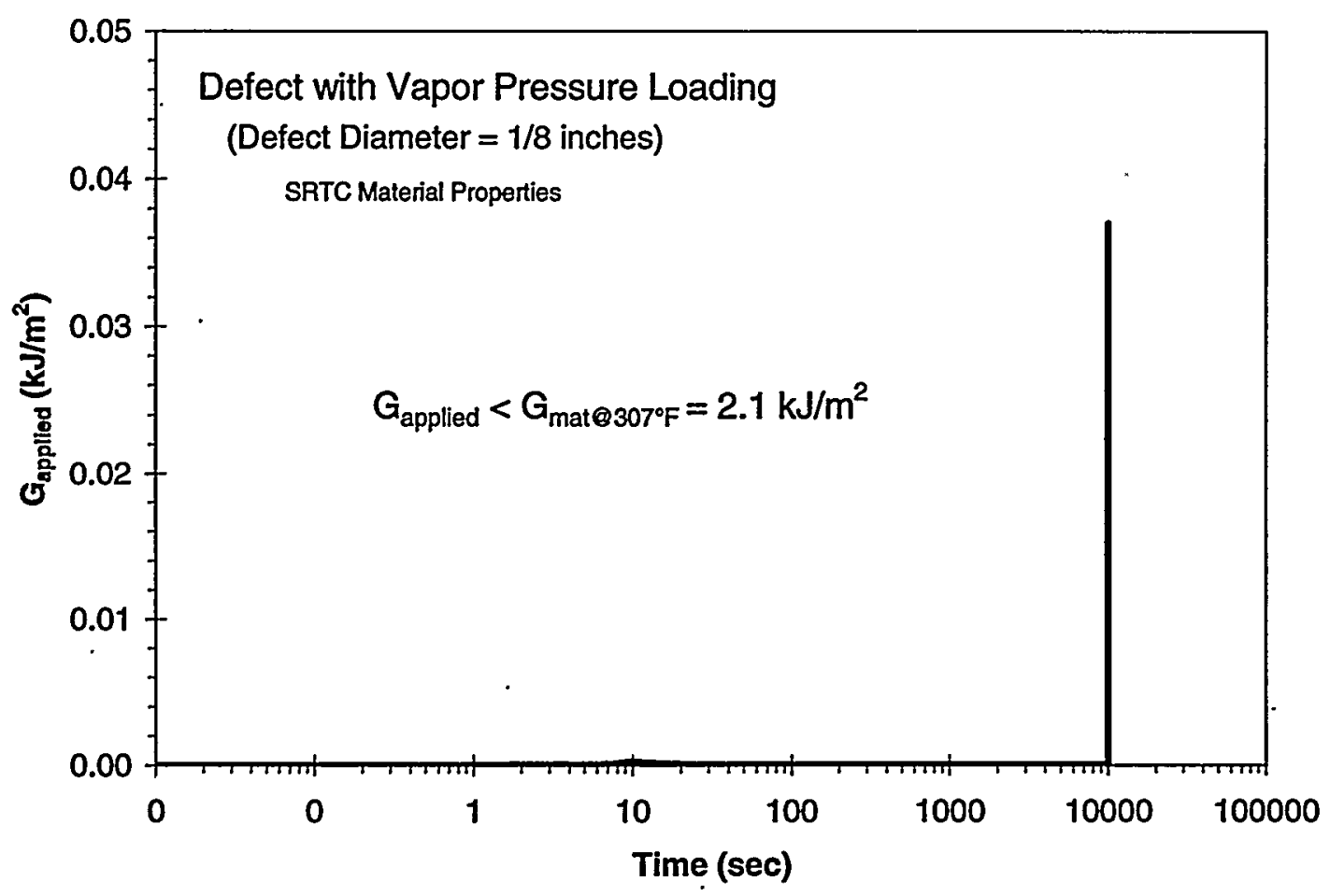

Figure 3-10. Applied G-Values at the Edge of a Small Vapor Pressurized Defect (Diameter 1/8") during DBA Test (Logarithmic Time Scale). 


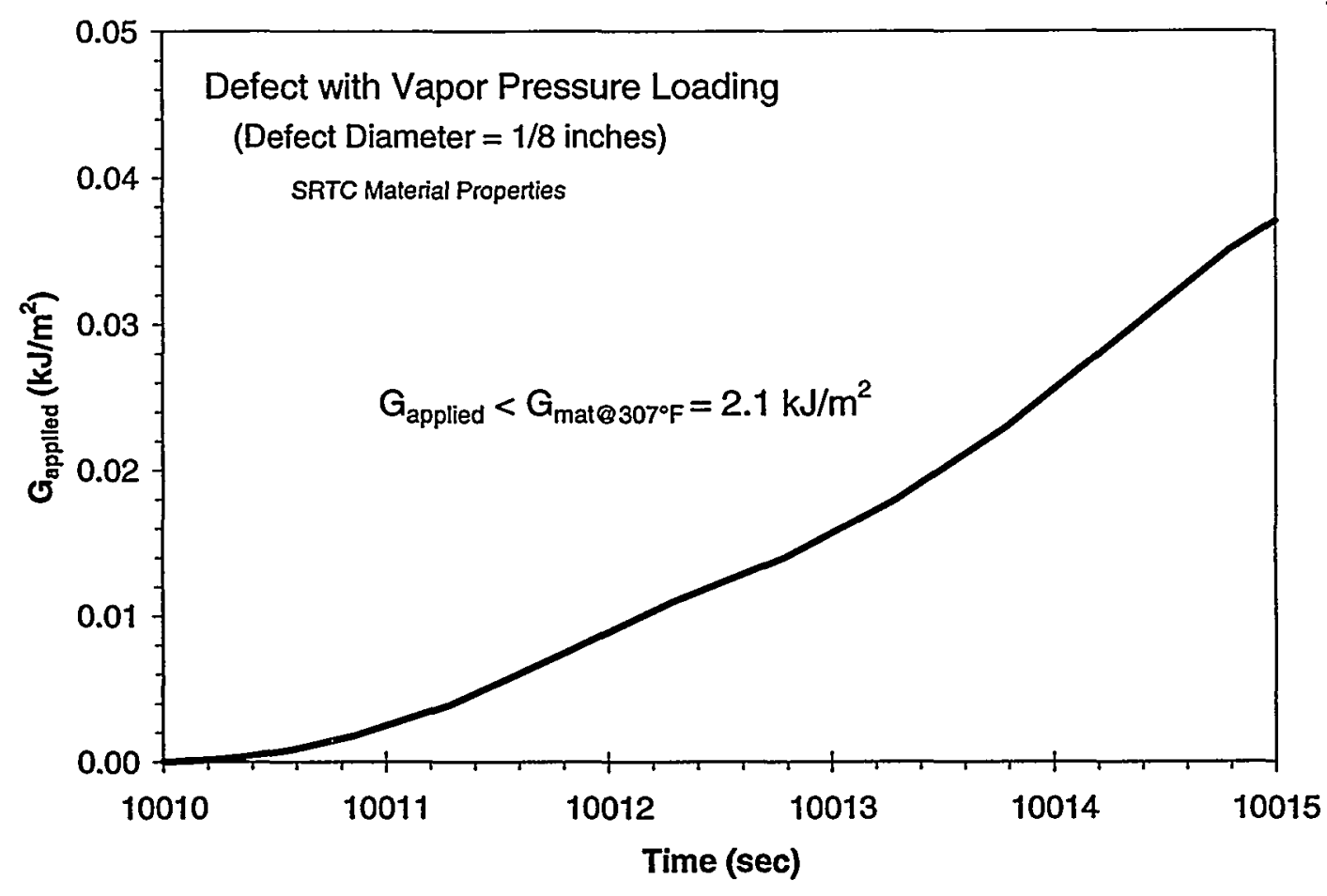

Figure 3-11. Applied G-Values at the Edge of a Small Vapor Pressurized Defect (Diameter 1/8') during Cooling Phase in DBA Test (Linear Time Scale).

The SRTC tensile test also identified the ultimate (peak) stresses and the failure strains of Amercoat ${ }^{\circledR} 370$ (Table 31). The material was non-irradiated and was in a wet environment. High stresses and strains are developed when the blister over the defect is formed due to vapor pressure. Without pressure loading, the stress and strain in Amercoat ${ }^{\circledR} 370$ will be below the critical values, and failure will not occur.

Figures 3-12 and 3-13 show the tensile stress and strain, respectively, near the edge of the defects (diameters $1 / 2$ " and $1 / 8^{\prime \prime}$ ). The ultimate stress and failure strain were extrapolated to temperatures higher than $200^{\circ} \mathrm{F}$ (i.e., 250 and $307^{\circ} \mathrm{F}$ ) to demonstrate the temperature effect. Based on the stress criterion (Figure 3-12), the defect with $1 / 2$ " diameter would exceed the peak stress value at 0.05 seconds after the cooling begins. On the other hand, the defect with $1 / 8$ " diameter fails by the stress criterion at 0.75 seconds after cooling.

Figure 3-13 shows the results using the failure strain criterion. It indicates that the Amercoat ${ }^{\circledR} 370$ coating would fail at 0.2 and 4.2 seconds, respectively, after the cooling begins. 


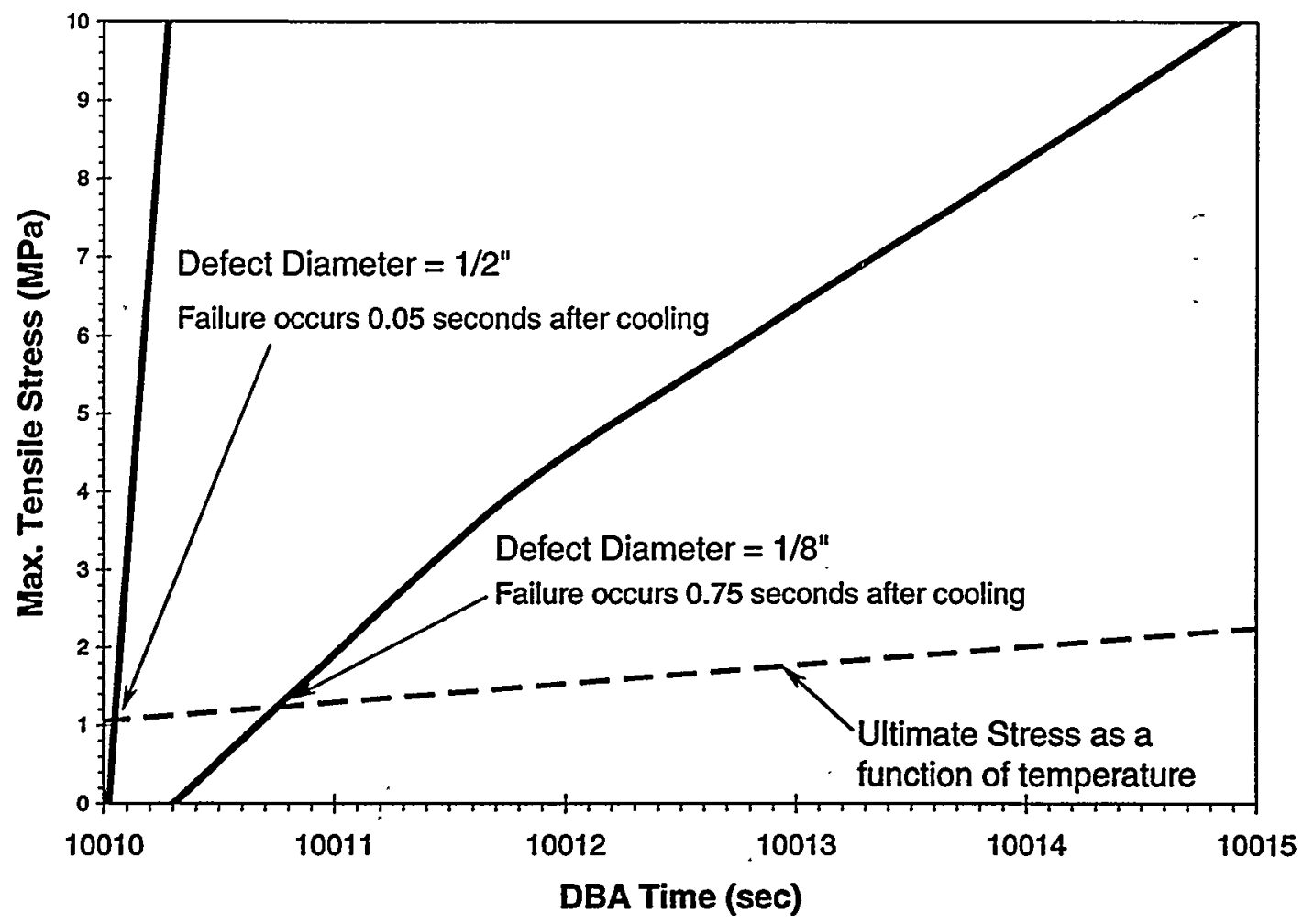

Figure 3-12. Failure of Mode 1 Defects based on Peak Stress Criterion

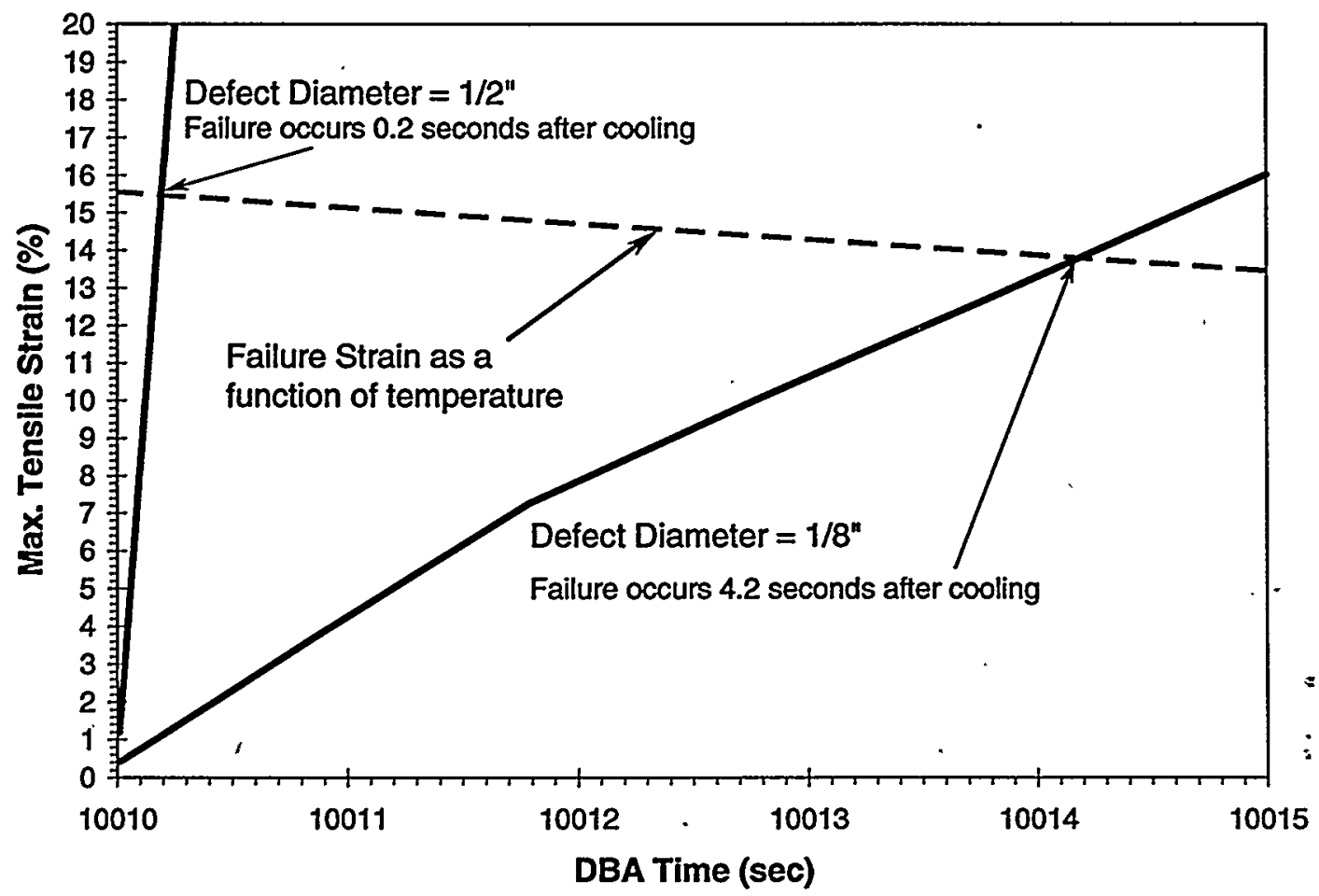

Figure 3-13. Failure of Mode 1 Defects based on Failure Strain Criterion 


\subsubsection{Predictions}

The finite element modeling method for coating deformation can predict deformations that precede failure or "incipient failure" (blister formation \& growth, cracking, peel-back of cracked films). It is noted that failure is the complete disbondment of a portion of the coating that is debris source term (see Section 2).

The intact (non-defected), non-irradiated coating System 5 using Amercoat ${ }^{\circledR} 370$ is not predicted to undergo incipient failure under DBA conditions because a compressive stress exists in the coating throughout.the time period. For the same reason, a coating containing Type 2 defects will not result in peel-back (Mode 2) deformation.

However, incipient failure would be predicted for the coating if it contains Type 1 defects with entrapped water. The timing of the significant events (cracking of the blister) for a Mode 1 deformation depend on the delamination and cracking criteria (see Section 2.2). With the assumption that the DBA temperature and pressure drop from 307 to $250^{\circ} \mathrm{F}$ is completed in 5 seconds, it can be concluded:

(i) G-value criterion

The $1 / 8$ " diameter defect remains adhered to the substrate whereas the $1 / 2$ " diameter defect would propagate.

(ii) Peak stress criterion; failure strain criterion

Stress: Both defects (diameters $1 / 2$ " and 1/8") would fail at 0.05 and 0.75 seconds, respectively, after the cooling and pressure drop begins. Strain: Both defects (diameters $1 / 2$ " and 1/8") would fail at 0.2 and 4.2 seconds, respectively, after the cooling and pressure drop begins.

Failure predictions would be refined based on coating performance testing, such as the DBA tests with the SRTC mini-ETC. In addition, replicate material properties are recommended for reliably predicting material response under LOCA or DBA conditions.

\subsection{Measured Performance Under DBA Conditions}

Three DBA profiles are used in this study. Details of the construction and operation of the SRTC system are available in appendices $\mathrm{D}$ and $\mathrm{E}$.

The standard DBA temperature and pressure profile for qualification of coating system is given in ASTM standard D3911-95 and is termed the "full DBA profile" in this report. Figure 3-14 shows this profile, which is run for a total exposure period of approximately 1 week. An abbreviated version of the DBA profile (Figure 3-15) was developed and used in the program to facilitate the turnaround on results to allow many tests to be performed in the SRTC Mini Environmental Test Chamber.

Computer modeling has revealed rapid temperature-pressure transients to be the likely times for coating failure to occur (see Section 3.2). Transients are present in the temperature-pressure profile specified in ASTM D3911-95 during reductions in steam pressure from 75 psia to 30 psia, and again during reduction from 30 psia to 25 psia (Figure 3-14). The "abbreviated DBA" has been used to duplicate these high-stress transients, while minimizing specimen time-at-temperature to allow examination of a large number of samples (Figure 3-15). 


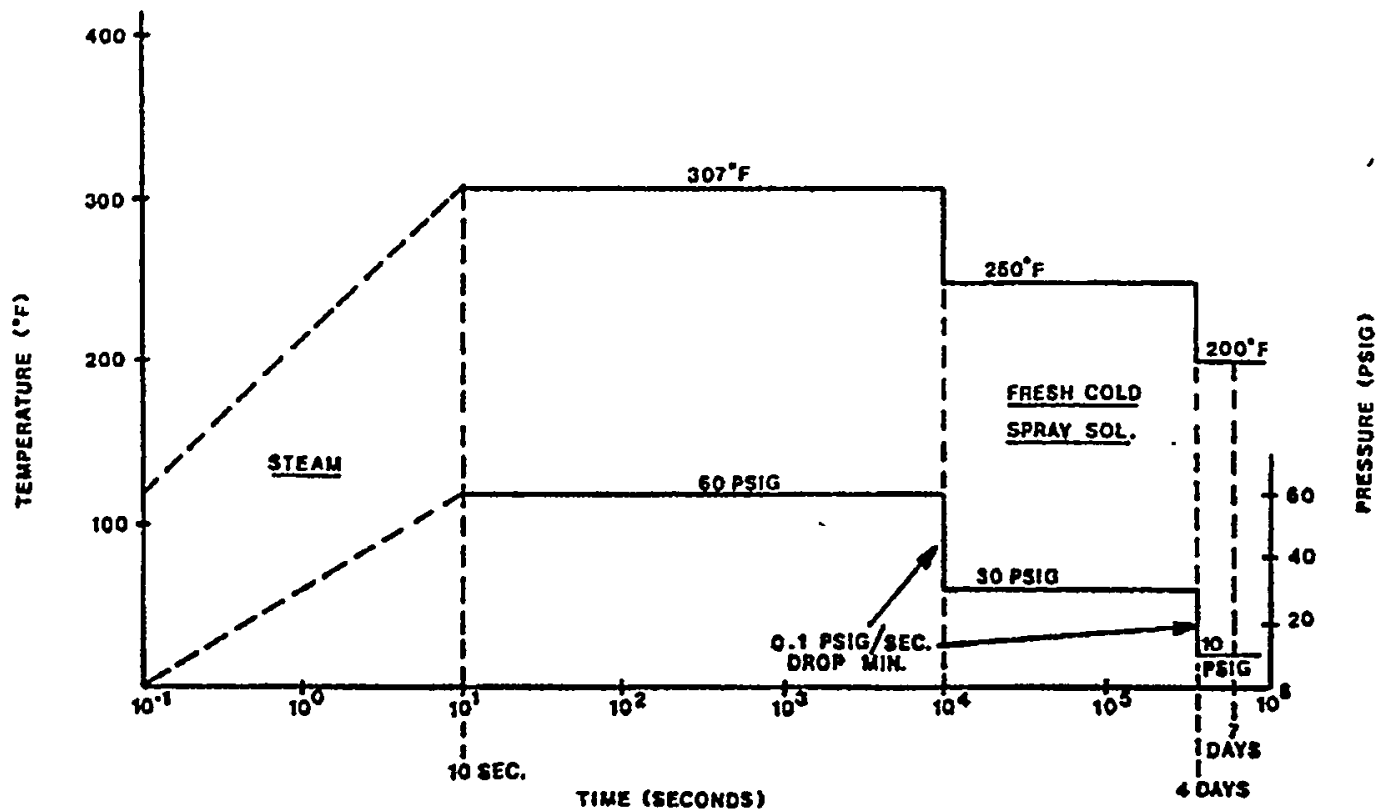

Figure 3-14. Typical Pressurized Water Reactor Design Basis Accident (DBA) Testing Parameters (from ASTM D3911-95). (Note: The ASTM figure contains an error: 30 psig should be 15 psig, which is equivalent to $30 \mathrm{psia})$.
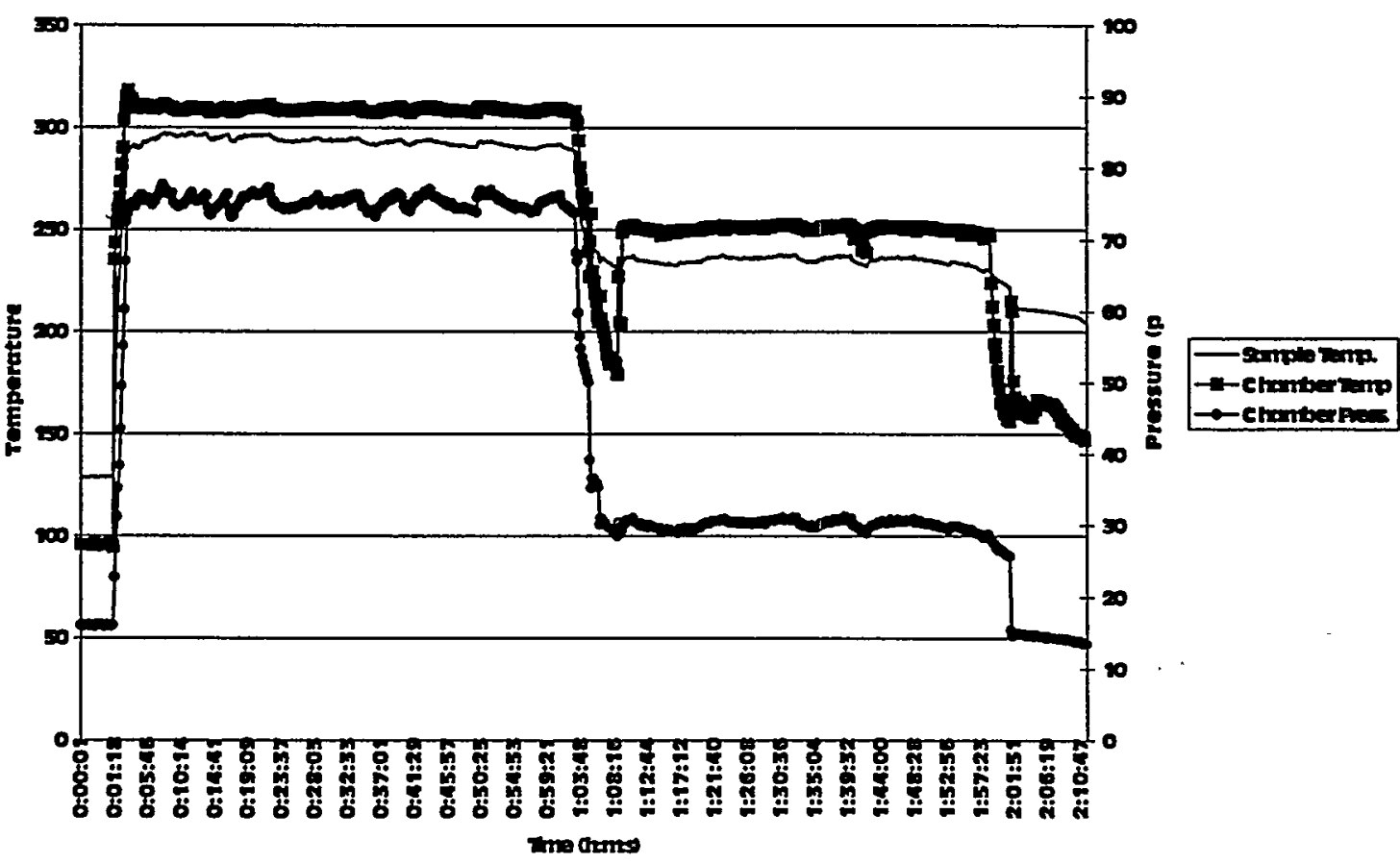

Figure 3-15. Temperature-pressure Profile Used in SRTC "Abbreviated DBA" Tests. 
Computer modeling has indicated a susceptibility to failure of a polyamide epoxy coating during a rapid pulse transient, if water were present beneath the coating (see Section 3.2). A similar rapid transient has been simulated in nuclear power plants using the MELCOR computer model (Figure 3-16). To examine System 5 coating performance in this type of event, the SRTC coatings performance evaluation system was used to subject a non-aged System 5 specimen to a rapid temperature-pressure pulse (Figure 3-17). A specimen containing Type 1 non-bond defects was used in the test. No evidence of coating failure was observed.

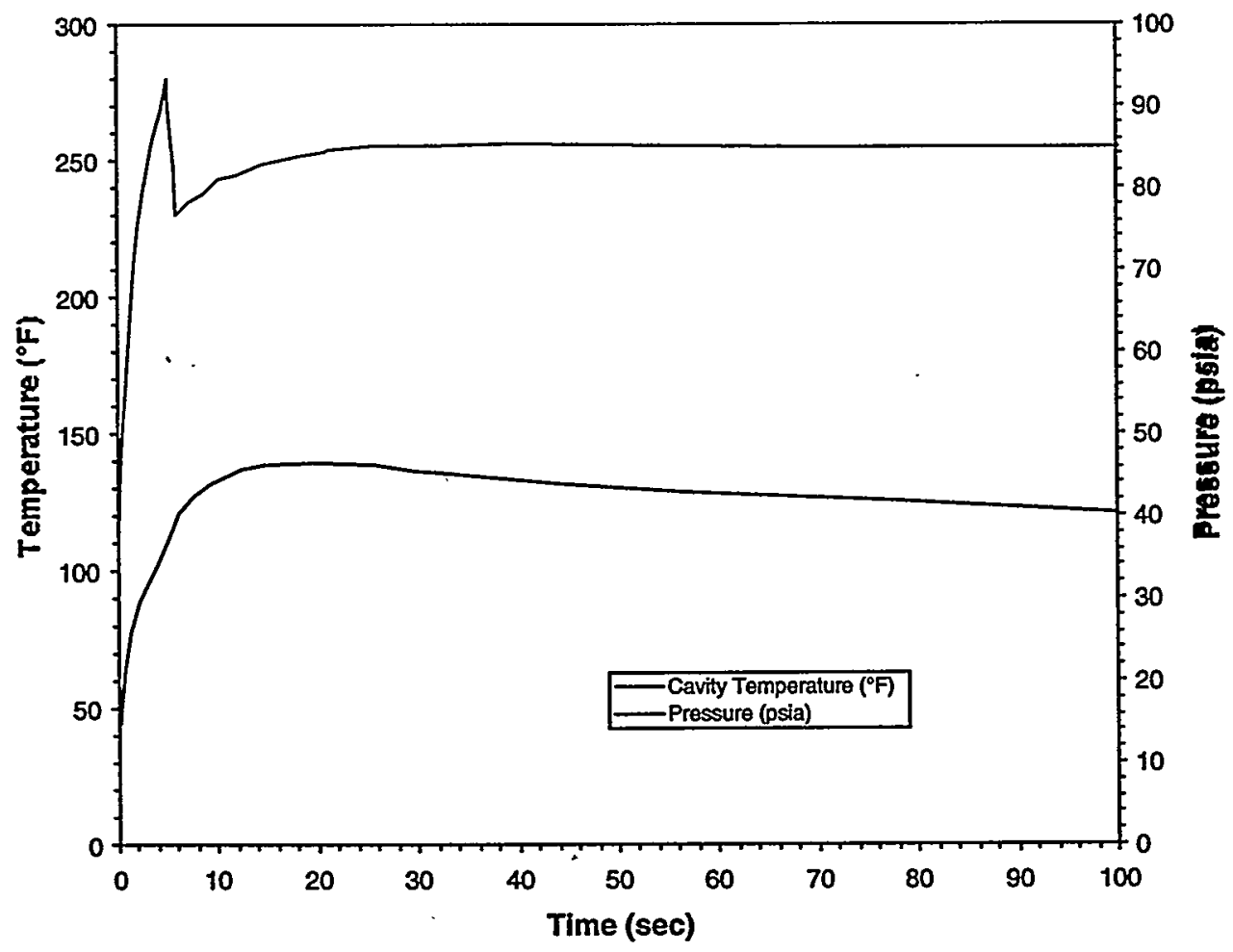

Figure 3-16. Zion Plant-specific Temperature-Pressure Pulse Simulation using MELCOR 
WSRC-TR-2000-00079

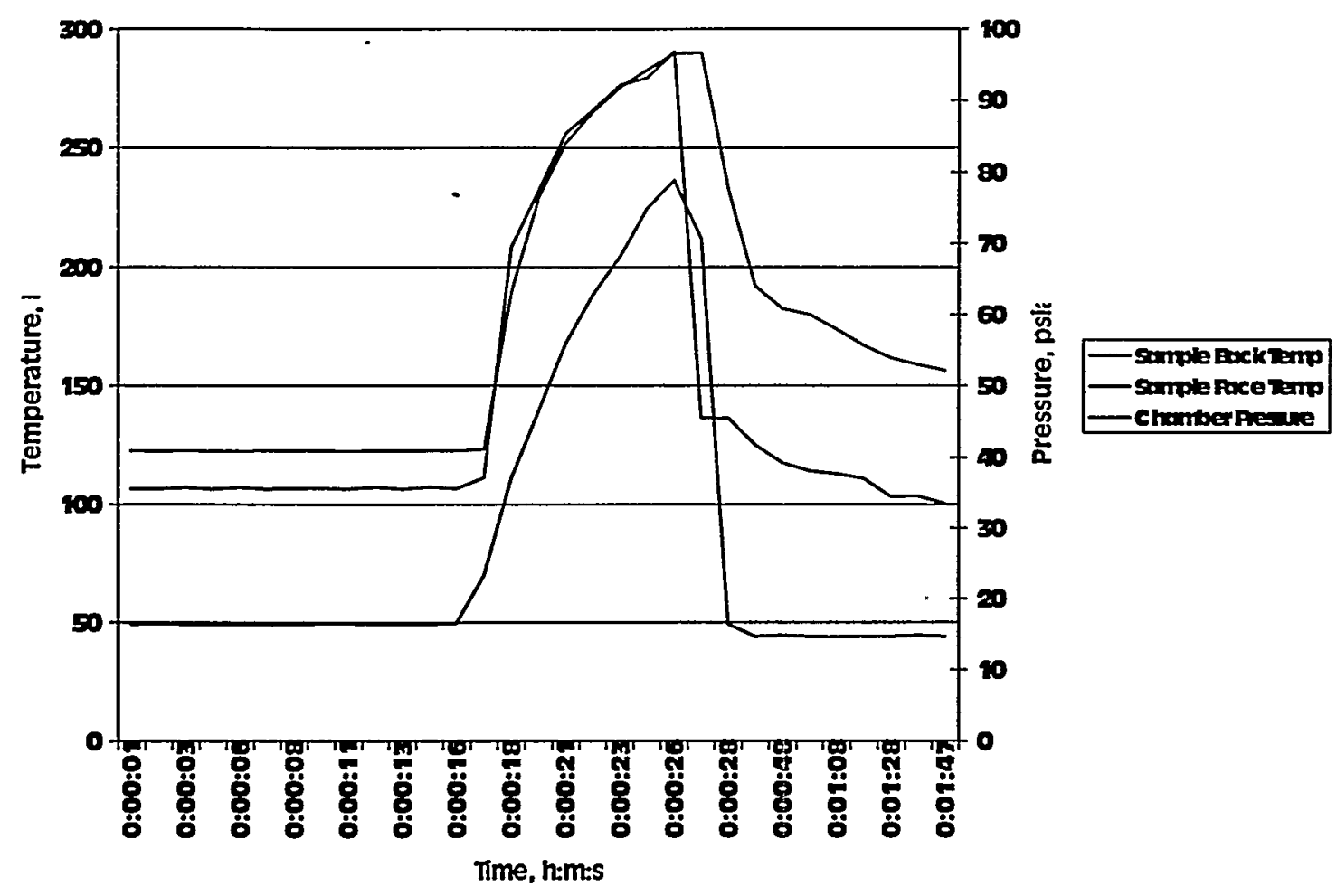

Figure 3-17. Temperature-Pressure Curves from SRTC Pulse Test

\subsection{Coating Performance}

Characterization of the performance of Amercoat ${ }^{\circledR} 370$ following irradiation aging, DBA exposure, and irradiation plus DBA exposure was performed by a variety of standard metallurgical and analytical techniques. Chemical and compound information was obtained using SEM/EDS and FT-IR Spectroscopy. Optical and SEM microscopy were used to provide details on the structure and debris source term geometric characteristics. Appendix F contains a description of the techniques applied to the coating specimens in the coatings research program at SRTC. The principal insights are the resistance of the non-aged coating to any apparent degradation and the development in the aged coating of blistering and checking.

Significant changes appear to occur in the near-surface layer of the aged (irradiated in air) System 5 coating. A surface color change from the unirradiated material (Figure 3-18) was observed. The color change extends a few mils into the topcoat, as seen in Figure 3-19. This darkened layer is thought to be coating that has been degraded by oxidation during the irradiation process. This hypothesis will be investigated by conducting radiation aging in an argon atmosphere.

An aged System 5 coupon showed evidence of incipient mode 1 (blistering followed by cracking) and mode 2 (cracking followed by delamination) failures after having been exposed to hot water or hot air, respectively (Figure 20). A portion of the coupon had been immersed overnight at $200^{\circ} \mathrm{F}$ in tap water, adhesion pull tested at $200^{\circ} \mathrm{F}$, and then returned to tap water immersion at ambient temperature for about 65 hours. Numerous blisters were observed upon removal of that portion from the ambient temperature immersion. Figure 3-21 shows an area of blistering beside the site of an adhesion pull test. The blisters appear to be quite thin compared to the 12-15 mil coating thickness, and are quite fragile when dry. Microscopic examination of a cross-section of the System 5 coupon shows that the blisters form in the near-surface layer (Figure 3-22). The thickness of the coating layer forming the blister is only about 0.001 inch ( $1 \mathrm{mil}$ ) while the total thickness of the polyamide epoxy System 5 coating is of the order of 12 mils. Some of the blisters were intact while others had ruptured. Figures 3-23 and 3-24 show magnified images of a ruptured blister. It is clearly seen that the blister ruptured from internal overpressure. The detachment of such blisters would constitute a portion of a coating debris source term. The portions of this plate which were subjected to blistering and loss of material are quantified in Table 3-5. 
The incipient mode 2 failure is illustrated in Figure 3-25, which shows a pattern of checking (cracking that does not penetrate to the steel substrate) on a portion of the System 5 coupon. The coupon had been adhesion tested (black adhesive is visible at the right) in air at temperatures up to $300^{\circ} \mathrm{F}$ and then subject to an abbreviated DBA test. The shallow penetration of the cracks could be seen at a free coating edge created by the milling of a type 2 defect. The depth appeared to only a few mils, which suggests that again it is in the putative oxidized layer that this failure mode propagated. These observations indicate the substantial role that aging may play in the development of coating failures.

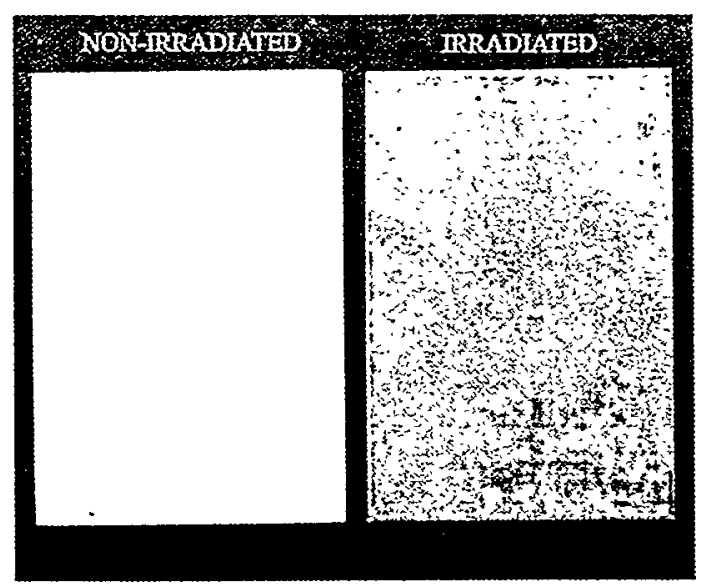

Figure 3-18. System 5 coupons before (left) and after (right) irradiation to $10^{9} \mathrm{Rad}$

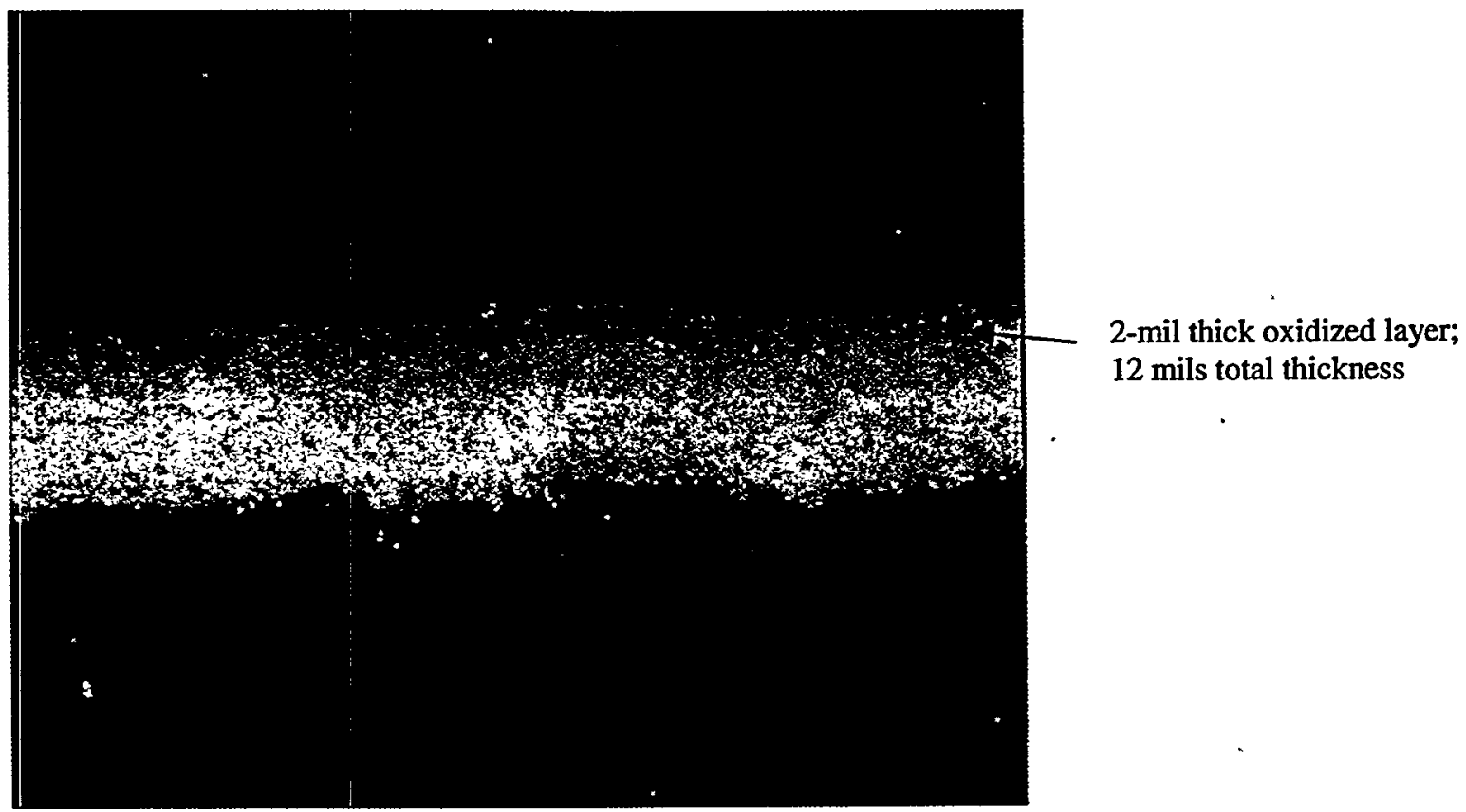

Figure 3-19. Cross-section of System 5 coating, irradiated to $10^{9} \mathrm{Rad}$, original optical magnification $64 \mathrm{X}$. 


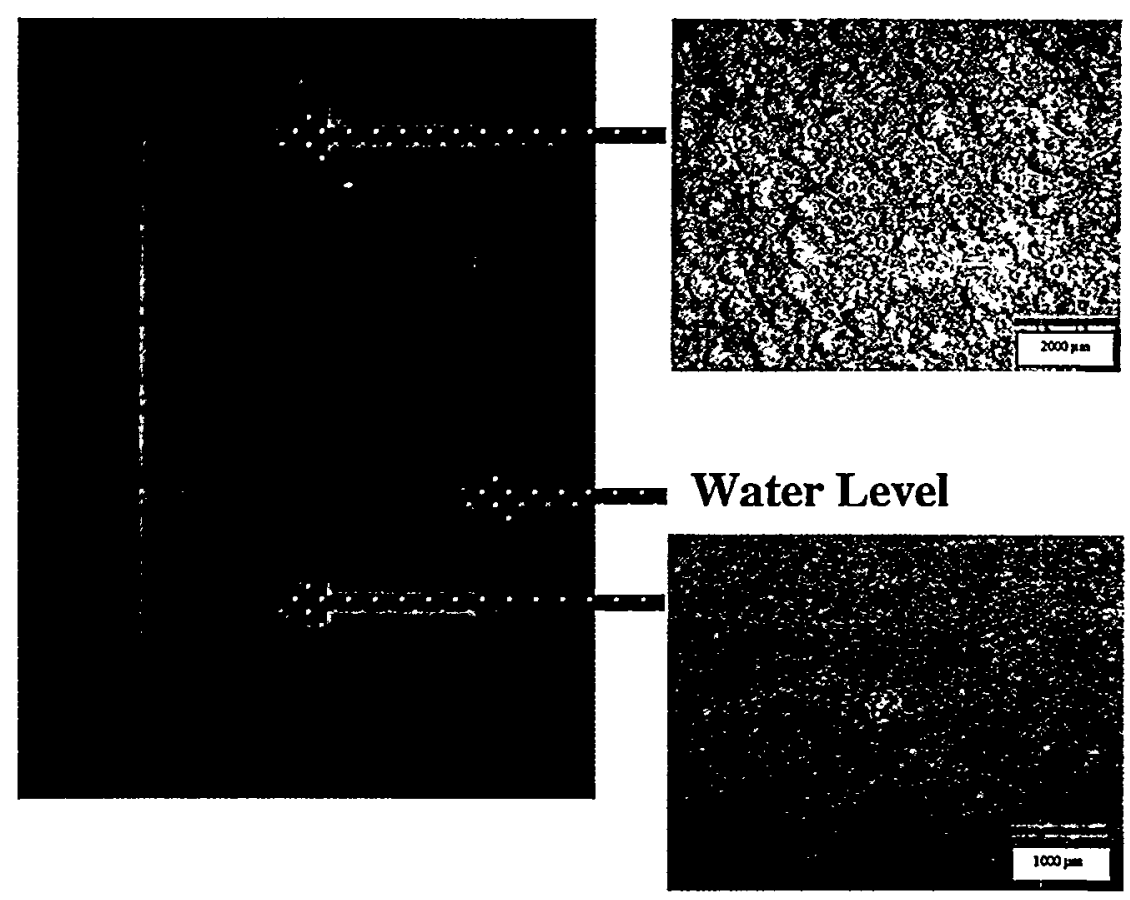

Figure 3-20. Aged System 5 coupon showing incipient mode 1 and mode 2 failures

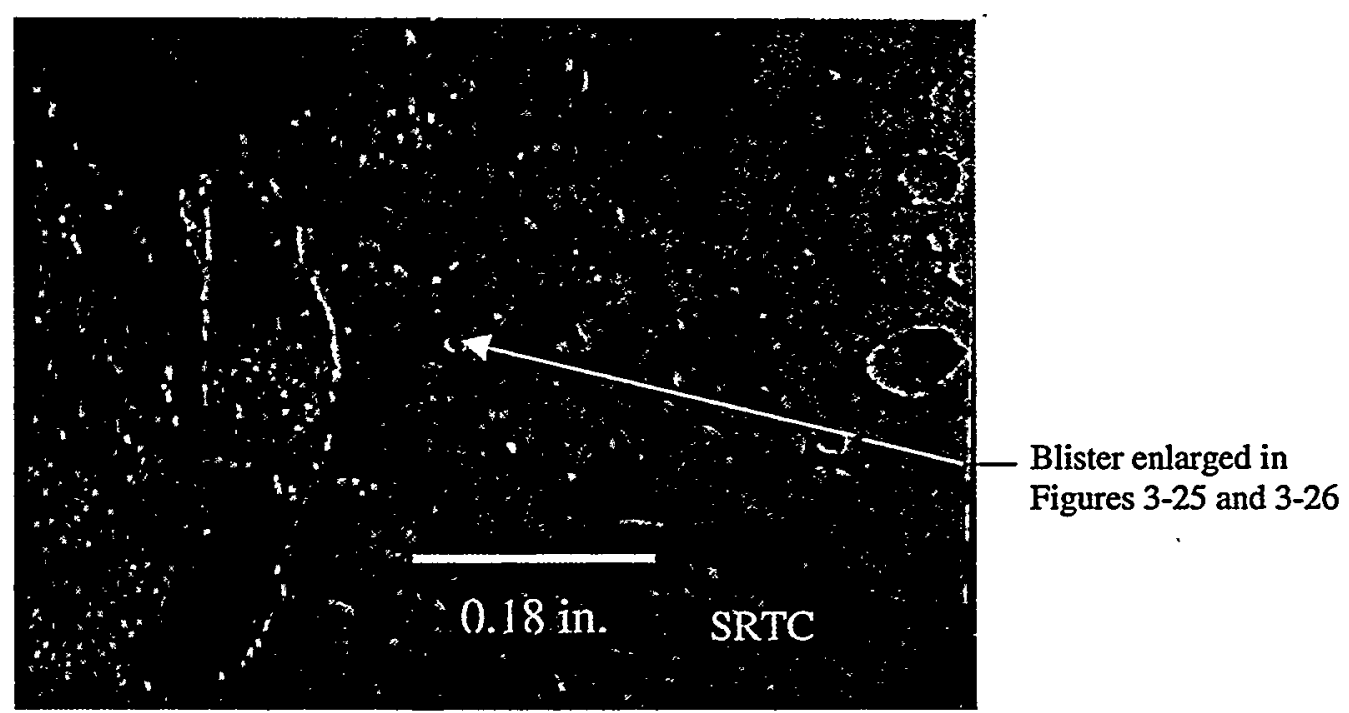

Figure 3-21. Micrograph of blistering formed on System 5. 


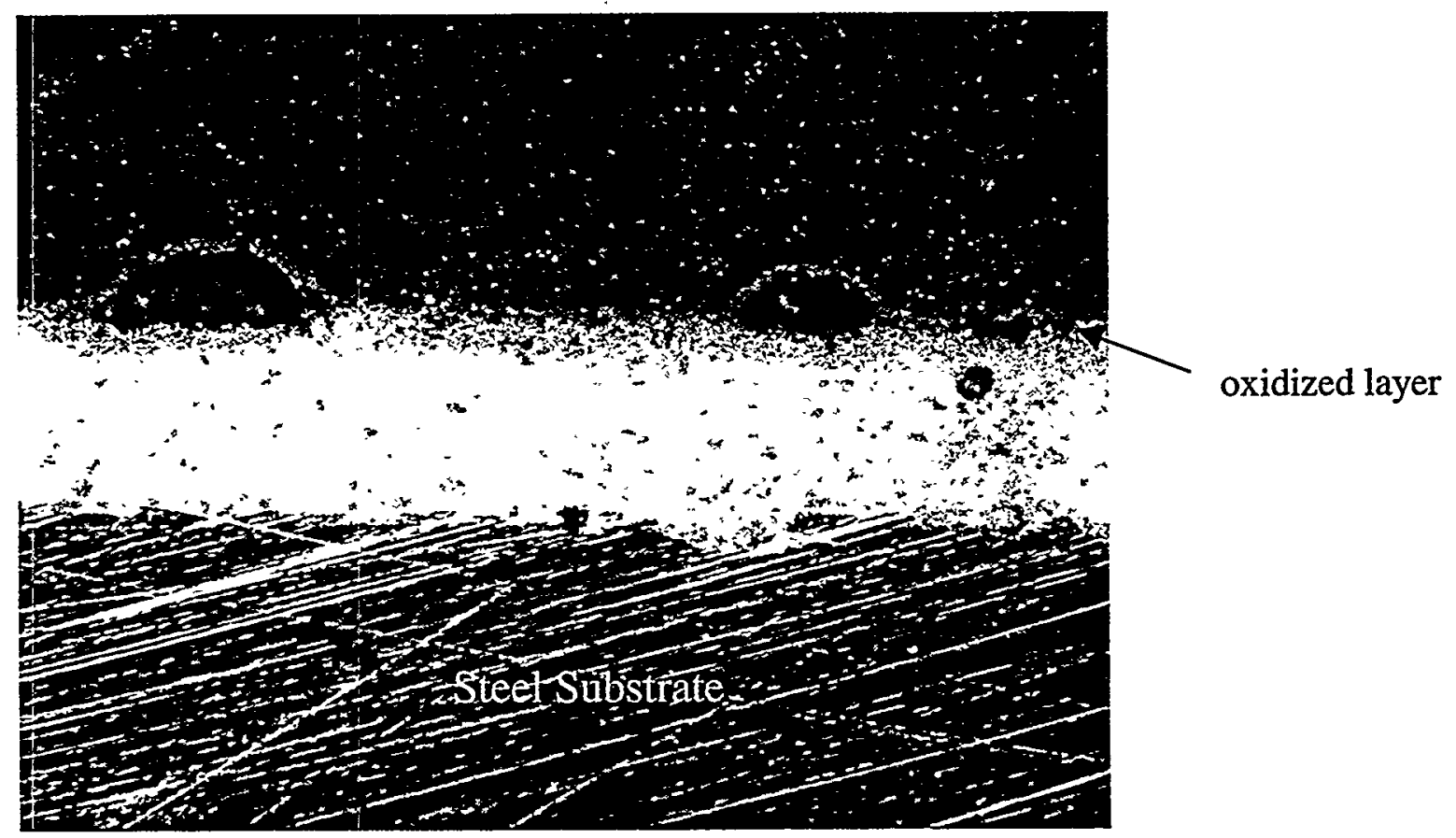

Figure 3-22. Cross-section of System 5 aged, DBA-tested showing blister formation in near-surface, oxidized layer.

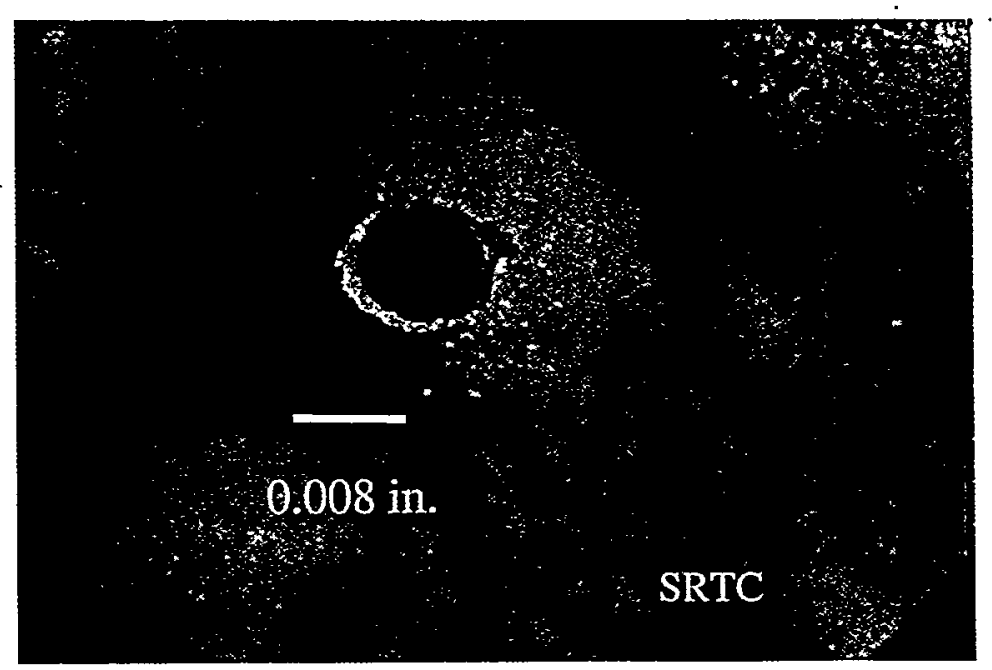

Figure 3-23. Ruptured blister, original magnification at 64X. Blister thickness is of the order of 1 mil. 


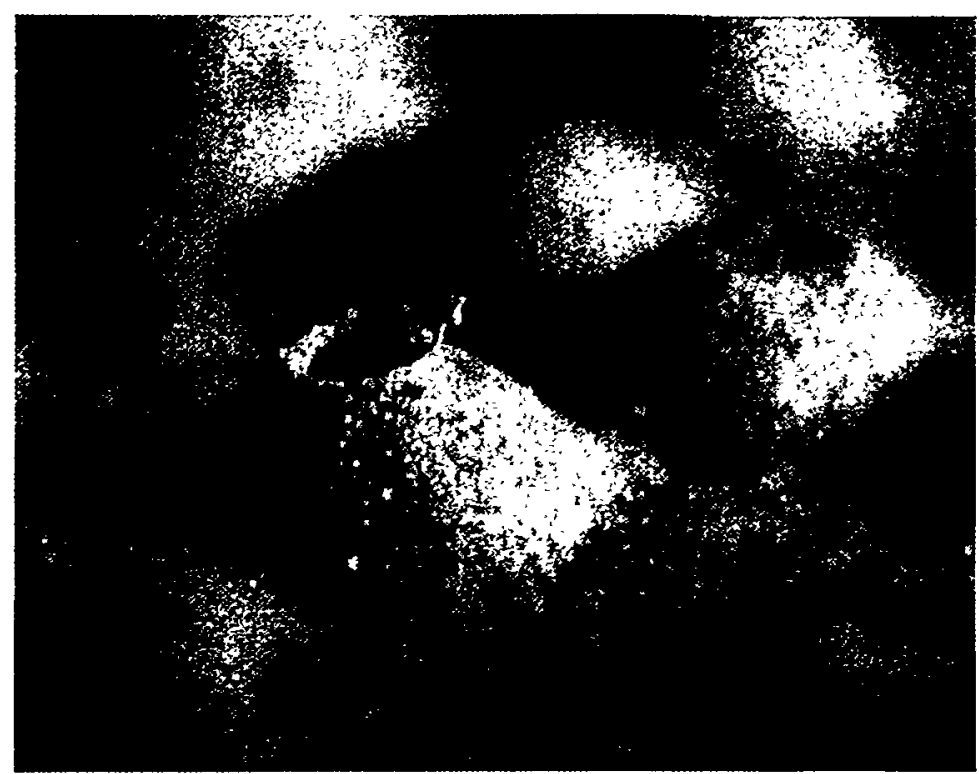

Figure 3-24. Ruptured blister of Figure3-24 in profile; blister is 15 mils tall, original magnification $64 X$.

Table 3-5. Analysis of Percentage of Blistered and Rupture Material in Aged DBA-Tested System 5 Coupon

\begin{tabular}{|c|c|c|c|c|c|c|}
\hline Image & Magnification & Blistering & Blister Count & $\begin{array}{c}\text { Ruptured } \\
\text { Material }\end{array}$ & Missing Count & M/B \\
\hline $12 \mathrm{~mm}$ & $15.4 \mathrm{x}$ & $19 \%$ & 115 & $0.30 \%$ & 59 & $51 \%$ \\
\hline $25 \mathrm{~mm} 1$ & $32 \mathrm{x}$ & $25 \%$ & 23 & $0.35 \%$ & 8 & $35 \%$ \\
\hline $25 \mathrm{~mm} 2$ & $32 \mathrm{x}$ & $21 \%$ & 19 & $0.80 \%$ & 10 & $53 \%$ \\
\hline $25 \mathrm{~mm} 3$ & $32 \mathrm{x}$ & $21 \%$ & 25 & $1.25 \%$ & 11 & $44 \%$ \\
\hline $25 \mathrm{~mm} 4$ & $32 \mathrm{x}$ & $21 \%$ & 25 & $0.70 \%$ & 12 & $48 \%$ \\
\hline mean & & $22 \%$ & 23 & $0.78 \%$ & 10.25 & $45 \%$ \\
\hline
\end{tabular}




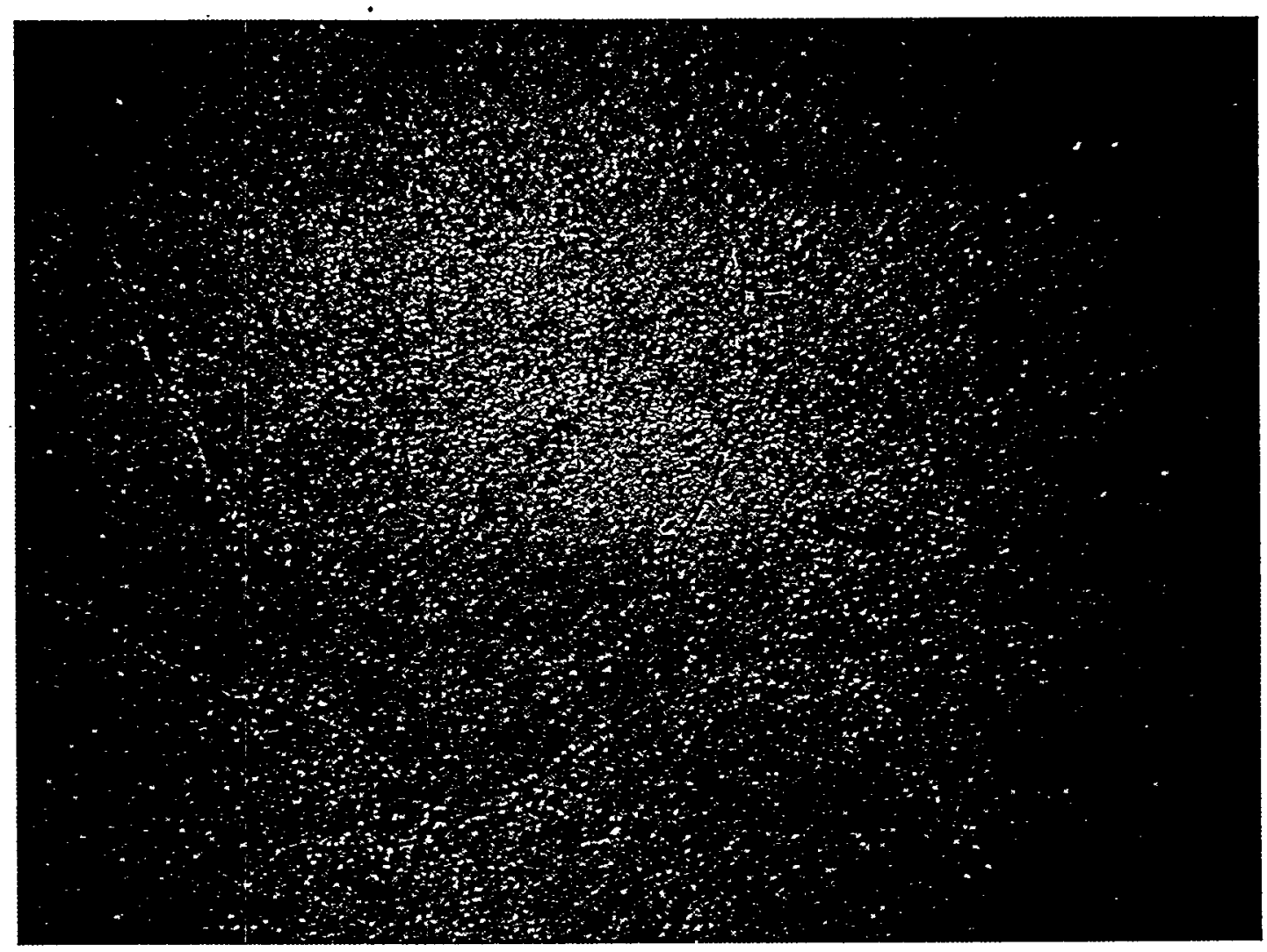

Figure 3-25. Checking in System 5 following "Full DBA" test (Mag 7X).

\section{References for Table 3-1}

1. W. F. Smith, Principles of Material Science and Engineering, $2^{\text {nd }}$ Ed., p. 378 (Table 7.10), McGraw Hill, 1990.

2. I. Skeist, Epoxy Resins, p. 91, Reingold Publ. Corp., 1958

3. M. M. Gauthier, Engineered Materials Handbook, Desk Ed., p. 259, ASM International, 1995.

4. C. E. Park, B. J. Han and H. E. Bair, Humidity Effects on Adhesion Strength Between Solder Ball and Epoxy Underfills, Polymer, Vol. 38, No. 15, pp. 3811-3818, 1997.

5. V. Baudinaud and M. Canevert, Thermal Expansion and Moisture Expansion of Carbo-Epoxy Composite Materials, High Temperature-High Pressure, Vol. 19, pp. 411-416, 1987.

6. M. M. Gauthier, Engineered Materials Handbook, Desk Ed., p. 368, ASM International, 1995.

7. D. F. Miner and J. B. Seastone (Eds.), Handbook of Engineering Materials, $1^{\text {st }}$ Ed., p. 2-05, Wiley Engineering Handbook Series, 1955.

8. D. F. Miner and J. B. Seastone (Eds.), Handbook of Engineering Materials, $1^{\text {st }}$ Ed., p. 2-04, Wiley Engineering Handbook Series, 1955.

9. C. L. Mantell, Engineering Materials Handbook, $1^{\text {st }}$ Ed., p. 13-65, McGraw Hill, 1958.

10. C. L. Mantell, Engineering Materials Handbook, $1^{\text {st }}$ Ed., Table 4-11, p. 4-23, McGraw Hill, 1958.

11. G. S. Brady and H. R. Clauser, Materials Handbook, $13^{\text {th }}$ Ed., p. 967, McGraw Hill, 1991.

12. T. Baumeister, et. al., (Eds.), Mark's Standard Handbook for Mechanical Engineers, $8^{\text {th }}$ Ed., p. 5 (Table 3), McGraw Hill, 1978.

13. T. Baumeister, et. al., (Eds.), Mark's Standard Handbook for Mechanical Engineers, $8^{\text {th }}$ Ed., p. 6-44, McGraw Hill, 1978.

14. M.M. Gauthier, Engineered Materials Handbook, Desk Ed., p. 389 (Table 26), ASM International, 1995.

15. H. Saechtling, International Plastics Handbook, p. 387, Hanser Publisher, 1983. 


\subsection{Summary and Significant Findings}

\subsection{Coating Research Program}

A research program to investigate the performance and potential for failure of Service Level I coating systems used in nuclear power plant containment is in progress. The research activities are aligned to address phenomena critical to failure as identified by a coatings industry expert panel. The period of interest for performance runs from application of the coating through 40 years of service, followed by a medium-to-large break loss-of-coolant accident, which is a design basis accident scenario.

The SRTC program consists of three major elements as shown in Figure 2-1 that are directed at determining Service Level I coatings performance under simulated DBA conditions. Coating material property data (not previously available) are acquired for input into predictive coatings failure models. The model predictions are then compared with simulated DBA environmental testing to arrive at insights into failed coating materials characteristics and degree of failure (i.e., amount of coatings debris) for use in NRC's GSI-191, "PWR Sump Blockage" research program. This interactive approach is discussed in the sections that follow.

\subsection{Performance of System 5 Coating}

The performance of one coating system (SRTC System 5), comprised of polyamide epoxy topcoat over a polyamide epoxy primer on top of carbon steel, has been investigated using the two-part methodology. Amercoat ${ }^{\circledR} 370$ has been used as the polyamide epoxy. Although this epoxy-base system had not been previously qualified as a Service Level I coating for application in NPP containments, it was selected to expedite the fabrication of specimens and validate the methodology for the research program. Coated coupon specimens were fabricated to represent: non-defected or correctly applied coatings, specimens containing an intentional delamination or embedded non-bond defect (called the Type 1 defect), and specimens containing a hole through the coating to the substrate (Type 2 defect). Specimens were exposed to DBA profiles (ASTM D3911-95 and other shortened DBA tests) to determine non-aged effects versus irradiation effects as represented by an irradiation to $10^{9} \mathrm{Rad}$ per ASTM D4082-95. The artificially introduced defected conditions represent potential failure characteristics identified by the industry PIRT panel.

The results from testing and analysis show that the performance of the System 5 coating depends upon:

- Aging Condition (Non-irradiated or irradiated)

- Defect Condition (Type, Size, Trapped Water)

- DBA Temperature/Pressure Exposure Profile (Full DBA and Plant-Specific DBA)

The "abbreviated DBA" profile was observed to yield the same predictive results with respect to transient behavior. Also, no additional significant degradation was observed in the "full DBA" exposure compared to the "abbreviated DBA" exposure. Therefore, no separate performance category has been constructed for the "abbreviated DBA" exposure.

The response of the System 5 coatings to various conditions is discussed below. The response includes the results from both the predictive modeling and the DBA testing as described in sections 3.2 and 3.4 of this report.

\section{Non-Aged}

The non-aged condition represents the properly applied and cured condition of the coating that has not been subject to temperature, irradiation, and humidity effects. Thus, the non-aged condition of the as-applied coating represents a baseline condition. 


\section{A. Non-defected}

No deformation or potential for failure was predicted with analytical modeling in both the "full DBA" and "plant-specific DBA" analyses. Testing of plate specimens also showed no damage in corresponding DBA exposures.

B. Defect Type 1 (Embedded Non-Bond or Blister)

\section{Without Trapped Water}

No significant deformation to cause failure was predicted with analytical modeling in both the "full DBA" and "plant-specific DBA" analyses. Testing of plate specimens also showed no damage in corresponding DBA exposures

\section{With Trapped Water}

\section{a. "Full DBA"}

The analysis results showed that a blister, only if of a sufficiently large size (> $1 / 8$ " diameter), would be subject to growth by delamination and eventually cracking. This is incipient failure. The timing of this event is the rapid cooldown from $307^{\circ} \mathrm{F}$ to $250^{\circ} \mathrm{F}$ in the ASTM D3911-95 DBA. Cracking was predicted in both the $1 / 8$ " and 1/2" diameter defects within seconds after the start of the first cool-down transient.

\section{b. "Plant-Specific DBA"}

The analysis results showed that even a large blister would not be subject to growth by delamination since the pulse is too short in duration to heat up the substrate and cause water vaporization to pressurize an existing blister defect.

\section{Defect Type 2 (Hole in Coating)}

No significant deformation leading to peel-back of the coating was predicted with analytical modeling in both the "full" and "plant-specific DBA" analyses. Testing of plate specimens also showed no peel-back damage. However, a debris source was formed from the corrosion of the exposed steel plate.

\section{Aged}

\section{- A. Non-defected}

The results from the DBA testing showed that the near-surface region-was subject to cracking and blistering. Failure of the coating did occur and a debris source term was formed. However, only the near surface ( $<2$ mils) region was affected. In addition, the debris source was a minor fraction of the surface area.

This formation occurred both in the "abbreviated DBA" and within the initial part of the "full DBA" (first 4 hours).

\section{B. Defect Type 1 (Embedded Non-bond or Blister)}

1. Without Trapped Water

Testing of plate specimens also showed no damage in an "abbreviated DBA" exposure.

2. With Trapped Water 
No testing or analysis was performed for this condition. The performance should be similar, however, to the findings for the coating system in the non-aged condition.

\section{Defect Type 2 (Hole in Coating) .}

Testing of plate specimens showed no peel-back damage. However, a debris source was formed from the corrosion of the exposed steel plate. This source is the iron oxide corrosion product.

\subsection{Summary of Major Findings for System 5 Performance}

1. No failure of a non-aged, non-defected System 5 coating will occur under "plant-specific" and "full DBA" profiles.

2. System 5 coatings that have been aged (irradiated to $10^{9}$ Rad per ASTM D4082-95) are subject to the formation of a debris source term. The debris formed as a result of blistering following by cracking of the blisters. A near-surface region of attack ( $<2$ mils) is observed. This degradation appears to be a consequence of oxidation of the coating and the depth of attack is expected to vary depending upon oxygen availability and permeability in the coating. The debris source is a small fraction of the surface area.

3. The presence of moisture within and under a coating would be expected to result in failure (blister growth and cracking leading to a source term) of the coating during the rapid cool-down portion of the DBA event (e.g., quench from $307^{\circ} \mathrm{F}$ to $250^{\circ} \mathrm{F}$ of ASTM D3911-95 PWR profile). The driving mechanism is the vapor pressure loading of the blister caused by a hot substrate and relatively cooler ambient conditions. 


\subsection{Future Activities}

Original formulations of generic coating Systems 1 and 2 (Phenoline ${ }^{\circledR} 305$ topcoat over CarboZinc ${ }^{\circledR} 11$ primer (steel) and qualfied surfacer products (for concrete)) are currently in process at Carboline Co. These products have been particularly challenging to obtain, particularly the CarboZinc ${ }^{\circledR}$ inorganic zinc primer, primarily due to the asbestos fiber used in the original formulation. SRTC, the industry PIRT panel (particularly its chairman, Jon Cavallo), and the NRC customer worked together to locate possible sources of the asbestos for the formulation. Steel samples have been fabricated by KTA-Tator, Inc. and are awaiting receipt of the IOZ primer for surface preparation and application. Concrete blocks are also being fabricated at SRTC for application of System 2.

Free-films of all coating products from Systems 1 and 2 are also being generated, with the exception of the IOZ primer, which is difficult, if not impossible, to obtain as a free-film due to its inherent structure. Free-films are required in order to be able to characterize inherent material properties independent of a bonded substrate. As with other free-films studied thus far, such properties will be used to further develop the understanding of coating behavior and the effects of long-term aging upon coating performance.

All samples irradiated to date in this program have been irradiated per ASTM D4082-95. Some initial samples were exposed to slightly lower cumulative dose levels due to the amount of time required to achieve a full $1 \times 10^{9}$ Rad dose and to obtain early insights. In all cases, damage due to radiation has thus far been limited to color changes and slight checking as expected, with most of the damage being observed in the immediate surface of the coating and not completely throughout the bulk of the material. This is as expected and is attributed primarily to the limited diffusion depth and availability of oxygen into the coating that can react with free radicals formed from the radiation-induced structural changes. This is also typical of materials irradiated at high dose rates $\left(1 \times 10^{6} \mathrm{Rad} / \mathrm{hr}\right)$ in relatively short periods of time (compared to actual service life), especially for materials of relatively low oxygen permeability.

As has been shown in many other investigations, there are significant limitations of conventional accelerated-aging methodologies, particularly for radiation exposure at much higher dose rates than anticipated in actual service. These limitations include:

- Diffusion-limited oxidation

- Dose-rate effects (chain scission vs. cross-linking)

- Synergistic effects of long-term oxidation, temperature, moisture, chemicals, etc.

- Variation in thermal transitions

Such effects are known to cause significant variation in performance and properties of materials such as thermoplastics (particularly polyolefins) and elastomers, which are more permeable by oxygen and moisture. The time to reach a particular level of degradation or degree of property change (e.g., $50 \%$ reduction in elongation) can be significantly less for such materials irradiated at lower dose rates to the same cumulative dose than for the same material exposed at higher dose rates. In fact in some cases, the effect is also observed to be worse at lower temperatures than higher temperatures due to a "self-healing" effect which occurs. In some polyolefin-based electrical cable insulation materials, samples exposed to the same total dose at varying dose rates and at higher temperatures exhibited less reduction in properties because the temperature was high enough to induce cross-linking. This is believed to somewhat offset the amount of chain scission induced by the radiation.

Because this is a well-known phenomenon for other polymers and due to the fact that existing commercial nuclear power plants may be required to be qualified for life extension of up to 60 years, the effects of long-term oxidation and low-level radiation are of significant interest to the project team. In fact, the only true measure of a coating's DBA performance and subsequent debris generation (if any) is to expose or "requalify" a coating under DBA conditions that has been in service for 15,20 , even 25 years. Although such effects are not expected to be catastrophic, this aspect of protective coatings in nuclear power plants has not been investigated. Radiation exposure, DBA exposure, and characterization of recently-applied coatings, regardless of formulation, is of limited value in understanding and predicting actual long-term performance and DBA response of older, in-service coatings. 
For this reason, SRTC, the industry PIRT panel, and the NRC customer have worked to obtain several samples of coated substrate (primarily steel) and/or coating debris from nuclear power plants for such investigation.

Specifically, samples have been received from the San Onofre Nuclear Generating Station (SONGS, Unit 3), Oconee Nuclear, Trojan Nuclear, and Braidwood, Unit 2 power plants. Additional samples are forthcoming from Maine Yankee. Of these, the Trojan Nuclear samples are considered to best represent the coating formulations as identified by the PIRT panel as generic coating Systems 1 and 2, the most dominant and widely-used Service Level 1 coating systems in PWR power plants. These samples will be fully characterized in both the as-received (serviceaged) condition as well as following both radiation (at varying dose rates and possibly temperatures) and DBA exposure.

Characterization is expected to include: FT-IR analysis for structural/compositional changes, SEM for morphology and porosity changes, adhesion/G-value mechanical testing, optical microscopy, thermal property analysis such as TGA and DSC, as well as visual examination and image analysis of debris, if generated. As some if not most of these samples are considered to be radiologically contaminated or potentially contaminated, appropriate protocols and procedures will be followed for sample handling, analysis, and waste disposal as necessary. 


\section{Appendix A}

Mechanical Testing Description 
Mechanical properties are key inputs to the coatings failure model. The mechanical properties of interest in the coatings program are adhesion, adhesion G-value, tensile strength, elastic (Young's) modulus and cohesion. Adhesion is the measure of the load or strength (load divided by the load bearing area) to separate a coating from its underlying layer or substrate. The adhesion G-value is the designation given in the coating failure model for the resistance to the separation of the coating layer from an underlying layer - or substrate. The adhesion G-value may be considered the fracture toughness of the interface at which separation occurs. The tensile strength is the standard material science property of the maximum load on a specimen divided by the area bearing the load. In the coatings program the tensile strength is measured in the so-called free-film coating specimen. The free film is simply the cured coating that has been removed from a very weakly adherent substrate, such as polyethlyene sheet. The elastic or Young's modulus can be measured from the load-elongation curve of the free-film specimen. It is assumed that the coating material is isotropic in these properties.

Cohesion is used here to designate the resistance to tearing of the free film. The cohesion test specimen is similar to the tensile test specimen except that it contains a notch or slit in its edge to initiate the tearing. The tests to obtain these properties were performed on an Instron universal (i.e., capable of both compression and tensile testing) testing machine (model 4507) equipped with an oven for elevated temperature testing. This appendix describes the methods developed for performing the tests.

\section{A.1 Adhesion and Adhesion G-value Tests}

The adhesion and adhesion G-value tests were developed from two American Society for Testing and Materials standard test methods. These are D5179-98 "Standard Test Method for Measuring Adhesion of Organic Coatings to Plastic Substrates by Direct Tensile Testing" and D4541-95 "Standard Test Method for Pull-Off Strength of Coatings Using Portable Adhesion Testers." These methods use a stud or puller affixed to a coating by an adhesive that is then pulled normal to the surface by a tensile machine in the former method or a manually operated apparatus in the latter. Figure A-1 shows three pullers affixed to a test specimen. The pullers are $1.4 \mathrm{in}$. high and $0.5 \mathrm{in}$. in diameter; their design was adapted from that given in D5179-98. The total displacement of the puller normal to the coating surface between initial loading and separation of the puller from the specimen is of the order of a few thousandths of an inch. Such small displacements are not accurately measurable with the simple recording of the displacement of the Instron's moving crosshead. This is so because the movement in taking up slack in the linkages of the gripping system, such as in the universal couplings that ensure loading in a direction normal to the specimen, is of the same magnitude as the displacements encountered in pulling the thin coatings to failure. In these tests the displacement of the puller was measured with a single-arm extensometer that was mounted to contact the top of the puller. The extensometer was a Materials Testing Systems model number $632-06 \mathrm{~B}-20$ with a full-scale range of $\pm 0.160 \mathrm{in}$. and capable of operating to $300^{\circ} \mathrm{F}$.

The upper grip for the pullers (design adapted from ASTM D5179-98 also) was machined with a pocket to accommodate the extensometer arm (Figure A-2). The upper grip was rigidly attached to a pull rod that was connected through a universal joint to a 20,000-1b load cell mounted in the Instron's fixed, upper crosshead. The lower grip held the 4-in. by 6 -in. by 0.25 -in. coupons and was connected rigidly to the Instron's moving crosshead. Threaded couplings with backing nuts were used to make rigid the connections between the upper pull rod and the upper grip and between the lower pull rod and the lower grip (Figure A-3). Two flexible couplings remained in the load chain: the universal joint through which the upper pull rod is connected to the Instron's load cell and the connection between the upper grip and the stud. These allow necessary motion for alignment, yet they require little force (compared to the load supported by the coating) to "set" themselves. A plumb bob was used to position the puller on the load axis. These steps ensure that the puller is pulled normally to the coupon (Figure A-4). The lower grip was equipped with a rectangular metal pan 1 in. in height that was filled with water to keep a test specimen wetted when experimental conditions demanded. 


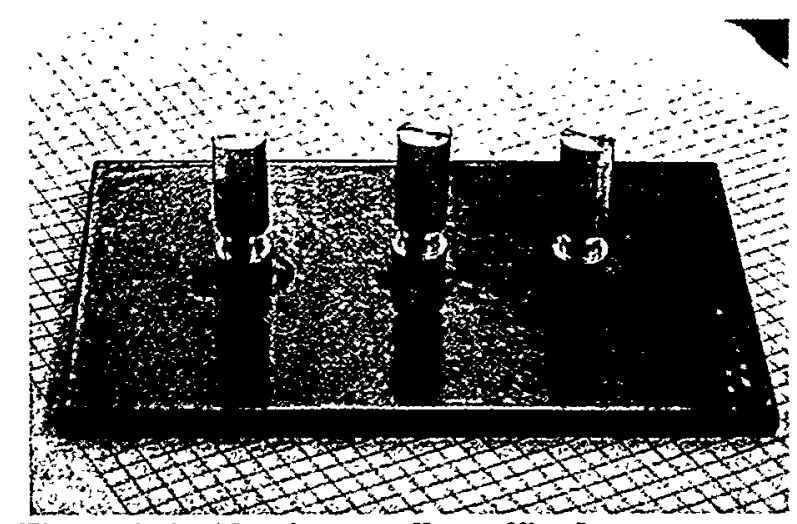

Figure A-1. Aluminum pullers affixed to a test coupon with epoxy adhesive.

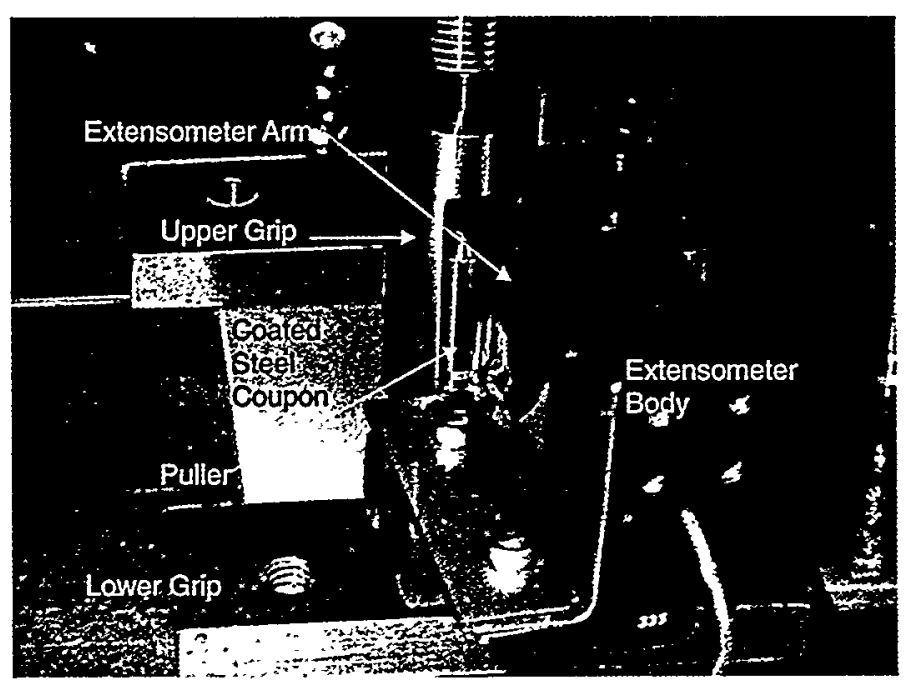

Figure A-2. Extensometer and grip for aluminum puller. 


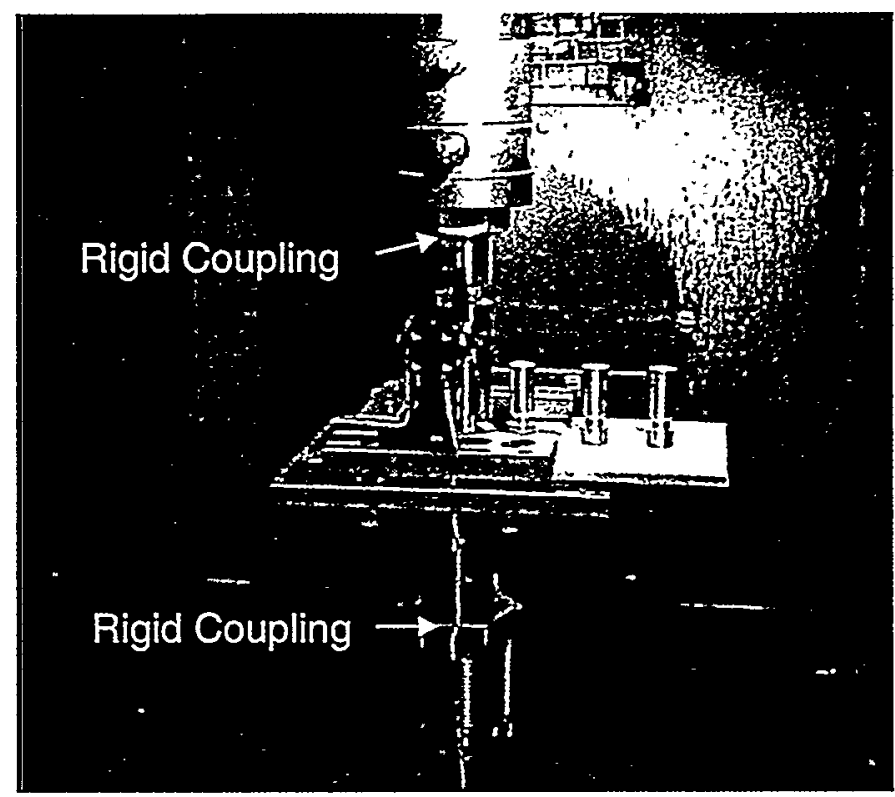

Figure A-3. Rigid coupling of upper and lower grips to Instron.

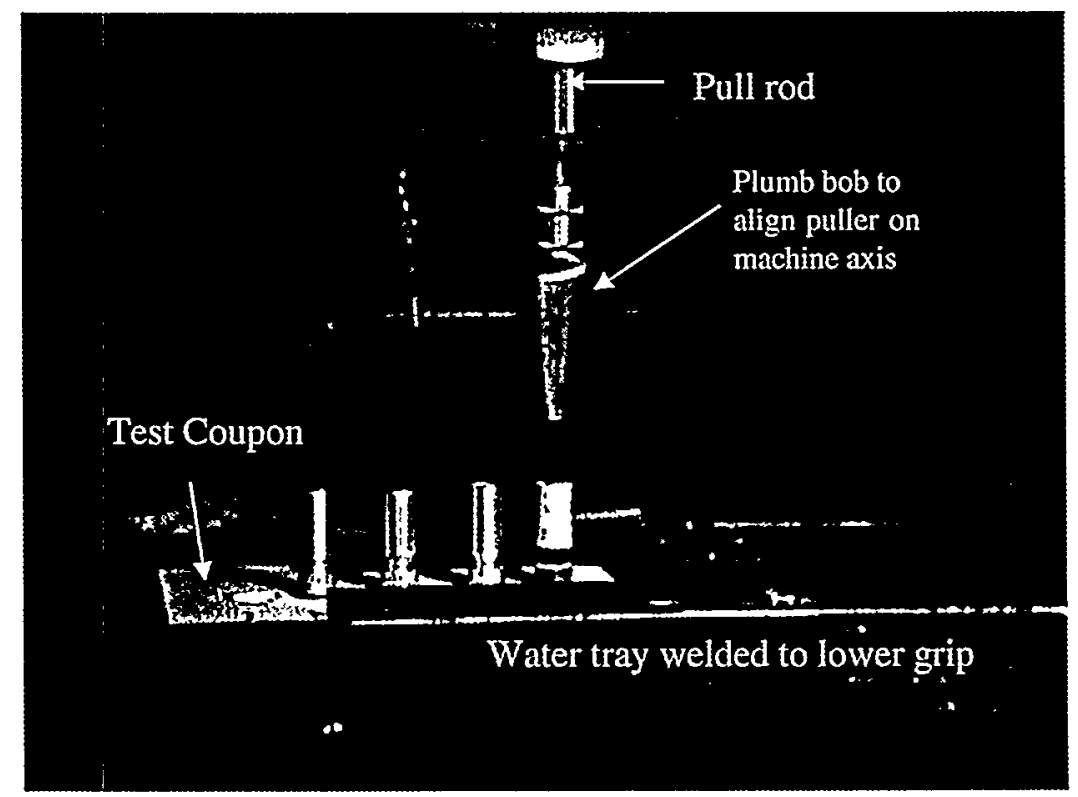

Figure A-4. Plumb bob arrangement to locate center of puller on Instron load axis. 
A common 0.5-in. diameter puller was used for both the adhesion test and the adhesion G-value test. They were affixed to the test coupon by Cotronics 4525 high-temperature $\left(500^{\circ} \mathrm{F}\right)$ epoxy (Cotronics Corp., Brooklyn, New York). This epoxy cures at room temperature in 16 hours.

The concept of the adhesion G-value test is shown in Figure A-5. As the puller is displaced from the coupon surface the zero-adhesion (so-called type 1 ) defect propagates radially until failure. The zero adhesion defect is created on the substrate by the build-up of polytetrafluoroethylene (PTFE). The process for this is shown in Figure A-6. Half-inch diameter holes are cut in a flexible magnetic mask material. The mask is placed in careful alignment on a clean, blasted steel coupon. PTFE is delivered to the steel surface by an aerosol spray of PTFE dry lubricant in multiple applications to build up a dense white color. The prepared coupon is then coated with primer and topcoat. The same mask is used to guide the attachment of the pullers.

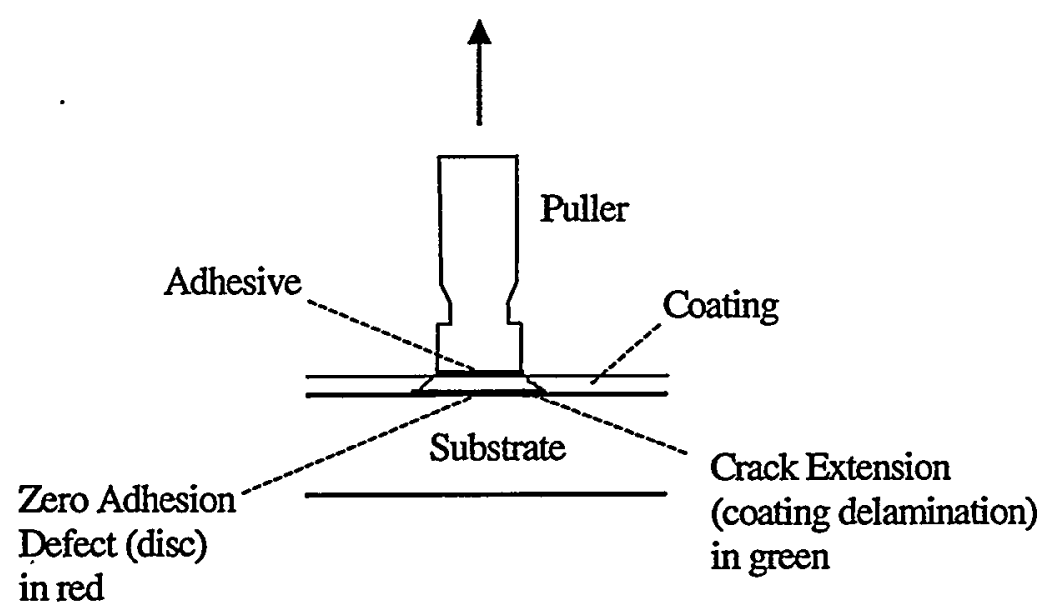

Figure A-5. Schematic diagram of the adhesion G-value test. 


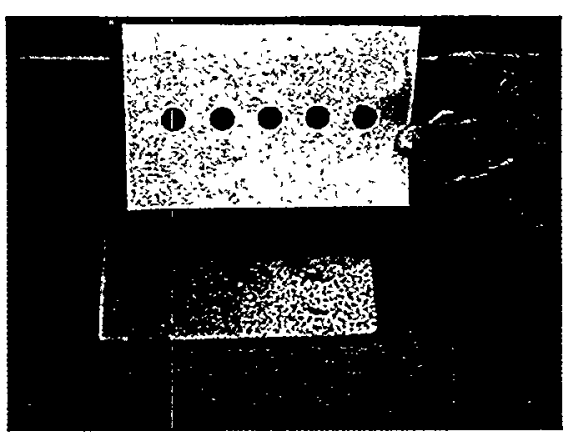

Flexible magnetic mask with 0.5 in. diam. holes

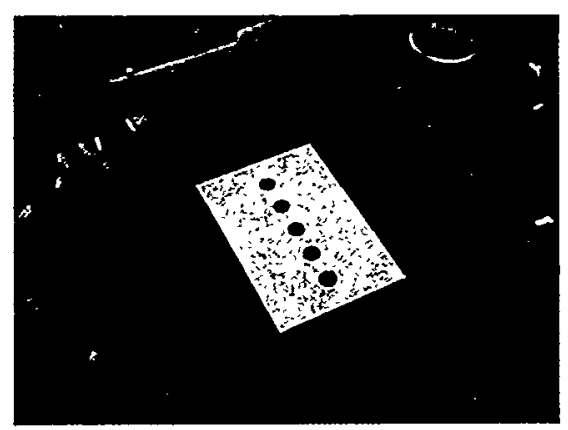

Polytetrafluoroethylene spray

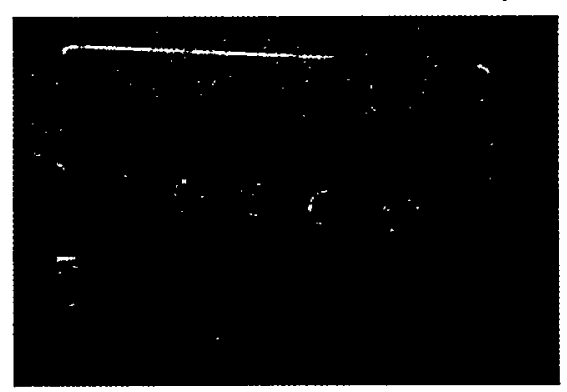

PTFE discs on steel coupon

Figure A-6. Method to create type 1 defects on steel for the adhesion G-value test.

\section{A.2 Tensile Test}

The tensile test employed so-called dogbone-shaped flat specimens that were cut from cured coating applied to a polyethylene sheet or that were molded on the sheet by spraying coating through a mask. The molded specimens were 4.5 inches in length overall with a 1.5 -in.-long by 0.25 -in.-wide gage section (Figure A-7). Specimens were pulled to failure at a crosshead speed of 0.02 in. per minute.

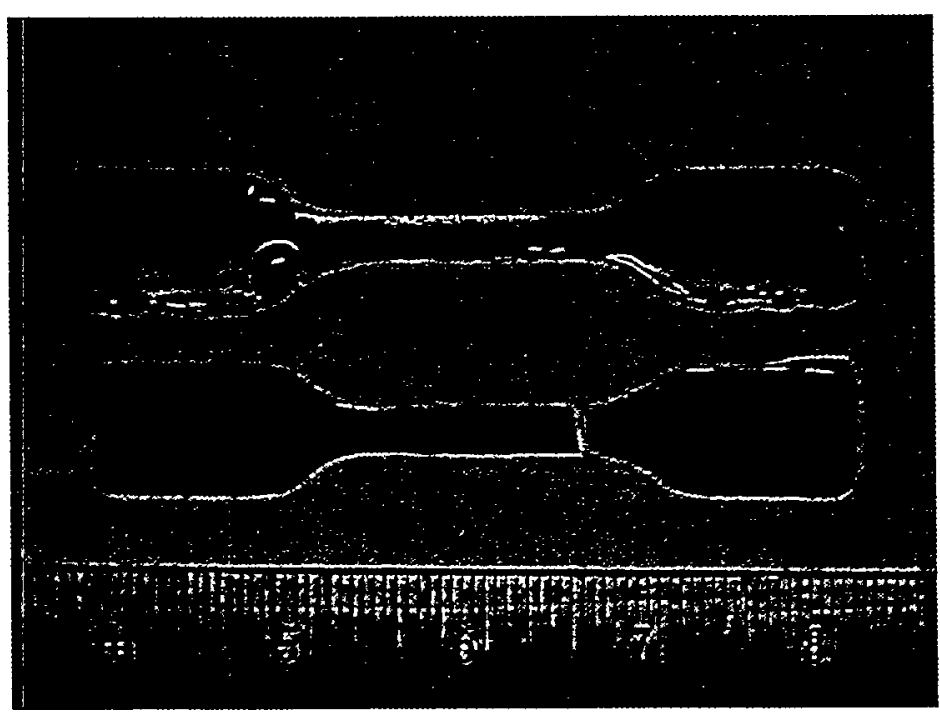

Figure A-7. Tensile specimens of Amercoat 370, as cured (above) and Irradiated and tested to failure (below). 
The specimens were securely held in knurled grips designed for relatively soft materials (Figure A-8).

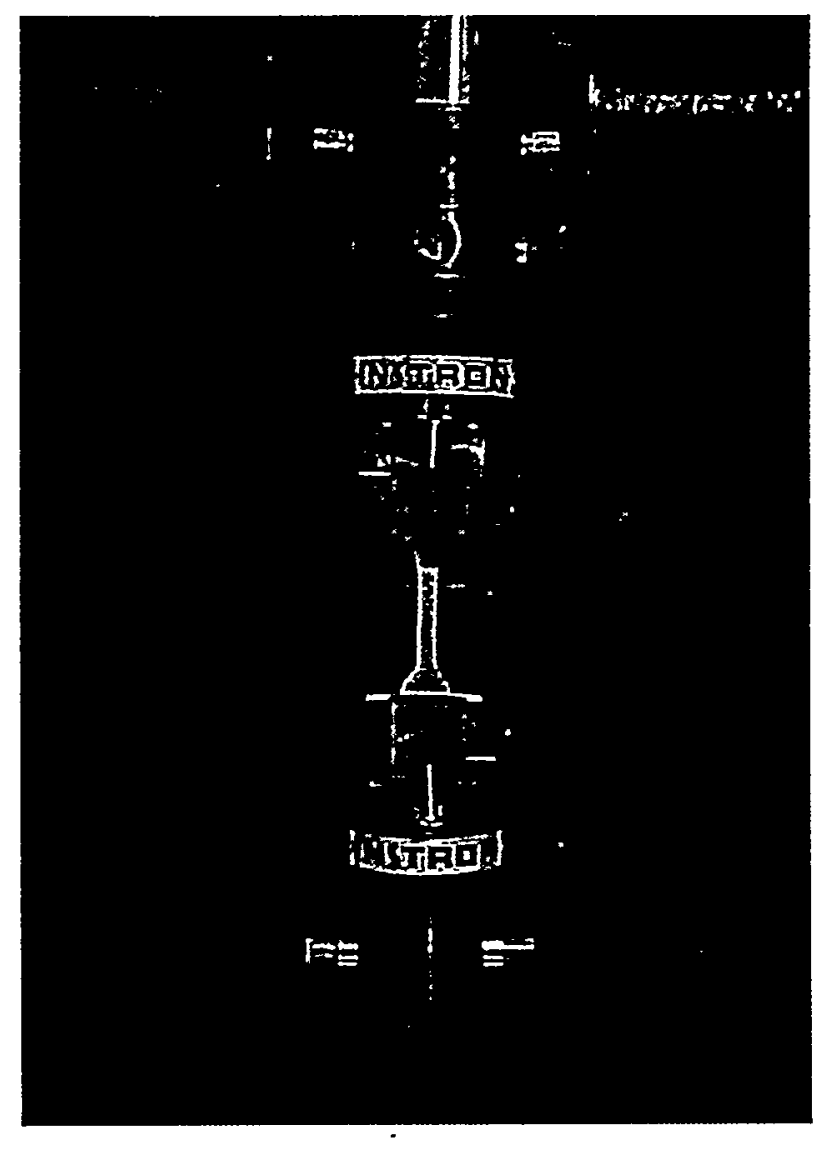

Figure A-8. Tensile specimen fixed in knurled grips. 


\section{Appendix B}

Irradiation Aging of Protective Coatings 
Many protective coatings based on thermosetting, highly cross-linked resins such as epoxies, epoxyphenolics, and polyurethanes have been shown to be quite resistant to gamma radiation to this cumulative dose level. Although thermally very stable, straight, unmodified phenolic coatings have been shown to be somewhat less resistant to gamma radiation and show evidence of degradation at levels as low as $1 \times 10^{8}$ Rads for some materials. For this reason as well as to improve toughness and durability, phenolic resins are typically either reinforced or modified with other resins (mostly epoxies).

Due to the range of variation in polymer processing, compound additives, specific formulations, curing agents, etc., radiation exposure testing is often necessary in order to evaluate the radiation resistance of a particular material or specific compound. In addition, it is often desirable to irradiate an intact component as would be installed in the actual application, rather than simply exposing a test sample.

Although there are limitations to the applicability of short-term, high dose-rate radiation exposure methods to predicting long-term performance, this is often the only rapid and cost-effective way to evaluate radiation effects upon critical properties. In some cases, exposure to a range of dose levels and rates can be used to develop an accelerated aging profile for a particular material to predict longer-term performance. This principle is known as superposition and has been applied to many materials qualified for long-term service in high radiation environments such as gaskets and electrical cable insulation.

The actual absorbed dose of a material depends upon its density and basic elemental composition, as well as mass absorption coefficients and other energy absorption properties. For most polymeric materials, including thermosetting polymers and protective coatings based thereon, the absorbed dose in Rads is assumed to be comparable to the energy of the radiation field applied. As the majority of polymers consist mainly of hydrogen and carbon, the mass absorption is generally comparable to that of water unless specifically measured.

There are two sources available for irradiation exposure. One is a Gammacell 220 (Figure B-1) with a current dose rate of 2.32E+04 R/hr. The second source is a J.L.Shepherd Model 109 Irradiator, with a current dose rate of $1.27 \mathrm{E}+06 \mathrm{R} / \mathrm{hr}$. Both of these are gamma irradiators with Co-60 as the isotope. The chamber size of both sources is 6" diameter by $7.5^{\prime \prime}$ high. Auxiliary systems to raise or lower ambient temp and to introduce air or gas or chemicals to the system can be added.

Accelerated-aging of protective coatings has historically been performed per ASTM D4082, "Standard Test Method for Effects of Gamma Radiation on Coatings for Use in Light-Water Nuclear Power Plants". The technical basis for this test method is that the cumulative exposure dose shall be $1 \times 10^{9}$ Rads, and the dose rate shall be controlled at $1 \times 10^{6} \mathrm{R} / \mathrm{hr}$ or higher. The field shall be uniform to within $10 \%$ between any two locations in the sample. The $1 \times 10^{9} \mathrm{Rad}$ total dose is historically based on a projected 40 -year service life and includes the radiation exposure during a design basis accident (DBA). The high gamma dose was also intended to exceed plant life gamma dose to also account for possible beta exposure as well. In addition, the temperature shall not exceed $140^{\circ} \mathrm{F}\left(60^{\circ} \mathrm{C}\right)$ during sample irradiation due to known synergistic effects of temperature and radiation. Following exposure, samples are examined per other ASTM standards to evaluate coating performance and presence of defects such as chalking, checking, cracking, blistering, flaking, peeling, and/or delamination. 


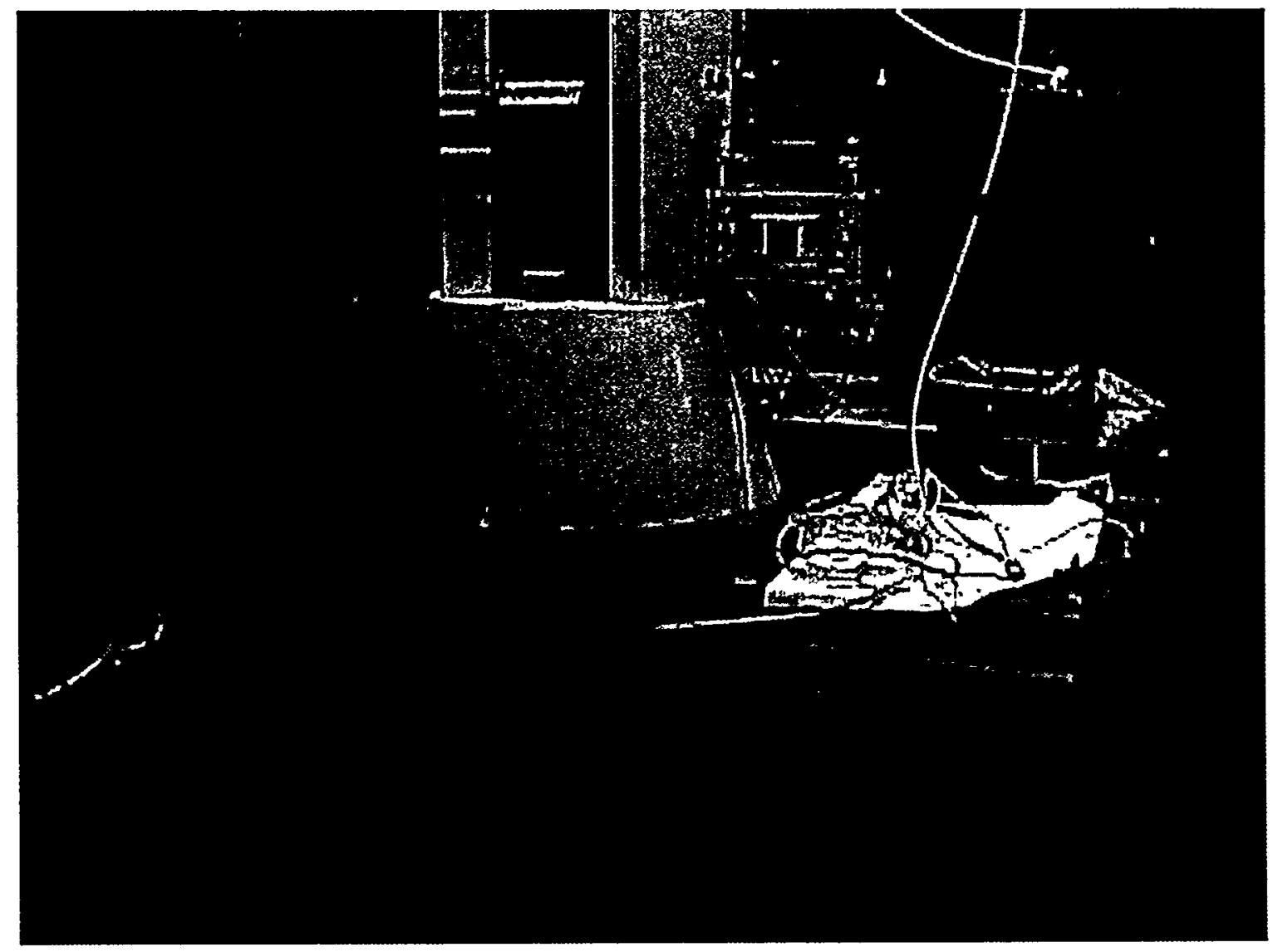

Figure B-1. GammaCell 220 


\section{Appendix C}

Application of Finite Element and Fracture Mechanics Analyses in Predicting Failure of NPP Coatings 


\section{C.1 Overview}

The NPP protective coating systems in general consist of multiple layers with various thicknesses and different properties which may be functions of environmental variables such as the temperature and wetness. The coating systems may be subjected to wide range of time-dependent loading conditions under the LOCA events. Initial defects may be postulated to exist in the coating system as a standard fracture mechanics procedure to determine the failure mechanisms.

The finite element method is considered an efficient analysis tool when many variables and scenarios are involved. There are three fundamental categories of inputs to the models:

1. Configuration - includes initial defect size, location of defect in the coating system, number of coatings and coating thickness, and type of substrate onto which coating is applied

2. Material Property - includes mechanical (modulus of elasticity or Young's modulus, adhesion energy, etc.) and physical (coefficient of thermal expansion, coefficient of thermal conductivity, etc.) properties or attributes of the coating layers and substrate materials

3. Loading - includes both direct loads (e.g., impingement of water) and environmental conditions that lead to coating stresses (e.g., thermal exposure leading to differential thermal expansion stresses)

The coating stress, strain, and the driving force leading to a defect growth will be calculated. With appropriate material failure criteria, the coating failure may be predicted and the conditions causing failure may be identified.

\section{C.2 Finite Element Model Description}

The finite element model used for most of the calculations contains 6210 rectangular elements and 6811 user-defined nodes. Heat transfer elements were used in the thermal transient analysis and continuum elements were used for the thermal stress analysis. The continuum elements can be either plane strain or axisymmetric, depending on the geometric characteristics of the problem. Only one-half of the analysis domain is modeled because of symmetry (with respect to the centerline or center-plane of the defect).

This model is capable of analyzing an intact three-layered coating system (topcoat, primer, and substrate), a defect at the topcoat-primer interface, a defect at the primer-substrate interface defect, or an intra-primer defect. There are 10 elements through the topcoat thickness and 16 through the primer. Coarser mesh was used in the substrate region except for the area adjacent to the primer for better transition. The mesh is refined greatly for the defect driving force calculation in the region where the postulated defect edge is located. The width of the model is about 5 times the size of a postulated defect and is divided into 138 elements with various sizes. The ABAQUS [1] finite element program was used.

\section{C.3 Solution Steps}

The coating system under the LOCA experiences temperature excursions. Because the different materials are used for the topcoat, primer, and the substrate, the mechanical property and thermal expansion mismatch will cause stress to develop in and between the layers. No external forces acting on the coating surface were considered throughout the present analyses. The thermal transient and stress analyses are uncoupled.

To achieve the coating failure prediction, a fracture mechanics approach was adopted. Several defect sizes were separately postulated in the coating system and modeled by the finite element method. The defect may be subject to vapor pressure loading in some cases due to the entrapped moisture at elevated temperature. This procedure allows the failure condition be established as a function of the defect size. As a result, a threshold defect size or a critical condition to cause failure may be determined. 
The calculation steps are listed below:

1. Thermal Analysis: Only conduction was considered in the current analysis. The temperature boundary condition was prescribed. Thermal transient analysis was performed based on the time-dependent ambient temperature profile, such as that given in ASTM D3911-95 DBA for PWRs. The physical properties input to the analysis are thermal conductivity, mass density, and specific heat. The properties may be temperature and radiation dependent. The temperature distribution was calculated in the finite element region.

2. Stress Analysis: A mesh identical to that of the thermal analysis was used. Only the finite elements were changed to the continuum type. The nodal temperatures obtained in Step 1 were directly input to the stress analysis model. Linear elastic analysis was performed in this preliminary assessment. The mechanical properties required for this calculation are the Young's modulus (modulus of elasticity), Poisson's ratio, and coefficient of thermal expansion. These properties also may be temperature and radiation dependent. The nodal displacement, element stress and strain are calculated. The defect growth driving force, or the adhesion G-value, is calculated with the J-integral [2] method in the ABAQUS [1] program. The finite element mesh was designed to allow five contour integrals to be assessed near the edge of the defect. The first contour, at the tip of the defect, is normally ignored due to inaccuracy. When moisture is postulated to be trapped inside the defect, a vapor loading condition may occur when the temperature is above the boiling temperature. In this case, the moisture temperature is assumed to be the substrate temperature directly underneath the defect. The corresponding saturated vapor pressure was obtained from the thermodynamic properties of steam [3]. The pressure differential between the external environment and the vapor gives a net pressure acting on the defect. When the external environment pressure is greater than or equal to the defect's vapor pressure, the pressure loading is zero. This vapor pressure loading condition is also time dependent.

3. With the changing temperature profile in the coating system and the possible vapor pressure loading within the defect, stress will develop in the coating system. In general, the coefficient of thermal expansion of the coating materials is several times higher than the substrate (e.g., coefficients of thermal expansion for the steel substrate is about $1 \times 10^{-5} \mathrm{~m} / \mathrm{m} /{ }^{\circ} \mathrm{C}$ and for the coating material is about $20 \times 10^{-5} \mathrm{~m} / \mathrm{m} /{ }^{\circ} \mathrm{C}$ ). This implies that the substrate temperature must be many times higher than that in the coating in order to negate the temperature-induced strain mismatch on the interface. This condition is very difficult to achieve because the coating materials normally are good thermal insulators (e.g., thermal conductivity for the steel is $43 \mathrm{~W} / \mathrm{m}^{\circ}{ }^{\circ} \mathrm{C}$, while for the coating material is less than $1 \mathrm{~W} / \mathrm{m}^{\circ}{ }^{\circ} \mathrm{C}$ ), unless the coating is subject to sudden cooling and the substrate remains sufficiently hot. The resulting stresses and strains will be output for assessment against the failure criteria.

4. The G-value due to the applied load (in the present case, temperature variation and pressure loading), denoted by $\mathrm{G}_{\text {applied, }}$ will be calculated at the edge of the defect by the CONTOUR INTEGRAL option in the ABAQUS finite element code [1]. In traditional fracture mechanics, this quantity is named the energy release rate, the crack driving force, or the J-integral; in the rubber industry, it is termed the tearing energy of the material. Physically, it is the force to extend the defect by a unit length, or the energy available per unit width to extend the defect by a unit length. The $G_{\text {applied }}$ obtained in the stress analysis is also time dependent. The value of $G_{\text {applied }}$ can be compared to $G_{\text {material }}$ (the material resistance to defect growth) obtained from testing of the coating materials, to determine if a defect grows in size.

\section{C.4 Defect Modes and Failure Criteria}

Two failure modes may be postulated, based on observations of irradiated and DBA tested coatings. These are termed Mode 1 and Mode 2.

I. Mode 1 Failure - Blistering followed by delamination and cracking 
Figure $\mathrm{C}-1$ shows an initial defect in the coating system. It can be an interfacial or intra-layer crack. Due to thermal expansion mismatch (leading to buckling) or vapor pressure loading, a blister may form. As the deformation progresses, the defect may grow in a self-similar manner, a delamination failure may occur but the blistering material remains adhered to the coating system. However, if the ultimate stress $\left(\sigma_{\mathrm{ult}}\right)$ or the failure strain $\left(\varepsilon_{\mathrm{f}}\right)$ is exceeded in the blistering/delaminating material, this defect will rupture, as depicted in Figure C-2. A local finite element mesh exhibiting the deformation of a Mode 1 defect is shown in Figure C-3. Therefore, two competing failure mechanisms may exist:

1. If $G_{\text {applied }} \geq G_{\text {material }}$ is met but $\varepsilon_{\text {applied }} \leq \varepsilon_{\mathrm{f}}$ and $\sigma_{\text {applied }} \leq \sigma_{\text {ult }}$, the defect delaminates to form a larger defect in a self-similar manner. The $\varepsilon_{\text {applied }}$ and $\sigma_{\text {applied }}$ represent the strain and stress due to the applied load, respectively.

2. If $\varepsilon_{\text {appliod }} \geq \varepsilon_{\mathrm{f}}$ or $\sigma_{\text {applied }} \geq \sigma_{\text {ult }}$, the defect should rupture at the location where the criterion is met.

When the Mode 1 defect is considered, axisymmetric finite elements are used in the calculation. Because the topcoat provides good thermal insulation, the temperature variation through the thickness of the coating system would be significant. Thermal transient analysis should be performed to obtain the temperature profile, which is then input to the subsequent stress analysis to determine the deformation and stress states of the defect.

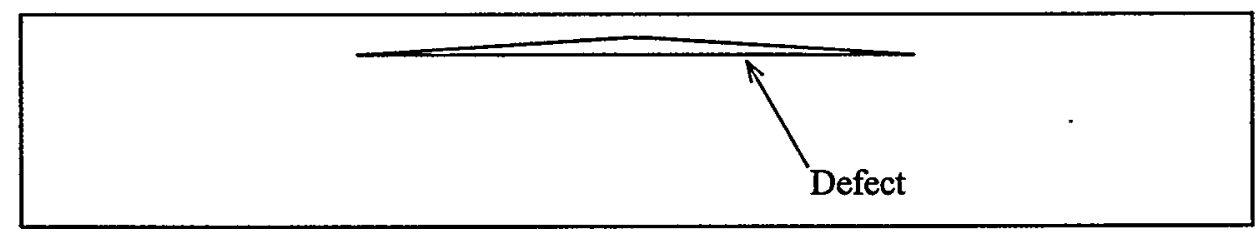

Figure C-1. Initial Mode 1 Defect

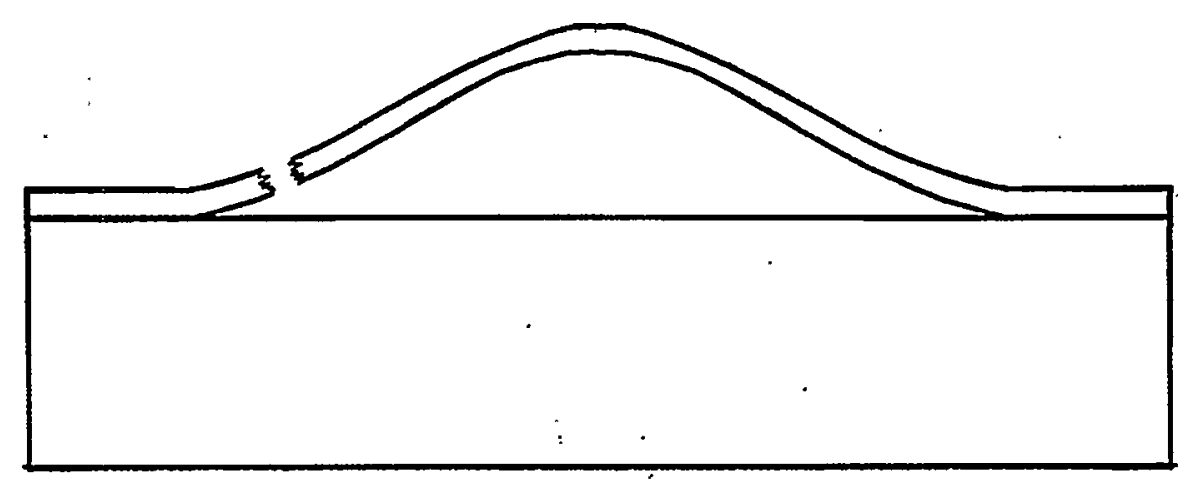

Figure C-2. Mode 1 Coating Failure 


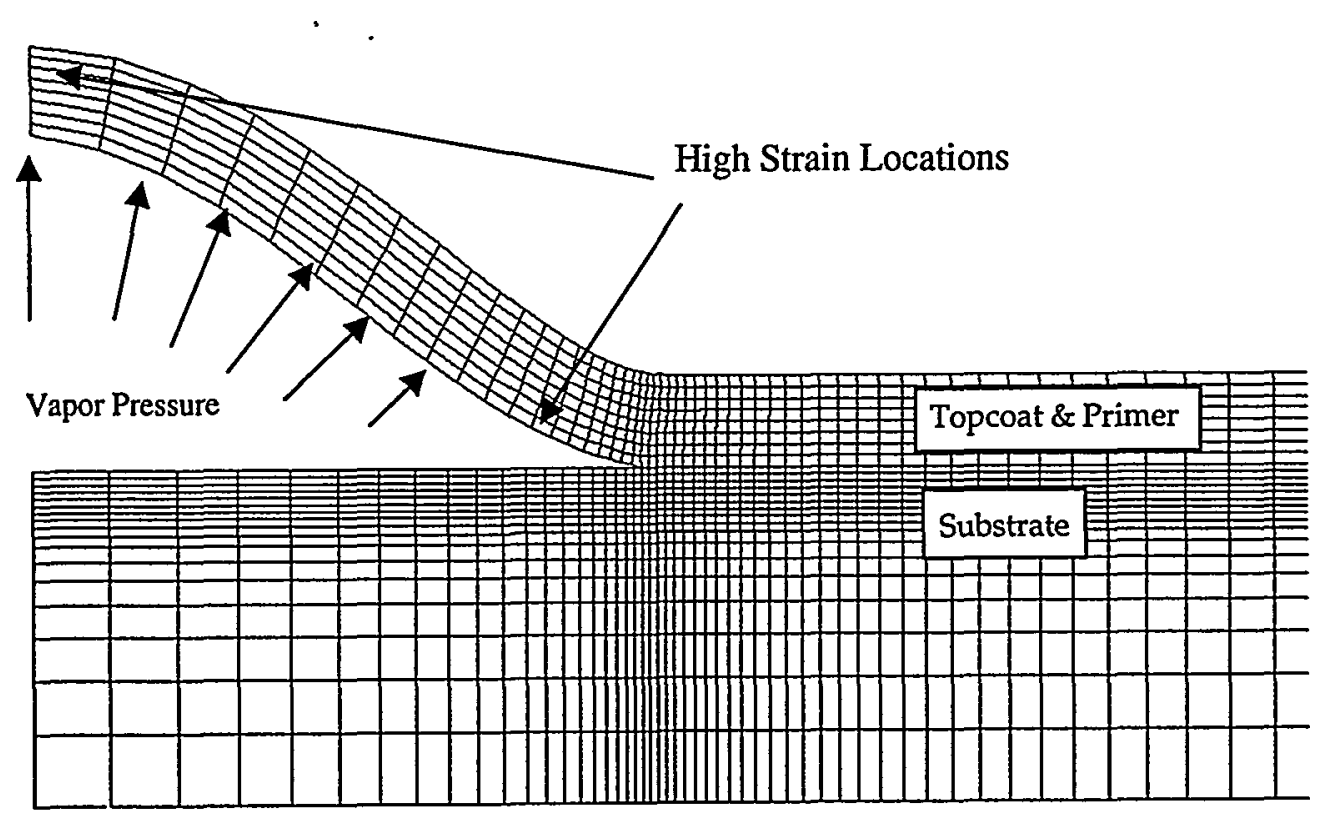

Figure C-3. Blistering due to buckling and/or vapor pressure loading

II. Mode 2 Failure - Cracking followed by delamination

A scratch-like crack penetrates through the topcoat to the primer or the substrate is assumed to exist. The main defect within the coating layer is perpendicular to this through-coating crack and is parallel to the coating layers (Figure C-4). Under the conditions of temperature variation and thermal expansion mismatch, this defect may peel back and the defect may grow when $G_{\text {applied }} \geq G_{\text {material. }}$ Eventually it will fall off the NPP containment wall when the condition $\varepsilon_{\text {applied }} \geq \varepsilon_{\mathrm{f}}$ or $\sigma_{\text {applied }} \geq \sigma_{\mathrm{ult}}$ is met. A deformed shape near the peel-back defect calculated by the finite element method is shown in Figure C-5.

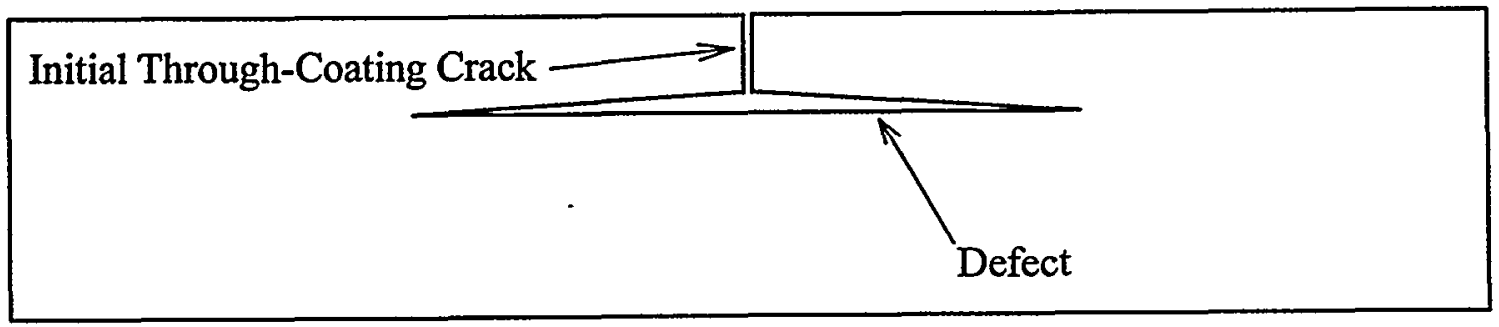

Figure C-4. Model for Mode 2 Coating Defect Analysis 


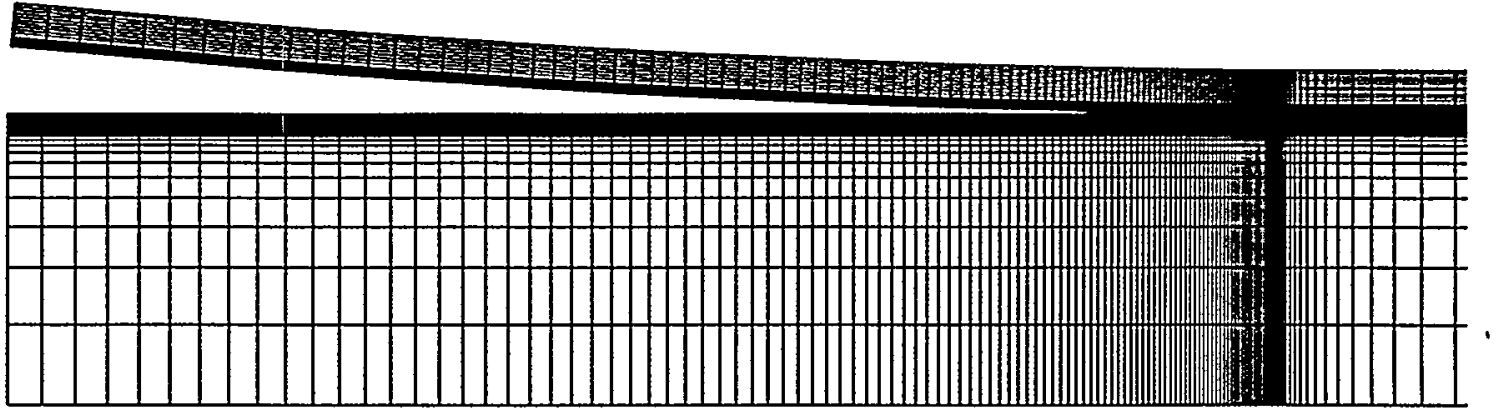

Figure C-5 - Peel-Back due to thermal expansion mismatch $\left(\alpha_{\text {lopcoat }}<\alpha_{\text {primer }}\right)$

Because of the initial, through-coating crack, the ambient temperature is short-circuited to the sublayer(s) which may have high thermal conductivity. This phenomenon is especially pronounced in the case of IOZ primer which is a zinc-rich layer and has even higher thermal conductivity than that of the steel substrate. Therefore, a uniform temperature is quickly reached throughout the entire coating system. As a result, thermal transient analysis is not needed to establish the temperature distribution through the coating thickness. The deformation (peel-back) and stresses are caused by the temperature differential and thermal expansion mismatch. Two-dimensional plane strain elements were used for the Mode 2 defect analysis.

\section{C.5 References}

1. ABAQUS/STANDARD, Version 5.8, Hibbitt, Karlsson \& Sorensen, Inc., Pawtucket, Rhode Island, 1999.

2. Rice, J. R., "A Path Independent Integral and the Approximate Analysis of Strain Concentration by Notches and Cracks," Journal of Applied Mechanics, Vol. 35, pp. 379-386, 1968.

3. Keenan, J. H. and Keyes, F. G., THERMODYNAMIC PROPERTIES OF STEAM INCLUDING DATA FOR THE LIQUID AND SOLID PHASES, First Edition, John Wiley \& Sons, New York, 1936. 


\section{Appendix D}

Mini-ETC Description 
The SRTC coatings performance evaluation system (Figure D-1) is used to examine the performance of NPP coatings in conditions simulating those expected to exist in a DBA LOCA. Figure D-2 shows a test specimen being placed into the coatings performance evaluation system. It is currently being used to simulate DBA conditions specified in ASTM D3911-95 (Figure D-3). However, most of the SRTC tests have been abbreviated to permit examination of a large number of samples (Figure D-4).

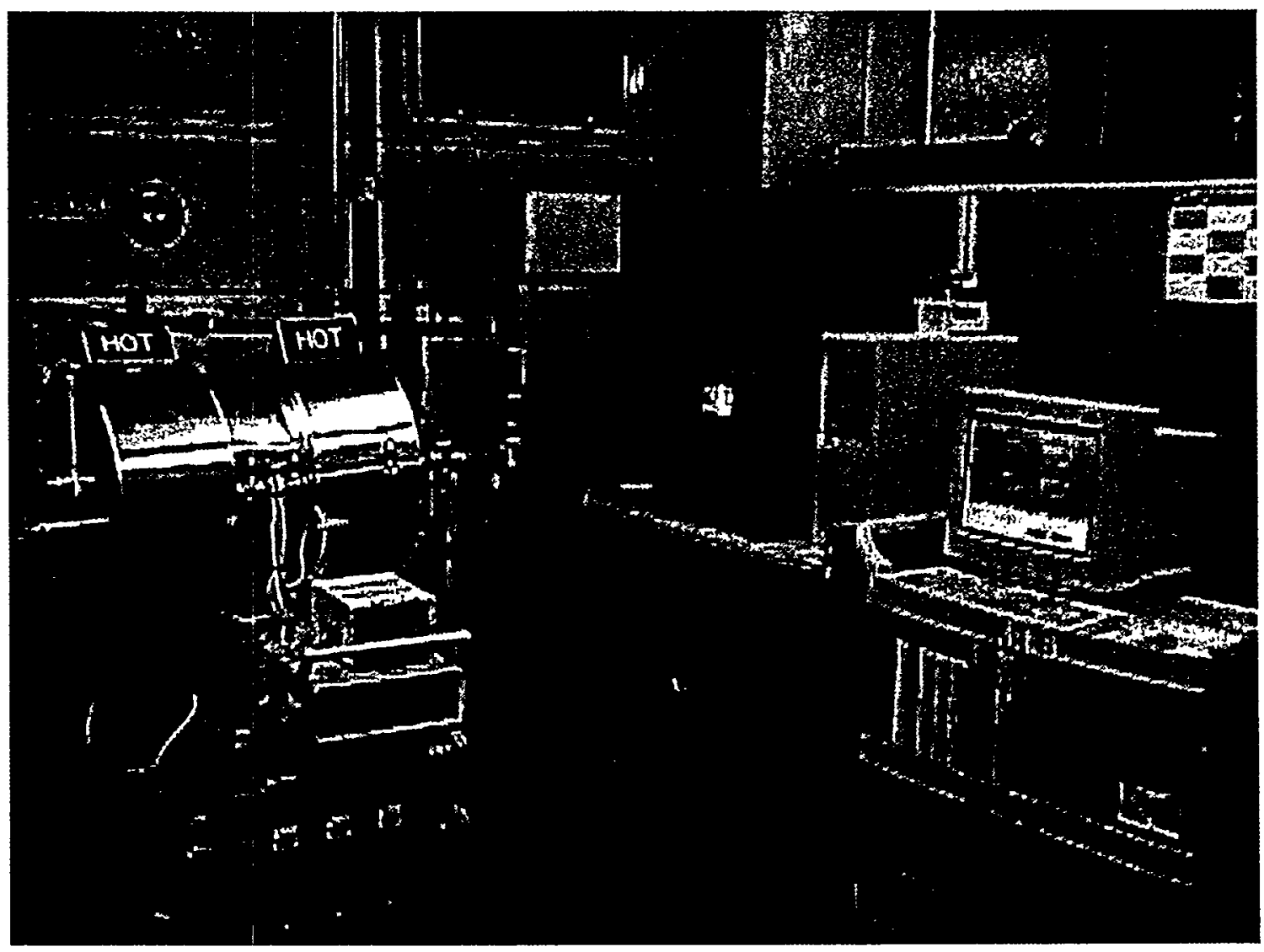

Figure D-1. SRTC Coatings Performance Evaluation System 


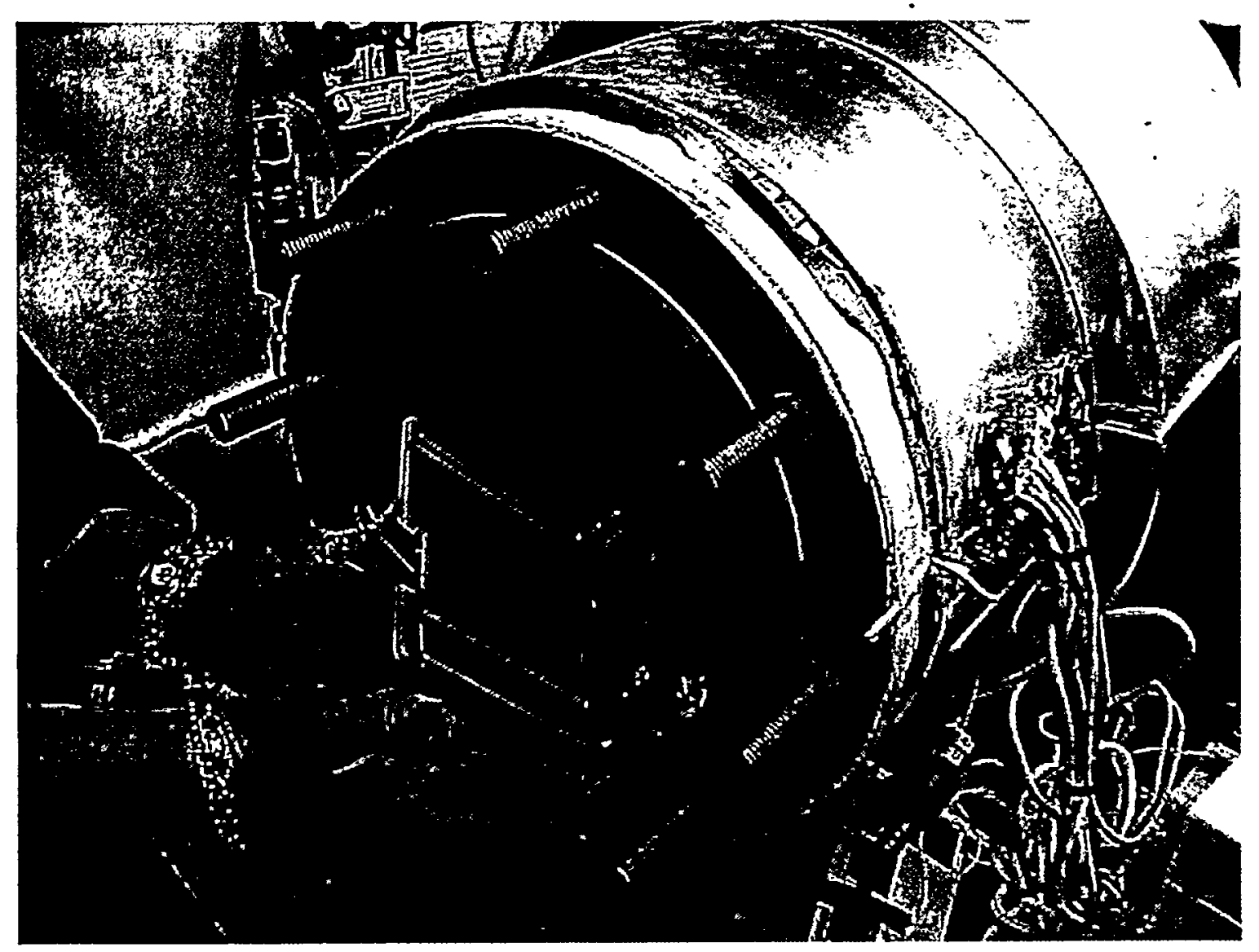

Figure D-2. Test Specimen being placed into the Coatings Performance Evaluation System

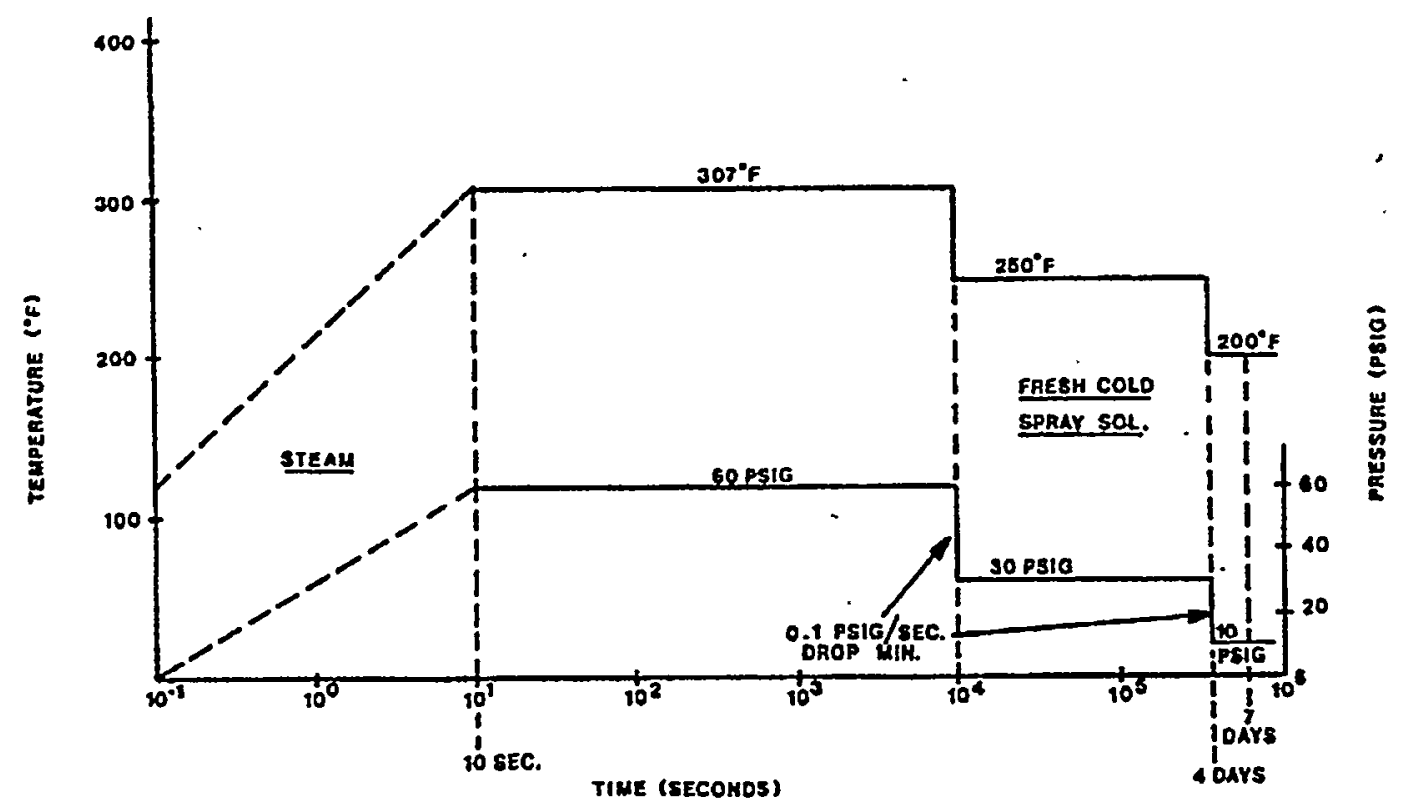

Figure D-3.' Typical Pressurized Water Reactor Design Basis Accident (DBA) Testing Parameters (from ASTM D3911-95). (Note: The ASTM figure contains an error: 30 psig should be $15 \mathrm{psig}$, which is equivalent to $30 \mathrm{psia})$. 


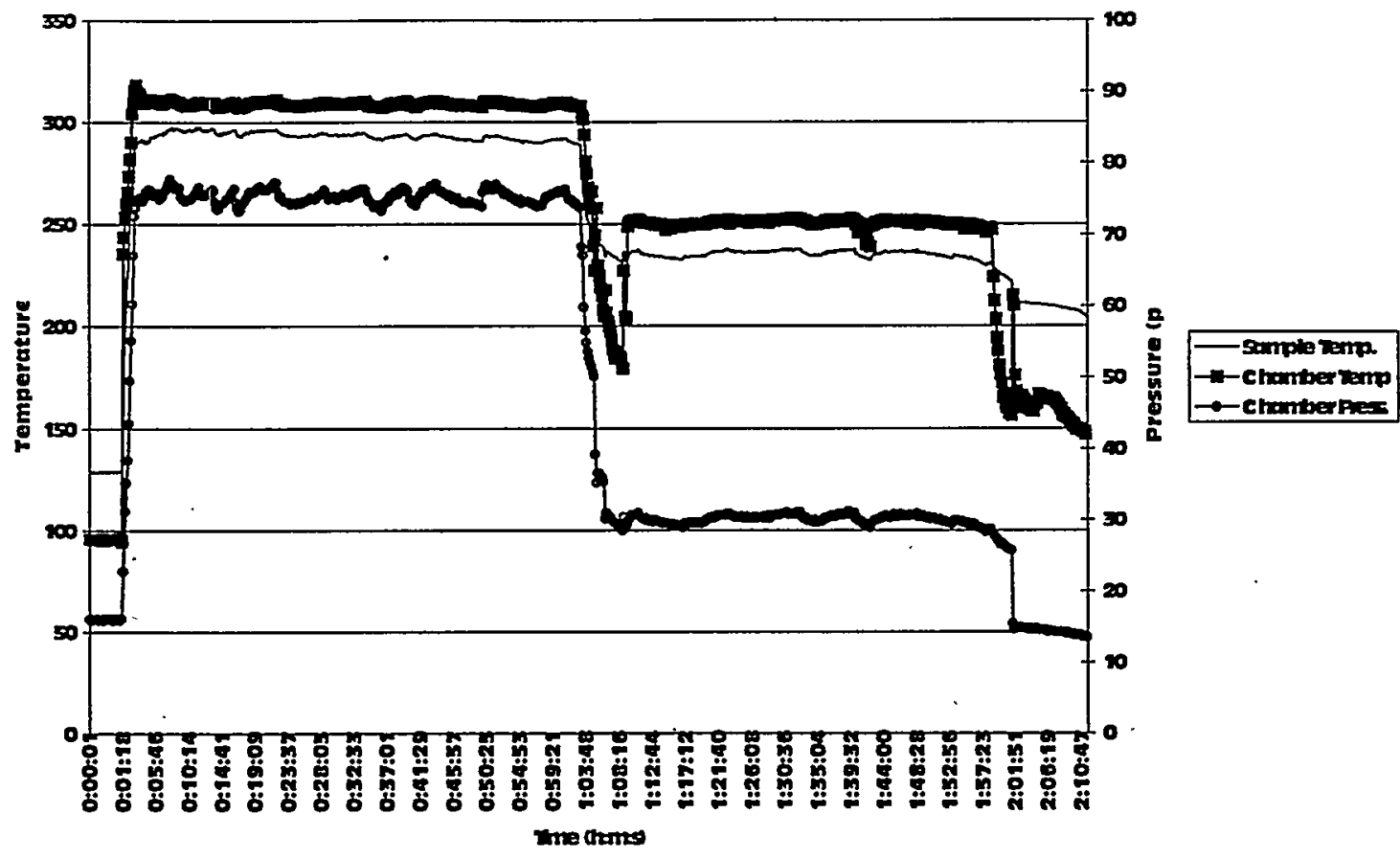

Figure D-4. Typical SRS “Abbreviated DBA" Cycle. Note: Sample cool-down time has been omitted from the figure.

The SRTC coating evaluation system is based on a monitored environmental test chamber (known as the which can be supplied with live steam and/or cooling water spray (Figure D-5). The environmental test chamber is an insulated 8-inch diameter by 12 -inch long pressure vessel, with flanged closures at each end. It is fabricated of Type 316 stainless steel. The ASTM code-stamped pressure vessel is protected with a 150 psi pressure relief valve. Strap and tape heaters are installed for supplemental control of temperature in the chamber (not shown in the schematic).

A 1-gallon, 3300-psi stainless steel autoclave provides steam to the test chamber. A 500-psi rupture disk is installed on the autoclave.

Pressure transducers and thermocouples are installed on the autoclave and the test chamber, and a data acquisition system using Labview ${ }^{\otimes}$ software is utilized to document specimen test conditions. A videoborescope is installed in the test chamber and connected to a videotape recorder to document specimen performance during testing. An image from the video borescope is shown in Figure D-6.

The cool-down phase of the ASTM D3911-95 DBA cycle, which simulates activation of the emergency spray cooling headers in the NPP, is facilitated by a spray system installed in the test chamber. The system consists of a $1000 \mathrm{psi}$ Baldor pump, a heat exchanger to cool the spray solution that is recirculated from the bottom of the chamber, and a storage reservoir. Solution is supplied to the chamber through 0.25 -inch diameter tubing. Two metering jet spray nozzles are installed in the chamber, each providing up to 0.030 gpm in a fine mist. Other spray configurations and rates are possible. All materials are Type $\mathbf{3 1 6}$ stainless steel to provide corrosion resistance to various spray solution compositions. 


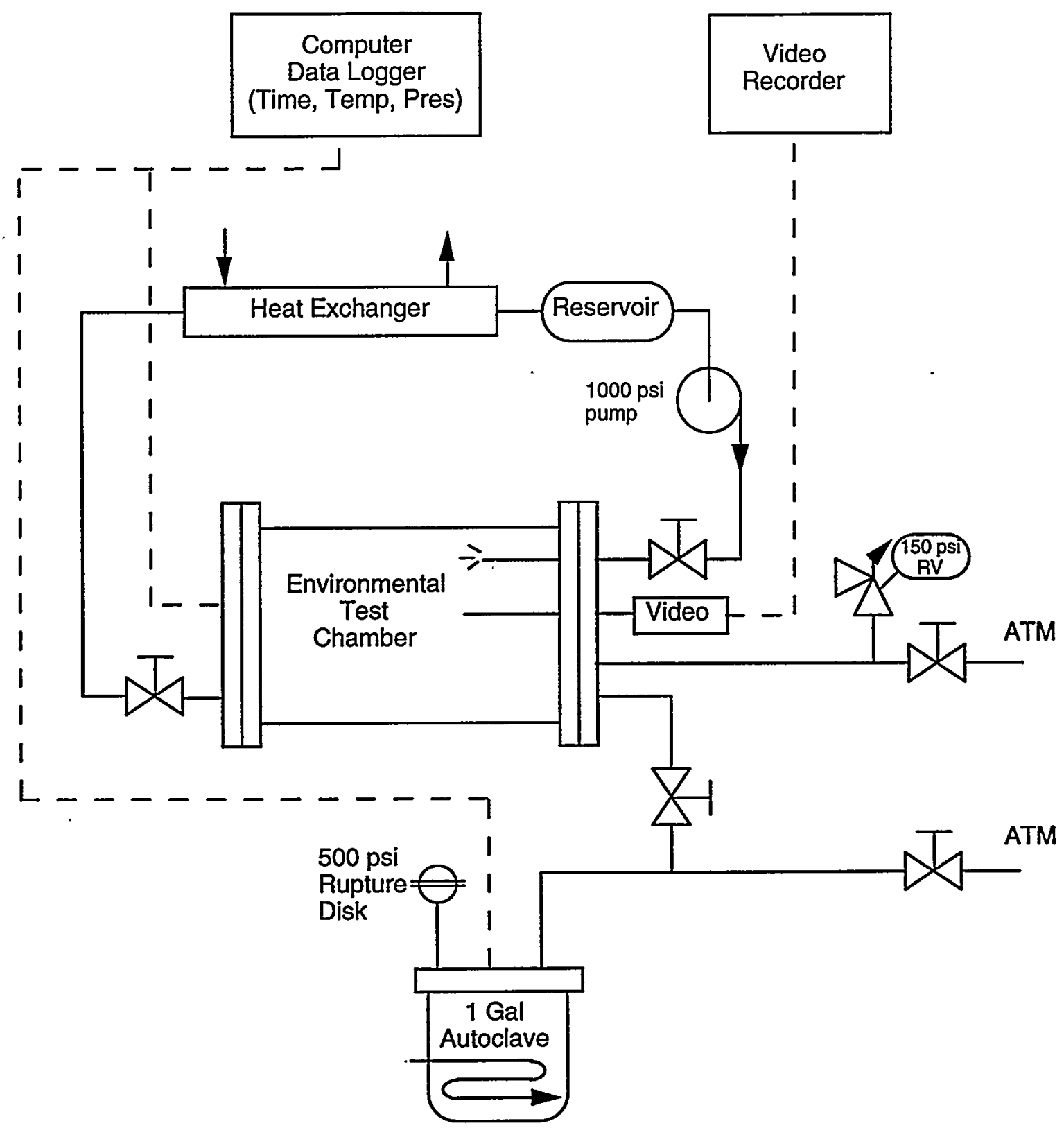

Figure D-5. Process schematic of coatings performance evaluation system 


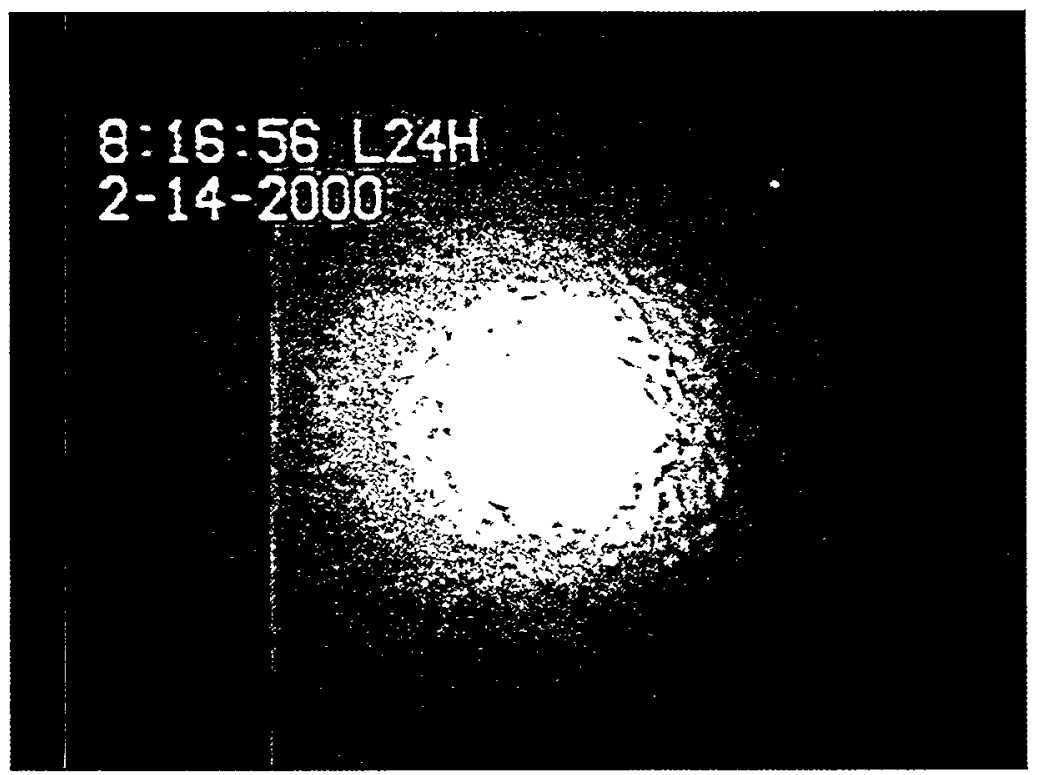

Figure D-6. Video Borescope Image of Aged (left) and Non-Aged (right) System 5 Specimens 


\section{Appendix E}

DBA Test Description

E-1 
The SRTC coatings performance testing system is used to subject coating specimens to conditions simulating those which would be expected to exist in a NPP during a DBA LOCA. The system, described in Appendix D, has been used to simulate the temperature and pressure profiles found in ASTM D3911-95, but with abbreviated exposure times to facilitate examination of a large number of specimens. A typical abbreviated exposure test proceeds as follows:

1. Place specimen into specimen holder within environmental test chamber. Affix thermocouple to back of specimen. Confirm borescope view of specimen. Seal test chamber.

2. Prepare videotape recorder and computer data logger for collection of test data.

3. Preheat autoclave steam generator. Preheat test chamber with external strap/tape heaters.

4. Introduce steam into test chamber so that chamber pressure reaches 75 psia within 10 seconds. Maintain chamber pressure.at 75 psia for 1 hour with supplemental strap/tape heaters. Judicious use of steam to maintain chamber pressure is permitted. Specimen temperature will be approximately $307^{\circ} \mathrm{F}$.

5. After 1 hour, activate spray cooling system. Monitor chamber pressure and vent as necessary to achieve 30 psia within 5 minutes. Maintain chamber pressure with supplemental strap/tape heaters and by control of recirculation rate of spray coolant. Specimen temperature will be approximately $250^{\circ} \mathrm{F}$.

6. After 1 hour, vent chamber to atmospheric pressure. Continue spray cooling, as necessary, to facilitate removal of heat from specimen and test chamber.

7. Remove specimen and examine for blistering, delamination, peeling, and/or cracking of coating. Per ASTM D3911-95: Blistering is limited to intact blisters, completely surrounded by sound coating bonded to the surface. Delamination and peeling are not permitted. Cracking is not considered a failure unless accompanied by delamination or loss of adhesion.

The SRTC coatings performance testing system will be used to subject selected coating systems to full DBA test sequences, as specified in ASTM D3911-95. These tests will proceed as describe in the abbreviated sequence above, with the exception of extended exposure times at $75 \mathrm{psia}$ ( 2.8 hours) and 30 psia (4 days). 


\section{Appendix F}

Characterization Facilities Description 
SRTC maintains a state-of-the-art testing and analytical capabilities to support the wide range of research and application programs related to nuclear applications. The materials and analytical research group total over 100 engineers, scientists and technicians. They have a broad range of experience in nuclear materials and applications and form the core of all the materials technology programs currently underway at SRTC. These range from materials applications involved in nuclear materials production, to reprocessing and waste storage and disposition.

A summary of the materials characterization facilities and available equipment and techniques is provided in Table F-1. 
Table F-1. Relevant SRTC Experimental and Analytical Capabilities

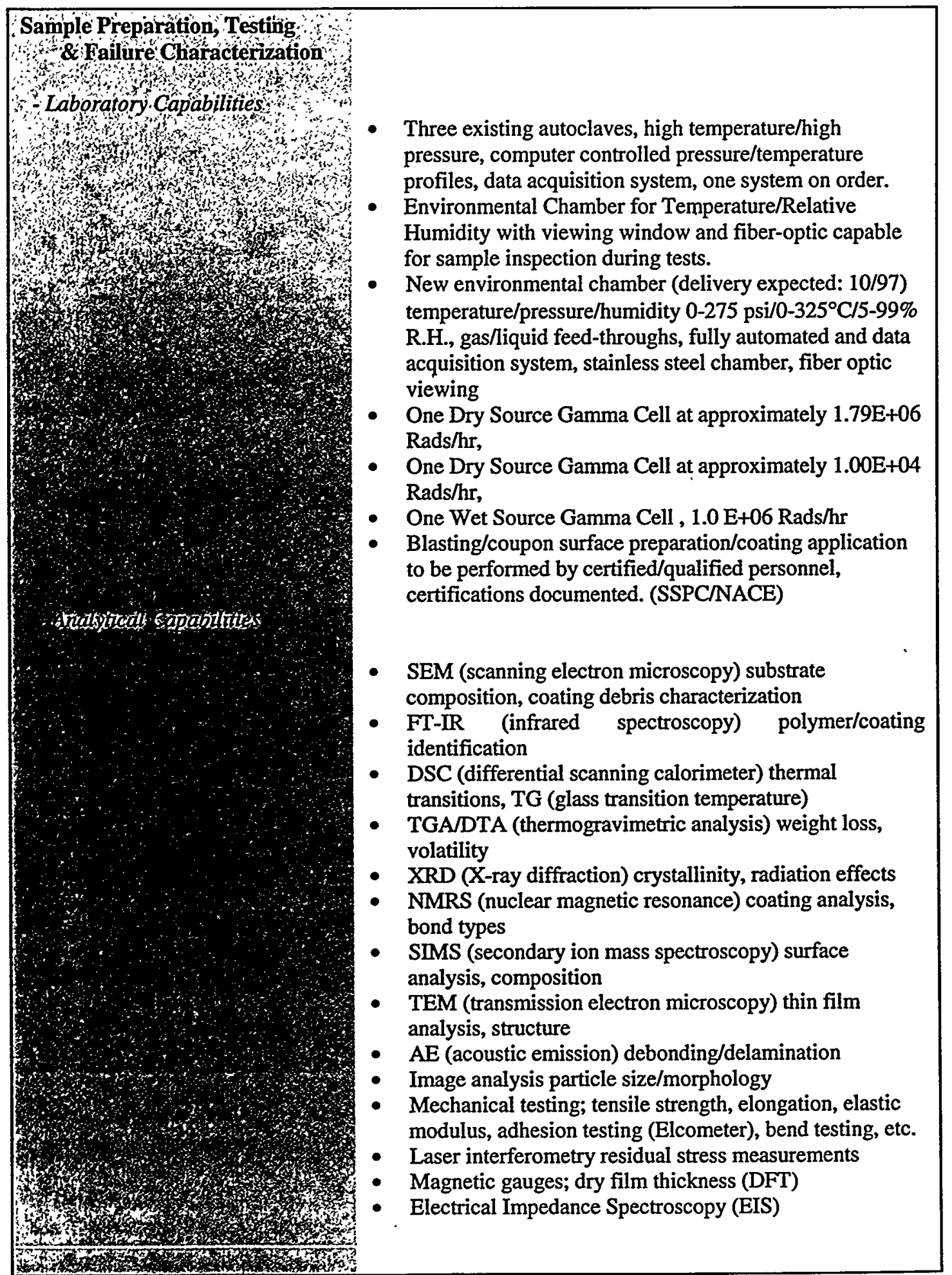


WSRC-TR-2000-00079
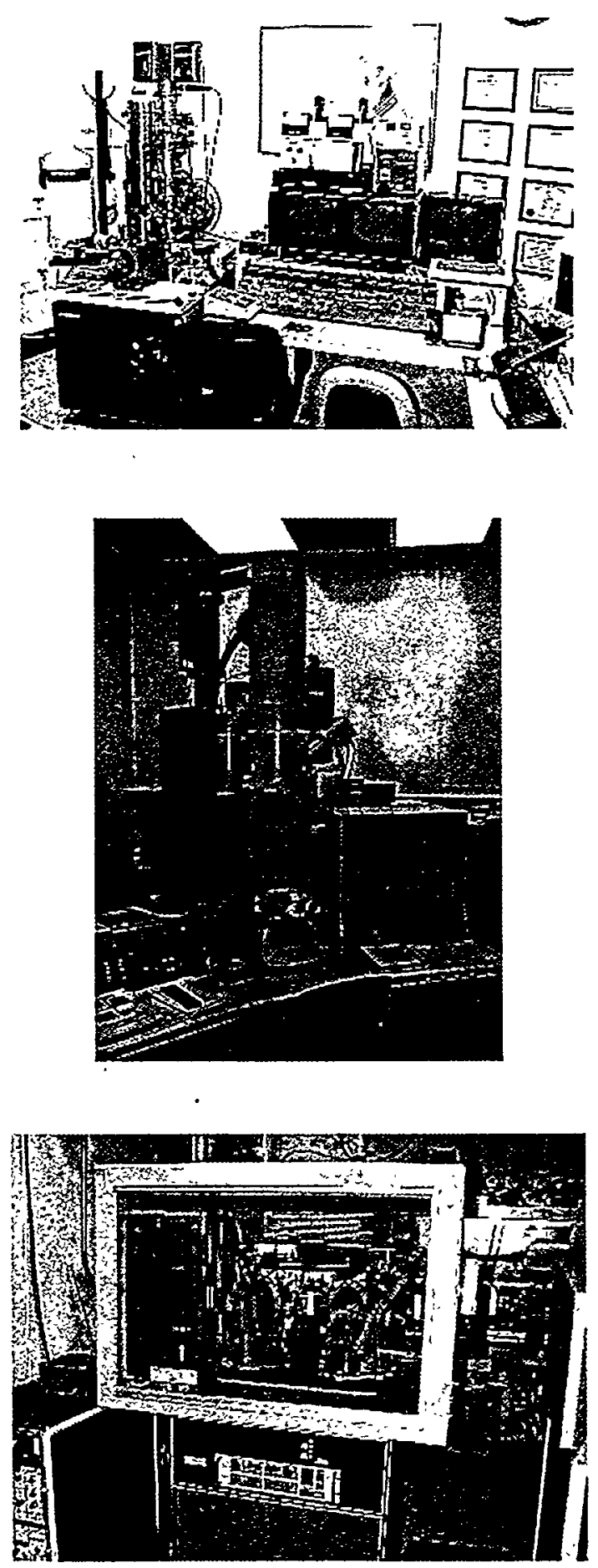

Figure F-1. SRTC Analytical Capabilities: Scanning Electron Microscope (top), Transmission Electron Microscope (middle), and X-ray Diffraction Unit (bottom) 


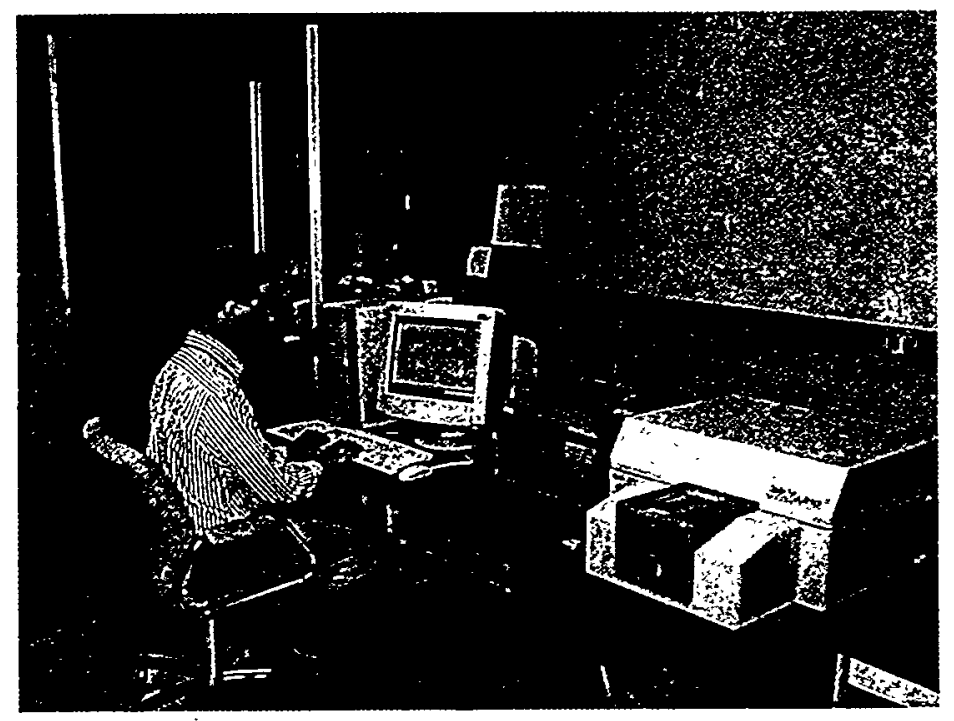

Figure F-2. FT-IR Spectrophotometry Equipment 


\section{Appendix G}

Phenomena Identification and Ranking Table Process

G-1 
WSRC-TR-2000-00079

\section{A.1 PIRT Process Overview}

The information obtained through the Phenomena Identification and Ranking Table (PIRT) process identifies phenomena derived requirements which are then integrated into experiments and/or analytical modeling to simulate accident scenarios or conditions of safety concern. Because importance ranking is a fundamental element of the PIRT process, judgments when prioritized with respect to their contribution to the accident scenario or safety concern, provide a structured approach to research program planning based on phenomena of highest importance. Since it is neither cost effective, nor required, to assess and examine all the parameters and models for arriving at a best-estimate code (or supporting experiments) in a uniform fashion, this methodology focuses on identifying those processes and phenomena that are expected to dominate the transient behavior, with the recognition that all plausible effects are considered in development of the PIRT. This screening of plausible phenomena, to determine those which dominate the plant response, ensures that a sufficient and efficient analysis of the problem has been performed. Since PIRTs are not computer code-specific, PIRTs are applicable to the accident scenario and plant design regardless of which code may be chosen to perform the subsequent safety analysis.

A typical application of the PIRT process is conceptually illustrated in Figure G-1 and is initiated by a definition of the problem and PIRT objectives. The PIRT process focuses on phenomena/processes that are important to the particular scenario, or class of transients in the specified nuclear power plant (NPP), i.e., those that drive events. Plausible physical phenomena and processes, and their associated system components are identified. From a modeling perspective, phenomena/processes important to a plant response to an accident scenario can be grouped in two separate-categories: 1) higher level system interactions (integral) between components/subsystems, and 2) those local to (within) a component/subsystem. Although the identification of plausible phenomena is focused toward component organization, experience gained has indicated it can be most helpful to relate the phenomena to higher level integral system processes. Time can often be saved when it can be demonstrated that a higher level integral system process is of low importance during a specific time phase. A subsequent and equally important step is the partitioning o the plant into components/subsystems. This latter step is a significant aid in organizing and ranking phenomena/processes. The phenomena/processes are then ranked with respect to their influence on the primary evaluation criteria, to establish PIRTs. Primary evaluation criteria (or criterion) are normally based on regulatory safety requirements such as those related to restrictions in fuel rods (peak clad temperature, hydrogen generation, etc.) and/or containment operation (peak pressure, emergency core cooling system performance, etc.). The rank of a phenomenon or process is a measure of its relative influence on the primary criteria. The identification and ranking are justified and documented.

The relative importance of environmental conditions and phenomena present is time dependent as an accident progresses. Thus, it is convenient to partition accident scenarios into time phases in which the dominant phenomena/processes remain essentially constant, each time phase being separately investigated. The processes and phenomena associated with each component are examined, as are the inter-relations between the components. Cause and effect are differentiated. The processes and phenomena and their respective importance (rank) are judged by examination of experimental data, code simulations related to the plant and scenario, and the collective expertise and experience of the evaluation team. Independent techniques to accomplish the ranking include expert opinion, subjective decision making methods (such as the Analytical Hierarchy Process), and selected calculations. The final product of the application of the PIRT process is a set of tables (PIRTs) documenting the ranks (relative importance) of phenomena and processes, by transient phase and by system component. Supplemental products include descriptions of the ranking scales, phenomena and processes definitions, evaluation criteria, and the technical rationales for each rank. In the context of the PIRT process application to PWR containment coatings failures, the primary elements of interest are described in Section 2. The PIRTs resulting from this specific application are documented in Section G.7.

\section{G.2 PIRT Objectives}

The industry coatings PIRT panel is comprised of the following industry identified specialists:

Jon Cavallo, Chm. Tim Andreycheck Jan Bostelman Dr. Brent Boyack
Corrosion Control, Consultants and Labs, Inc.

Westinghouse Electric Corp, Pittsburgh, PA

ITS Corporation

Los Alamos National Laboratory 

Garth Dolderer
Florida Power and Light
David Long
Keeler and Long (now retired)

The PIRT objectives identified by the panelists were:

a. To identify coatings systems applied to steel and concrete substrates in PWR containments to be considered for the PIRT process,

b. To identify phenomena and processes applicable to coatings applied inside PWR containments, and,

c. To rank those phenomena and processes with respect to their importance to coating failures.

\section{G.3 Generic PWR Containment Coating Systems}

The generic identification of protective coating materials applied to NPPs was derived from EPRI Report TR-106160, "Coatings Handbook for Nuclear Power Plants," plant responses to GL 98-04, June 1996, nuclear industry surveys and inputs from PWR Owners groups. EPRI TR-106160 lists data collected from 29 NPP respondents and represents over 200 commercial coating products applied to over 1000 different plant-specific areas or equipment. The industry coatings PIRT panel reviewed all available information, and based on their collective coatings knowledge identified following eight generic coatings systems for consideration in SRTC's coating research program.
a. Steel substrate, inorganic zinc primer, epoxy phenolic topcoat,
b. Steel substrate, epoxy phenolic primer, epoxy phenolic topcoat,
c. Steel substrate, inorganic zinc primer, epoxy topcoat,
d. Steel substrate, epoxy primer, epoxy topcoat, (SRTC System 5)
e. Concrete substrate, surfacer, epoxy phenolic topcoat,
f. Concrete substrate, surfacer, epoxy topcoat,
g. Concrete substrate, epoxy phenolic primer, epoxy phenolic topcoat,
h. Concrete substrate, epoxy primer, epoxy topcoat.

PIRTs for coating systems (a.) and (f) were prepared first and are reported in the Industry Coatings PIRT Report No. IC9901, July 21, 1999, which is available through the NRC Public Document Room. PIRTs for the outstanding coatings systems are nearing completion and will be submitted to the NRC. These systems were judged to be representative of coatings that were applied in the early to middle 1970 s.

A cross-referencing of coating systems identified by the PIRT panel and coatings products selected by SRTC to represent those generic systems is provided in Section 2 of this report.

\section{G.4 Coating System Components}

To enable development of the individual PIRTs, the industry coatings PIRT panel partitioned each coating system into components as follows:

\section{STEEL SUBSTRATE}
a. Substrate
b. Substrate/Primer Interface.
c. Primer
d. Primer/Topcoat Interface
e. Topcoat 


\section{CONCRETE SUBSTRATE}
a. Substrate
b. Substrate/Surfacer Interface
c. Surfacer
d. Surfacer/Topcoat Interface
e. Topcoat

Figure G-2 illustrates the layering of coating materials on a steel substrate and postulated coating defects that was used in the PIRT process.

\section{G.5 Accident Scenario}

The industry coatings PIRT panel discussed a number of accident scenarios postulated for occurrence in PWR plants and their potential effects on containment systems, structures, and components (SSCs), coating systems, and the generation of coating debris which could transport to PWR containment sump(s). The following coating failure scenario was selected by the panel for use in its subsequent deliberations:
a. Normal plant operation for 40 years (potentially longer due to plant life extension),
b. Mechanical damage (see Figure G-1 for illustration of incipient and developed defects in coatings on concrete and steel substrates),
c. Chemical damage (from plant process fluid leakage and over-spray/leakage of decontamination chemicals),
d. Normal plant operation for 40 years (potentially longer due to plant life extension) followed by intermediate / large LOCA without jet impingement (note: small break LOCA was not considered because containment spray is not initiated and thus significant coating debris transport to the sump(s) is not probable).

Scenarios a, b, c, and d above may occur independently or synergistically to cause coating failure.

Jet impingement due to a LOCA was omitted from the panel's deliberations, since industry test experience indicates that none of the coating systems applied to PWR SSCs will survive direct steam impingement.

\section{G.6 Scenario Phases}

The coating failure accident scenario divided into the following phases (or time intervals).

PHASE 1: Normal Operation Followed by LOCA, No Jet Impingement

(-) Time Coating System Installation -Surface Preparation

-Coating Application

-Curing

$\mathrm{T}=0 \quad$ Start of Power Operations

$\mathrm{T}=40$ years Medium or Large Break LOCA Occurs

( $T$ could be 60 years in the case of plant life extension) 
PHASE 2: $\quad 0$ to 40 Seconds After Start of LOCA

WSRC-TR-2000-00079

PHASE 3: $\quad 40$ Seconds to 30 Minutes After Start of LOCA

PHASE 4: $\quad 30$ Minutes to 2 Hours After Start of LOCA

PHASE 5: $\quad$ Greater Than 2 Hours After Start of LOCA

\section{G.6 Primary Evaluation Criterion}

The primary evaluation criterion, or parameter of interest, considered by the industry coatings PIRT panel concerning coatings on PWR containment SSCs is:

"Will the coating system detach from the surface to which it is applied?" or

"Will the paint fall off?"

The panel's focus was on the second question.

\section{G.7 Phenomena Ranking Scale}

PIRTs utilizing complex hierarchical, multi-leveled scenarios (see Figure G-1) and the Analytical Hierarchy Process ranking methodology applied to NPPs have been time consuming and labor intensive. The PIRT panel instead selected a simplified ranking scale that drew on the knowledge of panelists who had extensive experience in NPP coating application as well as NPP accident analysis requirements and the PIRT process.

Basis for Ranking Selection:

High - Phenomena has a dominant impact on the primary parameter of interest (i.e. coating failure). Phenomena will be explicitly considered in the implementation of the Savannah, River Technical Center (SRTC) Research Program

Medium - Phenomena has a moderate influence on the primary parameter of interest.

Phenomena will also be considered in the implementation of the SRTC Research Program

Low - Phenomena has a small effect on the primary parameter of interest. Phenomena will be considered in the SRTC research program to the extent possible.

The PIRT ranking for System 5 is summarized in Table G- $i$, which shows the variation of process or phenomena ranking as a function of time. Blistering and de-lamination were judged to be a HIGH concern throughout the accident scenario for the substrate/primer and primer/topcoat interface.

Tables G-2 through G-6 detail the process \& phenomena rankings for the materials and material interfaces, rankings arrived at, and the definitions applied to those processes or phenomena to arrive at those rankings.

The integration of these PIRT panel findings with project activities is discussed in Section 2 of this report. 


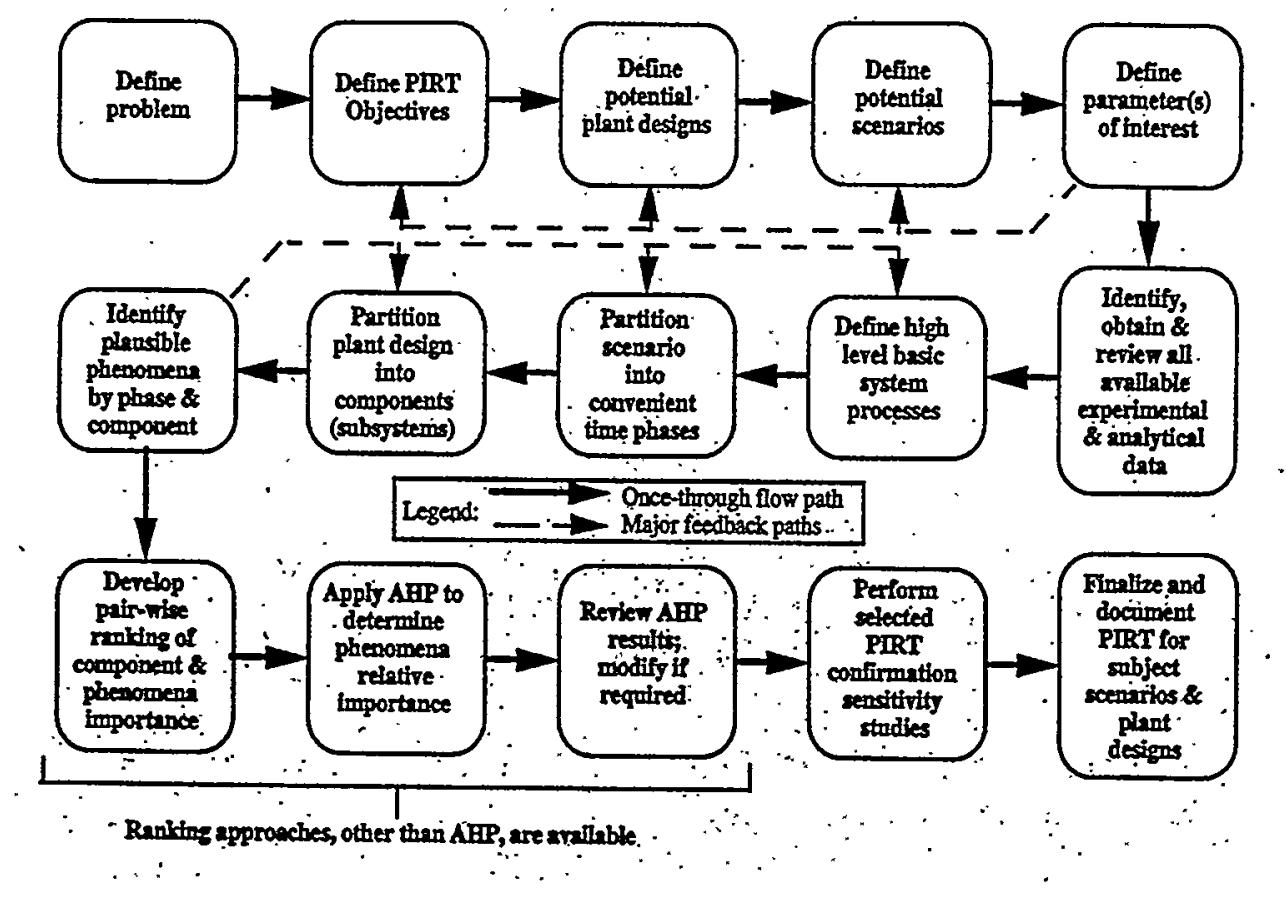

Figure G-1. PIRT Process

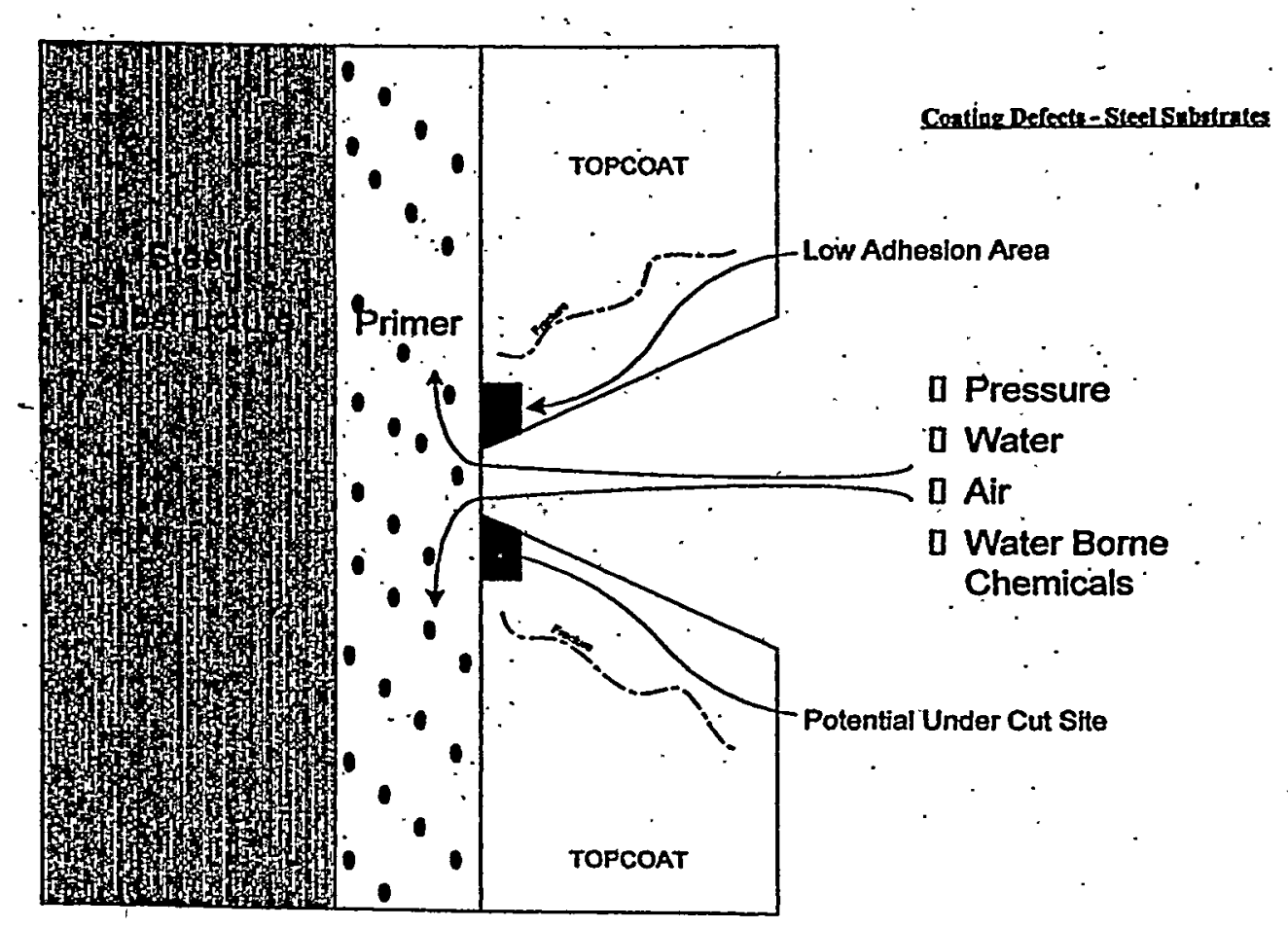


Figure G-2. Coating Defects and Phenomena of Importance

Table G-1. PIRT Ranking Summary

Steel Substrate - Epoxy Primer - Epoxy Top Coat

PIRT Coating System d, SRTC System 5

Phases - >

Process \& Phenomena

Substrate

(Steel)

\section{Substrate /Primer}

Interface

Primer

Primer/Top Coat

Interface

Topcoat
Blistering \& De-lamination

Oxidation

Environmental Exposure

Mechanical Damage

Minor coating anomalies

Air/water \& chemical intrusion

Above pool

Below pool

Air/Water \& Chemical Diffusion

Blistering \& De-lamination

Expansion and contraction

Environmental exposure

Mechanical damage

Minor coating anomalies

Air/water \& chemical intrusion

Above pool

Chemical attack
2

No High or Mediums identified.

$\begin{array}{lllll}\mathrm{H} & \mathrm{H} & \mathrm{H} & \mathrm{H} & \mathrm{H}\end{array}$

$\begin{array}{ccccc} & \mathrm{M} & & & \\ \mathrm{H} & \mathrm{M} & \mathrm{M} & \mathrm{M} & \mathrm{M} \\ \mathrm{H} & \mathrm{M} & \mathrm{M} & \mathrm{M} & \mathrm{M} \\ & & \mathrm{M} & \mathrm{M} & \mathrm{M} \\ & & & & \mathrm{M}\end{array}$

\section{Processes/Phenomena ranked HIGH and MEDIUM}

Blistering \& De-lamination

Oxidation

Environmental exposure

Mechanical damage

Minor coating anomalies

Air/water/chemical intrusion

Phase 1: Normal service from time of application and through 40 years operation.

Phase 2: 0 to 40 seconds into loss-of-coolant accident (LOCA).

Phase 3: 40 seconds to 30 minutes after a LOCA.

Phase 4: 30 minutes to 2 hours after a LOCA.

Phase 5: Beyond 2 hours after a LOCA. 
(Blank Page) 
INDUSTRY COATING PIRT SUMMARY - TABLE G-2 - NORMAL OPERATION

\section{COATING DESCRIPTION: Steel Substrate, Epoxy Primer, Epoxy Topcoat (SRTC System 5)}

\begin{tabular}{|c|c|c|c|}
\hline Component & Processes \& Phenomena & Rank & Definition \\
\hline $\begin{array}{l}\text { Substrate } \\
\text { (steel) }\end{array}$ & $\begin{array}{l}\text { Expansion and contraction } \\
\text { Increased radiation exposure }\end{array}$ & $\begin{array}{l}\text { Low } \\
\text { Low }\end{array}$ & $\begin{array}{l}\text { Liner plate response to changes in containment pressure } \\
\text { and temperature due to normal operation and ILRT's. } \\
\text { Neutron fluence generated due to operations. }\end{array}$ \\
\hline $\begin{array}{l}\text { Substrate/Primer } \\
\text { Interface }\end{array}$ & $\begin{array}{l}\text { Differential expansion and } \\
\text { contraction } \\
\text { Cold wall effect } \\
\text { Oxidation }\end{array}$ & $\begin{array}{l}\text { Low } \\
\text { Low } \\
\text { Low }\end{array}$ & $\begin{array}{l}\text { Different coefficients of thermal expansion between } \\
\text { substrate and primer. } \\
\text { Condensation of water from warmer, humid atmosphere } \\
\text { to surfaces of cooler steel structures. } \\
\text { Chemical interaction of moisture and air at the surface of } \\
\text { the substrate (substrate/primer interface). }\end{array}$ \\
\hline $\begin{array}{l}\text { Primer } \\
\text { (epoxy) }\end{array}$ & $\begin{array}{l}\text { Expansion and contraction } \\
\text { Oxidation } \\
\text { Environmental exposure } \\
\text { Minor coating anomalies } \\
\text { Mechanical damage } \\
\text { Increased radiation exposure }\end{array}$ & $\begin{array}{l}\text { Low } \\
\text { Low } \\
\text { High } \\
\text { Low } \\
\text { High } \\
\text { Low }\end{array}$ & $\begin{array}{l}\text { Primer response to changes in containment pressure and } \\
\text { temperature due to normal operation and ILRT's. } \\
\text { Chemical interaction of moisture, air and the primer coat. } \\
\text { Exposure to ambient conditions (heat) during operations. } \\
\text { Results from normal application process. } \\
\text { Damage due to dropped equipment. } \\
\text { Neutron fluence generated due to operations. }\end{array}$ \\
\hline $\begin{array}{l}\text { Primer/Topcoat } \\
\text { Interface }\end{array}$ & $\begin{array}{l}\text { Differential expansion and } \\
\text { contraction } \\
\text { Air, water and chemical intrusion } \\
\text { Blistering and delamination }\end{array}$ & $\begin{array}{l}\text { Low } \\
\text { Low } \\
\text { High }\end{array}$ & $\begin{array}{l}\text { Differing rates between primer and topcoat } \\
\text { Changes in concentration of air/water } \\
\text { Breaking of bonds between primer and topcoat. }\end{array}$ \\
\hline $\begin{array}{l}\text { Topcoat } \\
\text { (epoxy) }\end{array}$ & $\begin{array}{l}\text { Expansion and contraction } \\
\text { Oxidation } \\
\text { Environmental exposure } \\
\text { Discoloration } \\
\text { Minor coating anomalies } \\
\text { Mechanical damage } \\
\text { Increased radiation exposure }\end{array}$ & $\begin{array}{l}\text { Low } \\
\text { Low } \\
\text { High } \\
\text { Low } \\
\text { Low } \\
\text { High } \\
\text { Low }\end{array}$ & $\begin{array}{l}\text { Topcoat response to changes in containment pressure and } \\
\text { temperature due to normal operation and ILRT's. } \\
\text { Chemical interaction of moisture, air and the primer coat. } \\
\text { Exposure to ambient conditions (heat) during operations. } \\
\text { Polymer chemical changes. } \\
\text { Results from normal application process. } \\
\text { Damage due to.dropped equipment. } \\
\text { Neutron fluence generated due to operations. }\end{array}$ \\
\hline
\end{tabular}


INDUSTRY COATING PIRT SUMMARY - TABLE G-3 - 0-40 SEC. AFTER INITIATION OF LOCA

COATING DESCRIPTION: Steel Substrate, Epoxy Primer, Epoxy Topcoat

\begin{tabular}{|c|c|c|c|c|}
\hline \multicolumn{5}{|c|}{ COATING DESCRIPTION: Steel Substrate, Epoxy Primer, Epoxy Topcoat } \\
\hline \multirow{5}{*}{$\begin{array}{c}\text { Phase } 2 \\
\text { 0-40 Seconds } \\
\text { (outside Zone of Influence) }\end{array}$} & Component & Processes \& Phenomena & Rank & Definition \\
\hline & $\begin{array}{l}\text { Substrate } \\
\text { (steel) }\end{array}$ & $\begin{array}{l}\text { Expansion } \\
\text { Temperature gradient } \\
\text { Increased radiation exposure }\end{array}$ & $\begin{array}{l}\text { Low } \\
\text { Low } \\
\text { Low }\end{array}$ & $\begin{array}{l}\text { Containment pressurization and thermal expansion. } \\
\text { Conduction from surface through base metal. } \\
\text { Due to release of primary coolant to containment. }\end{array}$ \\
\hline & $\begin{array}{l}\text { Substrate/Primer } \\
\text { Interface }\end{array}$ & $\begin{array}{l}\text { Differential expansion and } \\
\text { contraction } \\
\text { Cold wall effect } \\
\text { Oxidation } \\
\text { Blistering and delamination }\end{array}$ & $\begin{array}{l}\text { Low } \\
\text { Low } \\
\text { Low } \\
\text { High }\end{array}$ & $\begin{array}{l}\text { Different coefficients of thermal expansion between } \\
\text { substrate and primer. } \\
\text { Condensation of water from warmer, humid atmosphere } \\
\text { to surfaces of cooler steel structures. } \\
\text { Chemical interaction of moisture and air at the surface of } \\
\text { the substrate (substrate/primer interface). } \\
\text { Breaking of bonds between primer and substrate. }\end{array}$ \\
\hline & $\begin{array}{l}\text { Primer } \\
\text { (Epoxy) }\end{array}$ & $\begin{array}{l}\text { Expansion and contraction } \\
\text { Oxidation } \\
\text { Environmental exposure } \\
\text { Minor coating anomalies } \\
\text { Mechanical damage } \\
\text { Increased radiation exposure } \\
\text { Temperature gradient } \\
\text { Air, water and chemical } \\
\text { diffusion } \\
\text { Air, water and chemical intrusion }\end{array}$ & $\begin{array}{l}\text { Low } \\
\text { Low } \\
\text { Medium } \\
\text { Low } \\
\text { Low } \\
\text { Low } \\
\text { Low } \\
\text { Low } \\
\text { Low }\end{array}$ & $\begin{array}{l}\text { Primer response to changes in containment pressure and } \\
\text { temperature due to LOCA. } \\
\text { Chemical interaction of moisture, air and the primer coat. } \\
\text { Exposure to ambient conditions (heat) during LOCA. } \\
\text { Results from normal application process. } \\
\text { Damage due to LOCA generated debris. } \\
\text { Neutron fluence generated due to LOCA. } \\
\text { Response to changing heat transfer at coating surface. } \\
\text { Increase in containment pressure. } \\
\text { Increase in concentration at damage sights. }\end{array}$ \\
\hline & $\begin{array}{l}\text { Primer/Topcoat } \\
\text { Interface }\end{array}$ & $\begin{array}{l}\text { Differential expansion and } \\
\text { contraction } \\
\text { Air, water and chemical intrusion } \\
\text { Blistering and delamination }\end{array}$ & $\begin{array}{l}\text { Low } \\
\text { Low } \\
\text { High }\end{array}$ & $\begin{array}{l}\text { Differing rates between primer and topcoat } \\
\text { Increased concentration of air/water } \\
\text { Breaking of bonds between primer and topcoat. }\end{array}$ \\
\hline
\end{tabular}


INDUSTRY COATING PIRT SUMMARY - TABLE G-3 - 0-40 SEC. AFTER INITIATION OF LOCA

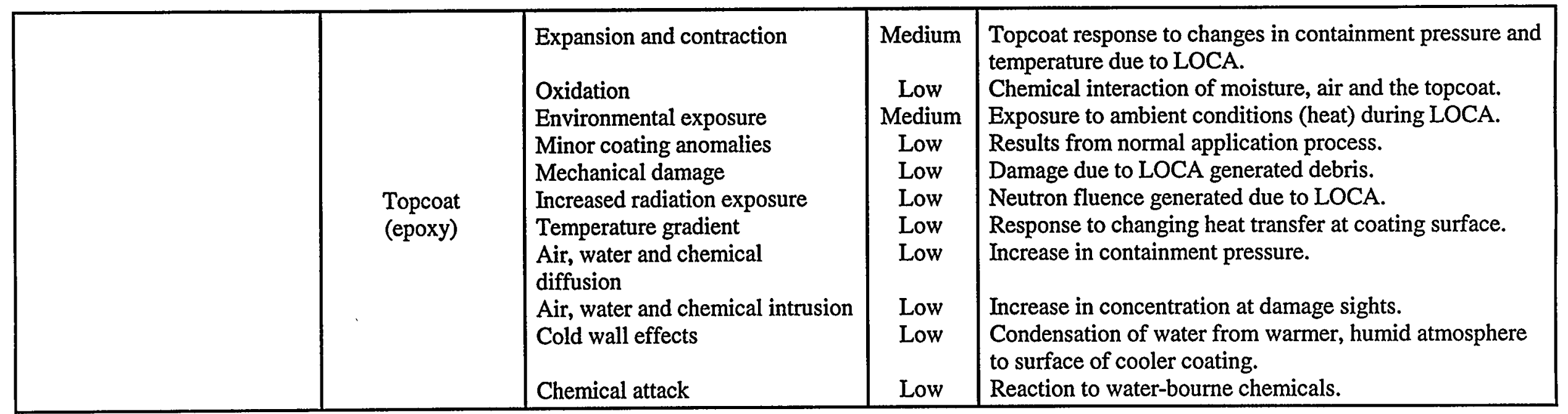


INDUSTRY COATING PIRT SUMMARY - TABLE G-4 - 40 SEC.-30 MIN. AFTER INITIATION OF LOCA

COATING DESCRIPTION: Steel Substrate, Epoxy Primer, Epoxy Topcoat

\begin{tabular}{|c|c|c|c|c|}
\hline \multicolumn{5}{|c|}{ COATING DESCRIPTION: Steel Substrate, Epoxy Primer, Epoxy Topcoat } \\
\hline \multirow{5}{*}{$\begin{array}{c}\text { Phase } 3 \\
40 \text { Sec }-30 \text { Min } \\
\text { (outside Zone of Influence) }\end{array}$} & Component & Processes \& Phenomena & Rank & Definition \\
\hline & $\begin{array}{l}\text { Substrate } \\
\text { (steel) }\end{array}$ & $\begin{array}{l}\text { Expansion } \\
\text { Temperature gradient } \\
\text { Increased radiation exposure }\end{array}$ & $\begin{array}{l}\text { Low } \\
\text { Low } \\
\text { Low }\end{array}$ & $\begin{array}{l}\text { Containment pressurization and thermal expansion. } \\
\text { Conduction from surface through base metal. } \\
\text { Due to release of primary coolant to containment. }\end{array}$ \\
\hline & $\begin{array}{l}\text { Substrate/Primer } \\
\text { Interface }\end{array}$ & $\begin{array}{l}\text { Differential expansion and } \\
\text { contraction } \\
\text { Cold wall effect } \\
\text { Oxidation } \\
\text { Blistering and delamination }\end{array}$ & $\begin{array}{l}\text { Low } \\
\text { Low } \\
\text { High } \\
\text { High }\end{array}$ & $\begin{array}{l}\text { Different coefficients of thermal expansion between } \\
\text { substrate and primer. } \\
\text { Condensation of water from warmer, humid atmosphere } \\
\text { to surfaces of cooler steel structures. } \\
\text { Chemical interaction of moisture and air at the surface of } \\
\text { the substrate (substrate/primer interface). } \\
\text { Breaking of bonds between primer and substrate. }\end{array}$ \\
\hline & $\begin{array}{l}\text { Primer } \\
\text { (Epoxy) }\end{array}$ & $\begin{array}{l}\text { Expansion and contraction } \\
\text { Oxidation } \\
\text { Environmental exposure } \\
\text { Minor coating anomalies } \\
\text { Mechanical damage } \\
\text { Increased radiation exposure } \\
\text { Temperature gradient } \\
\text { Air, water and chemical } \\
\text { diffusion } \\
\text { Air, water and chemical } \\
\text { intrusion } \\
\bullet \text { Above pool } \\
\text { - . B Below pool } \\
\text { Chemical attack }\end{array}$ & $\begin{array}{l}\text { Low } \\
\text { Low } \\
\text { Medium } \\
\text { Low } \\
\text { Low } \\
\text { Low } \\
\text { Low } \\
\text { Low }\end{array}$ & $\begin{array}{l}\text { Primer response to changes in containment pressure and } \\
\text { temperature due to LOCA. } \\
\text { Chemical interaction of moisture, air and the primer coat. } \\
\text { Exposure to ambient conditions (heat) during LOCA. } \\
\text { Results from normal application process. } \\
\text { Damage due to LOCA generated debris. } \\
\text { Neutron fluence generated due to LOCA. } \\
\text { Response to changing heat transfer at coating surface. } \\
\text { Increase in containment pressure. } \\
\\
\text { Increase in concentration at damage sights. } \\
\text { Increase in concentration at damage sights. } \\
\text { Reaction to water-bourne chemicals. }\end{array}$ \\
\hline & $\begin{array}{l}\text { Primer/Topcoat } \\
\text { Interface }\end{array}$ & $\begin{array}{l}\text { Differential expansion and } \\
\text { contraction } \\
\text { Air, water and chemical } \\
\text { intrusion } \\
\text { Blistering and delamination }\end{array}$ & $\begin{array}{l}\text { Low } \\
\text { Low } \\
\text { High }\end{array}$ & $\begin{array}{l}\text { Differing rates between primer and topcoat } \\
\text { Increased concentration of air/water } \\
\text { Breaking of bonds between primer and topcoat. }\end{array}$ \\
\hline
\end{tabular}


INDUSTRY COATING PIRT SUMMARY - TABLE G-4 - 40 SEC.-30 MIN. AFTER INITIATION OF LOCA

\begin{tabular}{|c|c|c|c|c|}
\hline - & $\begin{array}{l}\text { Topcoat } \\
\text { (epoxy) }\end{array}$ & $\begin{array}{l}\text { Expansion and contraction } \\
\text { Oxidation } \\
\text { Environmental exposure } \\
\text { Minor coating anomalies } \\
\text { Mechanical damage } \\
\text { Increased radiation exposure } \\
\text { Temperature gradient } \\
\text { Air, water and chemical } \\
\text { diffusion } \\
\text { Air, water and chemical } \\
\text { intrusion } \\
\bullet \quad \text { Above pool } \\
\bullet \quad \text { Below pool } \\
\text { Cold wall effects } \\
\text { Chemical Attack }\end{array}$ & $\begin{array}{l}\text { Low } \\
\text { Low } \\
\text { Medium } \\
\text { Medium } \\
\text { Low } \\
\text { Low } \\
\text { Low } \\
\text { Low } \\
\\
\text { Medium } \\
\text { Low } \\
\text { Low } \\
\text { Low }\end{array}$ & $\begin{array}{l}\text { Topcoat response to changes in containment pressure and } \\
\text { temperature due to LOCA. } \\
\text { Chemical interaction of moisture, air and the topcoat. } \\
\text { Exposure to ambient conditions (heat) during LOCA. } \\
\text { Results from normal application process. } \\
\text { Damage due to dropped equipment. } \\
\text { Neutron fluence generated due to LOCA. } \\
\text { Response to changing heat transfer at coating surface. } \\
\text { Increase in containment pressure. } \\
\text { Increase in concentration at damage sights. } \\
\text { Increase in concentration at damage sights. } \\
\text { Condensation of water from warmer, humid atmosphere } \\
\text { to surface of cooler coating. } \\
\text { Reaction to water-bourne chemicals. }\end{array}$ \\
\hline
\end{tabular}


INDUSTRY COATING PIRT SUMMARY - TABLE G-5 - 30 MIN.-2 HRS. AFTER INITIATION OF LOCA

\begin{tabular}{|c|c|c|c|c|}
\hline \multicolumn{5}{|c|}{ COATING DESCRIPTION: Steel Substrate, Epoxy Primer, Epoxy Topcoat } \\
\hline \multirow{5}{*}{$\begin{array}{c}\text { Phase } 4 \\
30 \text { min }-2 \text { hrs } \\
\text { (outside Zone of Influence) }\end{array}$} & Component & Processes \& Phenomena & Rank & Definition \\
\hline & $\begin{array}{l}\text { Substrate } \\
\text { (steel) }\end{array}$ & $\begin{array}{l}\text { Expansion } \\
\text { Temperature gradient } \\
\text { Increased radiation exposure }\end{array}$ & $\begin{array}{l}\text { Low } \\
\text { Low } \\
\text { Low }\end{array}$ & $\begin{array}{l}\text { Containment pressurization and thermal expansion. } \\
\text { Conduction from surface through base metal. } \\
\text { Due to release of primary coolant to containment. }\end{array}$ \\
\hline & $\begin{array}{l}\text { Substrate/Primer } \\
\text { Interface }\end{array}$ & $\begin{array}{l}\text { Differential expansion and } \\
\text { contraction } \\
\text { Cold wall effect } \\
\text { Oxidation } \\
\text { Blistering and delamination }\end{array}$ & $\begin{array}{l}\text { Low } \\
\text { Low } \\
\text { High } \\
\text { High }\end{array}$ & $\begin{array}{l}\text { Different coefficients of thermal expansion between substrate } \\
\text { and primer. } \\
\text { Condensation of water from warmer, humid atmosphere to } \\
\text { surfaces of cooler steel structures. } \\
\text { Chemical interaction of moisture and air at the surface of the } \\
\text { substrate (substrate/primer interface). } \\
\text { Breaking of bonds between primer and substrate. }\end{array}$ \\
\hline & $\begin{array}{l}\text { Primer } \\
\text { (epoxy) }\end{array}$ & $\begin{array}{l}\text { Expansion and contraction } \\
\text { Oxidation } \\
\text { Environmental exposure } \\
\text { Minor coating anomalies } \\
\text { Mechanical damage } \\
\text { Increased radiation exposure } \\
\text { Temperature gradient } \cdot \\
\text { Air, water and chemical diffusion } \\
\text { Air, water and chemical intrusion } \\
\text { Above pool } \\
\text { Chemical attack }\end{array}$ & $\begin{array}{l}\text { Low } \\
\text { Low } \\
\text { Medium } \\
\text { Low } \\
\text { Low } \\
\text { Low } \\
\text { Low } \\
\text { Low } \\
\text { Medium } \\
\text { Low } \\
\text { Low }\end{array}$ & $\begin{array}{l}\text { Primer response to changes in containment pressure and } \\
\text { temperature due to LOCA. } \\
\text { Chemical interaction of moisture, air and the primer coat. } \\
\text { Exposure to ambient conditions (heat) during LOCA. } \\
\text { Results from normal application process. } \\
\text { Damage due to LOCA generated debris. } \\
\text { Neutron fluence generated due to LOCA. } \\
\text { Response to changing heat transfer at coating surface. } \\
\text { Increase in containment pressure. } \\
\text { Increase in concentration at damage sights. } \\
\text { Increase in concentration at damage sights. } \\
\text { Reaction to water-bourne chemicals. }\end{array}$ \\
\hline & $\begin{array}{l}\text { Primer/Topcoat } \\
\text { Interface }\end{array}$ & $\begin{array}{l}\text { Differential expansion and } \\
\text { contraction } \\
\text { Air, water and chemical intrusion } \\
\text { Blistering and delamination }\end{array}$ & $\begin{array}{l}\text { Low } \\
\text { Low } \\
\text { High }\end{array}$ & $\begin{array}{l}\text { Differing rates between primer and topcoat } \\
\text { Increased concentration of air/water } \\
\text { Breaking of bonds between primer and topcoat. }\end{array}$ \\
\hline
\end{tabular}


INDUSTRY COATING PIRT SUMMARY - TABLE G-5 - 30 MIN.-2 HRS. AFTER INITIATION OF LOCA

\begin{tabular}{|c|c|c|c|c|}
\hline & $\begin{array}{l}\text { Topcoat } \\
\text { (epoxy) }\end{array}$ & $\begin{array}{l}\text { Expansion and contraction } \\
\text { Oxidation } \\
\text { Environmental exposure } \\
\text { Minor coating anomalies } \\
\text { Mechanical damage } \\
\text { Increased radiation exposure } \\
\text { Temperature gradient } \\
\text { Air, water and chemical } \\
\text { diffusion } \\
\text { Air, water and chemical intrusion } \\
\text { Above pool } \\
\text { Cold wall effects } \\
\text { Chemical attack }\end{array}$ & $\begin{array}{l}\text { Low } \\
\text { Low } \\
\text { Medium } \\
\text { Medium } \\
\text { Low } \\
\text { Low } \\
\text { Low } \\
\text { Low } \\
\text { Medium } \\
\text { Low } \\
\text { Low } \\
\text { Low }\end{array}$ & $\begin{array}{l}\text { Topcoat response to changes in containment pressure and } \\
\text { temperature due to LOCA. } \\
\text { Chemical interaction of moisture, air and the topcoat. } \\
\text { Exposure to ambient conditions (heat) during LOCA. } \\
\text { Results from normal application process. } \\
\text { Damage due to LOCA generated debris. } \\
\text { Neutron fluence generated due to LOCA. } \\
\text { Response to changing heat transfer at coating surface. } \\
\text { Increase in containment pressure. } \\
\text { Increase in concentration at damage sights. } \\
\text { Increase in concentration at damage sights. } \\
\text { Condensation of water from warmer, humid atmosphere } \\
\text { to surface of cooler coating. } \\
\text { Reaction to water-bourne chemicals. }\end{array}$ \\
\hline
\end{tabular}

$\stackrel{P}{\mathrm{~N}}$ 
INDUSTRY COATINGS PIRT SUMMARY - TABLE G-6 - >2 HRS. AFTER INITIATION OF LOCA

COATING DESCRIPTION: Steel Substrate, Epoxy Primer, Epoxy Topcoat

\begin{tabular}{|c|c|c|c|c|}
\hline \multicolumn{5}{|c|}{ COATING DESCRIPTION: Steel Substrate, Epoxy Primer, Epoxy Topcoat } \\
\hline \multirow{5}{*}{$\begin{array}{c}\text { Phase } 5 \\
2 \text { hrs - end } \\
\text { (outside Zone of Influence) }\end{array}$} & Component & Processes \& Phenomena & Rank & Definition \\
\hline & $\begin{array}{c}\text { Substrate } \\
\text { (steel) }\end{array}$ & $\begin{array}{l}\text { Expansion } \\
\text { Temperature gradient } \\
\text { Increased radiation exposure }\end{array}$ & $\begin{array}{l}\text { Low } \\
\text { Low } \\
\text { Low }\end{array}$ & $\begin{array}{l}\text { Containment pressurization and thermal expansion. } \\
\text { Conduction from surface through base metal. } \\
\text { Due to release of primary coolant to containment. }\end{array}$ \\
\hline & $\begin{array}{l}\text { Substrate/Primer } \\
\text { Interface }\end{array}$ & $\begin{array}{l}\text { Differential expansion and } \\
\text { contraction } \\
\text { Cold wall effect } \\
\text { Oxidation } \\
\text { Blistering and delamination }\end{array}$ & $\begin{array}{l}\text { Low } \\
\text { Low } \\
\text { High } \\
\text { High }\end{array}$ & $\begin{array}{l}\text { Different coefficients of thermal expansion between } \\
\text { substrate and primer. } \\
\text { Condensation of water from warmer, humid atmosphere } \\
\text { to surfaces of cooler steel structures. } \\
\text { Chemical interaction of moisture at the surface of the } \\
\text { substrate (substrate/primer interface). } \\
\text { Breaking of bonds between primer and substrate. }\end{array}$ \\
\hline & $\begin{array}{l}\text { Primer } \\
\text { (epoxy) }\end{array}$ & $\begin{array}{l}\text { Expansion and contraction } \\
\text { Oxidation } \\
\text { Environmental exposure } \\
\text { Minor coating anomalies } \\
\text { Mechanical damage } \\
\text { Increased radiation exposure } \\
\text { Temperature gradient } \\
\text { Air, water and chemical } \\
\text { diffusion } \\
\text { Air, water and chemical intrusion } \\
\text { Above pool } \\
\text { Chemical attack }\end{array}$ & $\begin{array}{l}\text { Low } \\
\text { Low } \\
\text { High } \\
\text { High } \\
\text { Low } \\
\text { Low } \\
\text { Low } \\
\text { Medium } \\
\\
\text { High } \\
\text { High } \\
\text { Low }\end{array}$ & $\begin{array}{l}\text { Primer response to changes in containment pressure and } \\
\text { temperature due to LOCA. } \\
\text { Chemical interaction of moisture, air and the primer coat. } \\
\text { Exposure to ambient conditions (heat) during LOCA. } \\
\text { Results from normal application process. } \\
\text { Damage due to LOCA generated debris. } \\
\text { Neutron fluence generated due to LOCA. } \\
\text { Response to changing heat transfer at coating surface. } \\
\text { Increase in containment pressure. } \\
\text { Increase in concentration at damage sights. } \\
\text { Increase in concentration at damage sights. } \\
\text { Reaction to water-bourne chemicals. }\end{array}$ \\
\hline & $\begin{array}{l}\text { Primer/Topcoat } \\
\text { Interface }\end{array}$ & $\begin{array}{l}\text { Differential expansion and } \\
\text { contraction } \\
\text { Air, water and chemical intrusion } \\
\text { Blistering and delamination }\end{array}$ & $\begin{array}{l}\text { Low } \\
\text { Low } \\
\text { High }\end{array}$ & $\begin{array}{l}\text { Differing rates between primer and topcoat } \\
\text { Increased concentration of air/water } \\
\text { Breaking of bonds between primer and topcoat. }\end{array}$ \\
\hline
\end{tabular}


INDUSTRY COATINGS PIRT SUMMARY - TABLE G-6 - >2 HRS. AFTER INITIATION OF LOCA

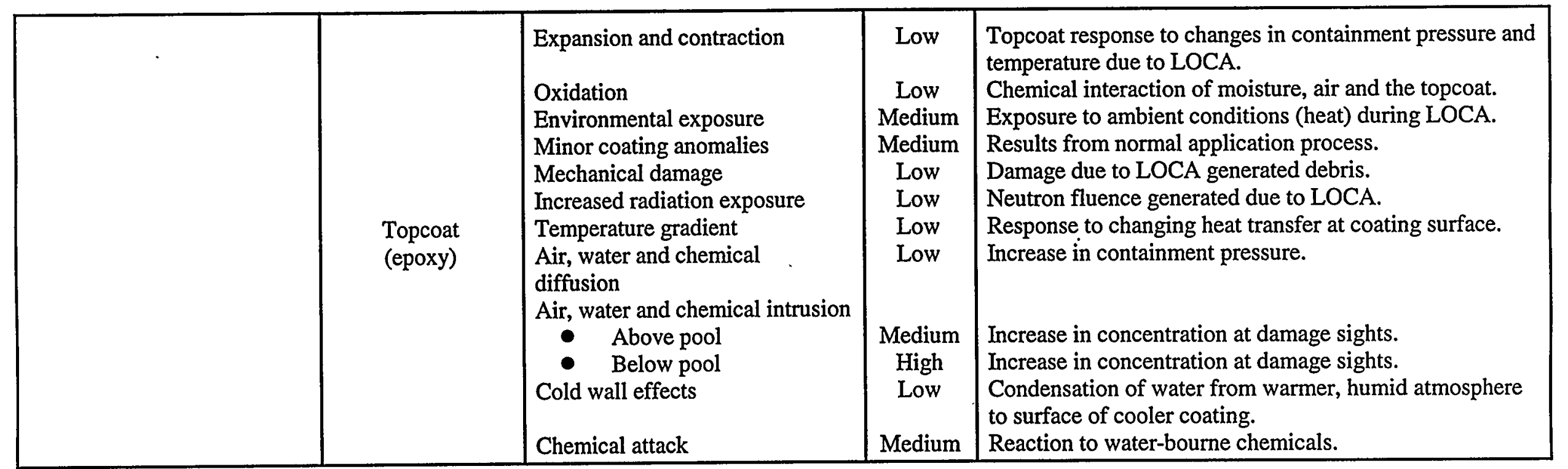


WESTINGHOUSE SAVANNAH RIVER CO. REPORT WSRC-TR-2000-00079

DISTRIBUTION

\section{SAVANNAH RIVER SITE}

S. Wood, 773-A

G. T. Wright, 773-A

C. R. Wolfe, 773-A

N. C. Iyer, $773-41 \mathrm{~A}$

R. L. Bickford, 730-A

G. T. Chandler, 773-A

M. E. Dupont, 773-41A

P-S. Lam, 773-41A

M.R. Louthan, Jr., 773-A

C. E. Sessions, 730-A

R. L. Sindelar, 773-41A

T. E. Skidmore, 730-A

K. Subramanian, 773-41A

S. L. West, 773-A

P. E. Zapp, 773-A

Site Records, 773-42A

External

A. W. Serkiz, NRC (25) 